\title{
Human thermoregulation; A synergy between physiology and mathematical modeling
}

Citation for published version (APA):

Kingma, B. R. M. (2012). Human thermoregulation; A synergy between physiology and mathematical modeling. [Doctoral Thesis, Maastricht University]. https://doi.org/10.26481/dis.20120227bk

Document status and date:

Published: 01/01/2012

DOI:

10.26481/dis.20120227bk

Document Version:

Publisher's PDF, also known as Version of record

\section{Please check the document version of this publication:}

- A submitted manuscript is the version of the article upon submission and before peer-review. There can be important differences between the submitted version and the official published version of record.

People interested in the research are advised to contact the author for the final version of the publication, or visit the DOI to the publisher's website.

- The final author version and the galley proof are versions of the publication after peer review.

- The final published version features the final layout of the paper including the volume, issue and page numbers.

Link to publication

\footnotetext{
General rights rights.

- You may freely distribute the URL identifying the publication in the public portal. please follow below link for the End User Agreement:

www.umlib.nl/taverne-license

Take down policy

If you believe that this document breaches copyright please contact us at:

repository@maastrichtuniversity.nl

providing details and we will investigate your claim.
}

Copyright and moral rights for the publications made accessible in the public portal are retained by the authors and/or other copyright owners and it is a condition of accessing publications that users recognise and abide by the legal requirements associated with these

- Users may download and print one copy of any publication from the public portal for the purpose of private study or research.

- You may not further distribute the material or use it for any profit-making activity or commercial gain

If the publication is distributed under the terms of Article $25 \mathrm{fa}$ of the Dutch Copyright Act, indicated by the "Taverne" license above, 


\section{Human Thermoregulation}

\section{A synergy between physiology and mathematical modelling}




\section{iutim Iutiind}

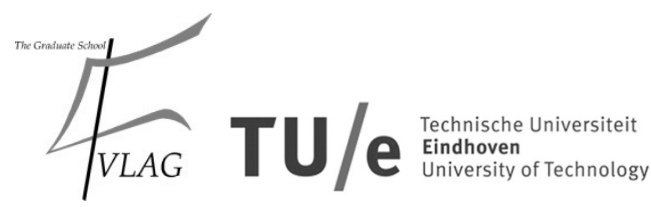

The research presented in this thesis was performed within NUTRIM School for Nutrition, Toxicology and Metabolism which participates in the Graduate School VLAG (Food Technology, Agrobiotechnology, Nutrition and Health Sciences), accredited by the Royal Netherlands Academy of Arts and Sciences. Furthermore, the research was performed in collaboration with Eindhoven University of Technology, department of Mechanical Engineering.

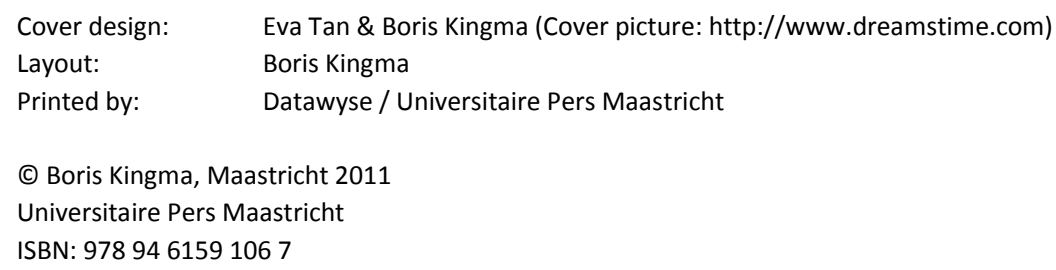




\title{
Human Thermoregulation
}

\section{A synergy between physiology and mathematical modelling}

\author{
PROEFSCHRIFT \\ ter verkrijging van de graad van doctor \\ aan de Universiteit Maastricht \\ op gezag van de Rector Magnificus \\ Prof. mr. G.P.M.F. Mols \\ volgens het besluit van het College van Decanen \\ in het openbaar te verdedigen \\ op vrijdag 27 januari 2012 om 14.00 uur \\ door \\ Boris René Motrona Kingma \\ geboren te Wilrijk (B) op 19 februari 1982
}

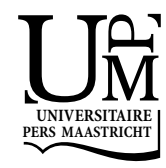




\section{Promotores}

Prof. Dr. Ir. W. H. M. Saris

Prof. Dr. Ir. A. A. van Steenhoven (TU Eindhoven)

\section{Co-Promotores}

Dr. W. D. van Marken Lichtenbelt

Dr. Ir. A. J. H. Frijns (TU Eindhoven)

\section{Beoordelingscommissie / Assessment Committee}

Prof. Dr. G. J. van der Vusse (voorzitter)

Dr. N. D. Bouvy

Prof. Dr. H. A. M. Daanen (VU Amsterdam / TNO Defence, Security and Safety)

Dr. D. Fiala (Ergonsim - Comfort Energy Efficiency / Stuttgart University)

Prof. Dr. Ir. R. Peeters

Prof. Dr. L. P. A. J. Schrauwen

The research described in this thesis was supported by a grant of AgentschapNL (EOS-LT 03001).

\section{PERIMED}

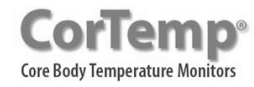

Financial support for printing this thesis by AgentschapNL, Perimed and CorTemp is greatly acknowledged. 


\section{Table of Contents}

Chapter 1

Chapter 2

Chapter 3

Chapter 4

Chapter 5

Chapter 6

Chapter 7

Appendix

Summary

Samenvatting

Dankwoord

List of Publications

Thermophysiological Simulation Model

Eindhoven Maastricht

9

The thermoneutral zone: implications for metabolic studies

Increased systolic blood pressure after mild cold and rewarming: effect of age and cold induced thermogenesis

Incorporating neurophysiological concepts in mathematical thermoregulation models

Mathematical model of thermal sensation based on the neurophysiology of thermal reception

Curriculum vitae 157 


\section{List of symbols}

\begin{tabular}{|c|c|c|}
\hline Symbol & Description & Unit \\
\hline A & Surface area & {$\left[\mathrm{m}^{2}\right]$} \\
\hline a & Distribution or weighting coefficient & {$[-][A U]$} \\
\hline c & Heat capacitance & {$\left[\mathrm{J} \mathrm{kg}^{-1}{ }^{\circ} \mathrm{C}^{-1}\right]$} \\
\hline Cs & Vasoconstriction & {$[-]$} \\
\hline D & Sign operator for direction of response & {$[-]$} \\
\hline $\mathrm{DI}$ & Vasodilation & {$[-]$} \\
\hline$f$ & Neuron fire rate & [pulse s ${ }^{-1}$ ] \\
\hline$f_{c l}$ & Clothing surface area factor & {$[-]$} \\
\hline G & Gain factor for neuron fire rate & {$[-]$} \\
\hline $\mathrm{h}$ & Surface heat transfer coefficient & {$\left[\mathrm{W} \mathrm{m}^{-2}{ }^{\circ} \mathrm{C}^{-1}\right]$} \\
\hline$h_{x}$ & Counter current heat transfer coefficient & {$\left[W^{\circ} \mathrm{C}^{-1}\right]$} \\
\hline $\mathrm{H}$ & Hypothalamic neuron fire rate & pulse $s^{-1}$ \\
\hline $\mathrm{i}_{c l}$ & Moisture permeability coefficient of clothing & {$[-]$} \\
\hline $\mathrm{I}_{\mathrm{cl}}$ & Heat resistance of clothing & [Clo] \\
\hline $\mathrm{k}$ & Conductivity & {$\left[\mathrm{W} \mathrm{m}^{-1}{ }^{\circ} \mathrm{C}^{-1}\right]$} \\
\hline $\mathrm{K}$ & Gain factor for dynamic part of neuron fire rate & {$[-]$} \\
\hline L & Length & [m] \\
\hline Le & Lewis constant & {$\left[{ }^{\circ} \mathrm{CPa}^{-1}\right]$} \\
\hline $\mathrm{m}$ & Mass & [kg] \\
\hline $\mathrm{N}$ & Neural regulatory signal for skin blood flow & {$[-]$} \\
\hline $\mathrm{p}$ & $\begin{array}{l}\text { Probability of obtaining a test-statistic at least as extreme as the one } \\
\text { observed }\end{array}$ & {$[-]$} \\
\hline$p_{\text {air }}$ & Air pressure & {$[\mathrm{Pa}]$} \\
\hline$P$ & Peripheral afferent neural drive & [pulse s ${ }^{-1}$ ] \\
\hline q & Surface heat transfer & {$\left[\mathrm{W} \mathrm{m}^{-2}\right]$} \\
\hline $\mathrm{q}_{\mathrm{m}}$ & Metabolic heat production & {$\left[\mathrm{W} \mathrm{\textrm {m } ^ { - 3 } ]}\right.$} \\
\hline r & Radius & [m] \\
\hline $\mathrm{R}_{\mathrm{e}}$ & Skin permeability resistance & {$\left[\mathrm{W} \mathrm{m}^{-2} \mathrm{~Pa}^{-1}\right]$} \\
\hline S & Steady state neuron fire rate & pulse $s^{-1}$ \\
\hline s & Coefficient for steady state neuron fire rate & {$[-]$} \\
\hline Sh & Shivering & {$[\mathrm{W}]$} \\
\hline Sw & Sweating & {$\left[\mathrm{g} \mathrm{min}^{-1}\right]$} \\
\hline $\mathrm{t}$ & Time & [s] \\
\hline T & Temperature & {$\left[{ }^{\circ} \mathrm{C}\right]$} \\
\hline $\mathrm{U}_{\mathrm{cl}}$ & $\begin{array}{l}\text { Combined radiative and convective heat transfer coefficient (cloth- } \\
\text { ing) }\end{array}$ & {$\left[\mathrm{W} \mathrm{m}{ }^{-2}{ }^{\circ} \mathrm{C}^{-1}\right]$} \\
\hline$U_{e}$ & Evaporative heat transfer coefficient (clothing) & {$\left[\mathrm{W} \mathrm{m}{ }^{-2} \mathrm{~Pa}^{-1}\right]$} \\
\hline $\mathrm{v}$ & Speed & {$\left[\mathrm{m} \mathrm{s}^{-1}\right]$} \\
\hline $\mathrm{V}$ & Volume & {$\left[\mathrm{m}^{3}\right]$} \\
\hline$\dot{\mathrm{V}}$ & Respiration rate & {$\left[\mathrm{m}^{3} \mathrm{~s}^{-1}\right]$} \\
\hline $\begin{array}{l}\text { Greek } \\
\text { symbols }\end{array}$ & Description & Unit \\
\hline$\beta$ & Heat equivalent of blood flow & {$\left[\mathrm{W} \mathrm{m}^{-3}\right]$} \\
\hline$\gamma$ & Model constants for neurophysiological skin blood flow model & {$\left[s\right.$ pulse $\left.{ }^{-1}\right]$} \\
\hline$\Delta$ & Difference & {$[-]$} \\
\hline$\varepsilon$ & Emissivity & {$[-]$} \\
\hline$\kappa$ & Model constants for neurophysiological thermal sensation model & {$\left[s\right.$ pulse $\left.{ }^{-1}\right]$} \\
\hline$\phi$ & Relative humidity & {$[\%][-]$} \\
\hline$\varphi$ & Angle & {$\left[{ }^{\circ}\right]$} \\
\hline$\lambda$ & Heat of vaporization & {$\left[\mathrm{J} \mathrm{kg}^{-1}\right]$} \\
\hline
\end{tabular}




$\begin{array}{lll}\mu & \text { Proportionality constant for change in blood flow due to change in } & {\left[{ }^{\circ} \mathrm{C}^{-1}\right]} \\ & \text { metabolism } & \\ \psi & \text { View factor } & {[-]} \\ \rho & \text { Density } & {\left[\mathrm{kg} \mathrm{m}^{-3}\right]} \\ \sigma & \text { Stefan Boltzmann constant } & {\left[\mathrm{W} \mathrm{m}^{-2} \mathrm{~K}^{-4}\right]} \\ \omega & \text { Perfusion rate } & {\left[\mathrm{I} \mathrm{m}^{-3} \mathrm{~s}^{-1}\right]}\end{array}$

Subscripts and superscripts

\begin{tabular}{|c|c|}
\hline $\mathrm{a}$ & Arterial \\
\hline air & Air \\
\hline acc & Accumulation \\
\hline b & Blood \\
\hline bas & Basal, baseline \\
\hline c & Convective \\
\hline $\mathrm{cl}$ & Clothing \\
\hline cold & Cold \\
\hline e & Evaporative \\
\hline eff & Effective \\
\hline ex & Exhaled \\
\hline exc & Excitatory \\
\hline frc & Forced \\
\hline $\mathrm{H}_{2} \mathrm{O}$ & Water \\
\hline i & Index \\
\hline in & Inhaled \\
\hline inh & Inhibitory \\
\hline j & Index \\
\hline mean & Mean \\
\hline $\mathrm{m}$ & Metabolic \\
\hline $\max$ & Maximum \\
\hline $\operatorname{mix}$ & Mixed \\
\hline nat & Natural \\
\hline op & Operative \\
\hline r & Radiative \\
\hline res & Respiratory \\
\hline sat & Saturated \\
\hline sh & Shivering \\
\hline sk & Skin \\
\hline $\mathrm{sp}$ & Specific \\
\hline $\mathrm{sr}$ & Sector \\
\hline surf & Surface \\
\hline sw & Sweat \\
\hline sweatgland & Sweatgland \\
\hline $\mathrm{t}$ & Time \\
\hline vap & Vaporization \\
\hline w & Wall \\
\hline warm & Warm \\
\hline $\mathrm{x}$ & Counter current \\
\hline
\end{tabular}

Abbreviations and acronyms

\begin{tabular}{ll}
\hline ASHRAE & American Society of Heating, Refrigerating and Air-Conditioning Engineers \\
AVA & Arterio-venous anastamosis \\
AU & Arbitrary unit \\
BAT & Brown adipose tissue \\
BMI & Body mass index \\
BMR & Basal metabolic rate \\
BP & Blood pressure
\end{tabular}




\begin{tabular}{|c|c|}
\hline BPM & Beats per minute \\
\hline $\mathrm{BR}$ & Bretylium tosylate \\
\hline $\mathrm{CIT}$ & Cold induced thermogenesis \\
\hline $\mathrm{ClZ}$ & Core inter-threshold zone \\
\hline CVC & Cutaneous vascular conductance \\
\hline DIT & Diet induced thermogenesis \\
\hline $\mathrm{EE}$ & Energy expenditure \\
\hline $\mathrm{HR}$ & Heart rate \\
\hline HVAC & Heating Ventilation Air Conditioning \\
\hline LCT & Lower critical temperature \\
\hline LDF & Laser Doppler flowmetry \\
\hline MAP & Mean arterial blood pressure \\
\hline MSR & Mean squared residual \\
\hline NA & Noradrenalin (Nor-Epinephrine) \\
\hline NST & Non-shivering thermogenesis \\
\hline PMV & Predicted Mean Vote \\
\hline PU & Perfusion unit \\
\hline RMSR & (Square) Root of mean squared residual \\
\hline SBF & Skin blood flow \\
\hline SBP & Systolic blood pressure \\
\hline SE & Standard error of the mean \\
\hline SFT & Skinfold thickness \\
\hline SMR & Standard metabolic rate \\
\hline SP & Set point \\
\hline ThermoSEM & Thermophysiological Simulation Model Eindhoven Maastricht \\
\hline TNZ & Thermoneutral zone \\
\hline UCT & Upper critical temperature \\
\hline USA & United States of America \\
\hline VC & Vasoconstriction \\
\hline
\end{tabular}


CHAPTER 1

GENERAL INTRODUCTION 


\section{Human thermoregulation and the environment}

Human beings are warm-blooded animals, which means that they are able to maintain a stable temperature for their vital organs despite large fluctuations in environmental conditions. Humans do this by carefully balancing heat production and heat loss. If more heat is lost than produced, body temperature will drop. Vice versa, if more heat is produced than lost, body temperature will increase (1). Control of this heat balance is referred to as thermoregulation and is effectively executed by modulating behavior (e.g. changing clothes) and physiological mechanisms (e.g. shivering or sweating).

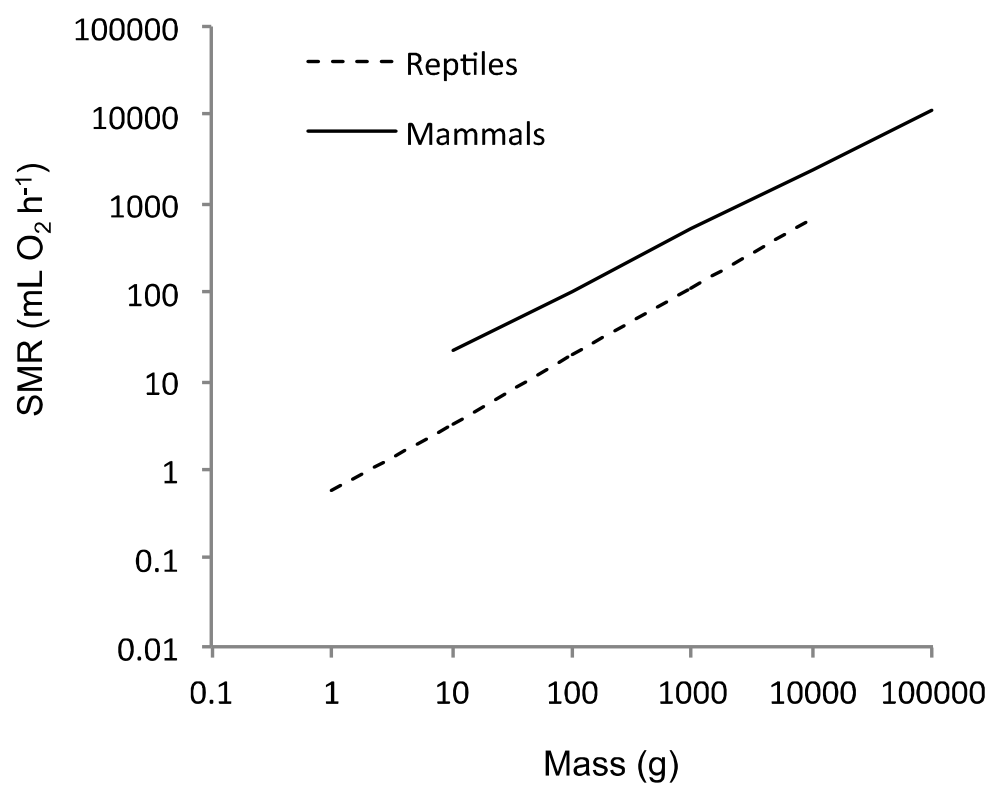

Figure 1: Standard metabolic rate vs. mass in reptiles (ectoterms) and mammals (endotherms). Modified from ref. (2).

Warm-blooded animals are also referred to as endotherms (from Greek, endos: inner, thermos: hot). Endothermy creates opportunities that cannot be exploited by ectotherms (Greek, ectos: outer; e.g. reptiles or amphibians) as long as there is enough fuel to keep the fire burning and enough water to cool the machinery down. For instance, ectotherms rely on environmental conditions to heat up before they can perform vital actions such as foraging or reproducing. Endotherms, in turn, are less dependent on environmental conditions and can therefore live in a wider range of climates, thereby reducing competition for resources and increasing chances of survival. Nevertheless, maintaining a stable body temperature comes at a cost, for 
the same body mass endotherms maintain higher energy expenditure than ectotherms (see Figure 1) (2).

Also in cold or hot environments, relatively more resources have to be spent to regulate body temperature than in thermoneutral environments. Therefore, it might not be coincidental that the earliest civilizations developed in climatic regions close to thermoneutrality (see Figure 2).

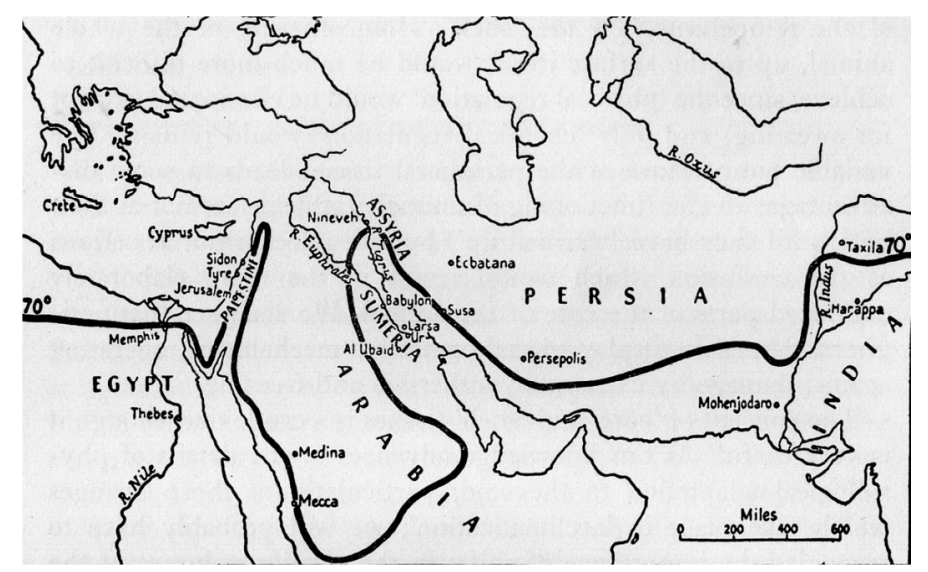

Figure 2: The $21^{\circ} \mathrm{C}$ isotherm (shown as $70^{\circ}$ Fahrenheit) and the sites of ancient civilizations. For simplicity the therm is shown as a line, but is rather a succesion of areas. (From Burton and Edholm, Man in a Cold Environment, Edward Arnold publ., 1955)

In general, humans are most productive and comfortable in thermoneutral conditions (3). However, continuously being in thermoneutral conditions is not necessarily healthy. In modern western societies, people tend to live most of their life in buildings where conditions are kept stable and within the thermoneutral zone. Hence, the body has to spend fewer resources to defend body temperature against thermal challenges. This may have a causal relation to the development of obesity and pathologies related to obesity $(4,5)$. Moreover, there are indications that reduced exposure to thermal challenges reduces the capacity to cope with thermal challenges in general (6). Thermoregulation thus seems to fit the "use it or lose it" paradigm. In terms of increased adiposity in obesity, it would change to "use it to lose it".

Given the above stated health issue, combined with current environmental and economical issues concerning global warming and scarcity of combustible resources, it may thus be beneficial to allow ambient temperature in buildings to drift more according to the time of day and season; thereby reducing the carbon footprint for living and reducing the risk for developing obesity and its related diseases. Furthermore, there are indications that temperature drifts within thermoneutral zone may further enhance comfort (7). However, allowing ambient temperature to drift must 
not interfere with comfort, health and productivity. Therefore, the allowable or "wise" range of temperature drift may differ between different subpopulations (e.g. young vs. elderly). Precise knowledge of thermoregulation and the effects of mild temperature challenges on these subpopulations is necessary to make informed decisions and design new energy efficient buildings. Furthermore, modern building design relies greatly on mathematical models to simulate both structural integrity and energy requirements. Since humans are the users of those buildings, inclusion of an accurate mathematical model of human thermo physiology seems appropriate. Such a model provides a relatively inexpensive method to simulate whether ambient conditions in a building are within the constraints for comfort, health and productivity of individuals (8). Here, it is evident that conditions that cause shivering or sweating are well beyond the scope of a liveable environment. Instead, during mild thermal challenges, more subtle thermoregulatory mechanisms such as skin blood flow and non-shivering thermogenesis are the key players. Therefore, it is especially important that the regulations of these specific mechanisms are well understood.

\section{Components of heat balance}

Balance of heat flow is one of the pillars of successful thermoregulation (1). Under resting, fasting and thermoneutral conditions total heat production is attributed to the chemical heat released by metabolic processes necessary to keep our bodies functioning. Heat production is counterbalanced through heat exchange with the environment. In general, the thermal environment is colder than our body surface. In that case all heat exchange with the environment is in fact heat loss. Several types of heat exchange can be discriminated. Diffusion of heat by direct contact is referred to as conduction. Heat lost by our feet to the ground is a form of conduction. Heat exchange by wind or any other moving medium is called convection. Conduction and convection are difficult to separate from each other. Therefore these components are often lumped together. Heat exchange with all surrounding surfaces without direct contact, is called radiative heat transfer. In radiative heat exchange, energy between surfaces is transported through electromagnetic waves (i.e. mainly infrared). Evaporation of moisture from the skin or respiratory tract also contributes to heat loss. In Table 1 the typical distribution of heat exchange between the body and environment is given (9).

\section{Physiology of human thermoregulation}

Regulation of body temperature takes place in a hierarchical order. Local mechanisms are at the bottom and central mechanisms are at the top (10). In general, central thermoregulation is composed of three major components namely (11): 1) thermal reception by temperature sensitive neurons, 2 ) integration through neural pathways and 3 ) the effective thermoregulatory response through separate branch- 
es of the nervous system (see Figure 3). Apart from neural control, also hormones influence thermoregulation, but these are generally associated with long-term adaptations and acclimatization (10). In central thermoregulation, information from the entire body is used to decide on the response, whereas in local thermoregulation only local information is used. Local mechanisms do not need central queues to function and often emerge from logical consequences (10). For instance, decreased oxygen levels greatly enhance blood flow because vessel walls cannot maintain contraction without oxygen. The increase in blood flow then restores oxygen levels and local regulation is a fact.

Table 1: Typical distribution of components of heat balance in resting, fasting and thermoneutral environment

\begin{tabular}{l|l}
\hline Heat balance component & Energy [W] \\
\hline Heat production & 86 \\
Metabolism & \\
\hline Heat loss & 24 \\
Conduction + Convection & 19 \\
Evaporation & 36 \\
Radiation & 7 \\
\hline Respiration & \\
\hline
\end{tabular}




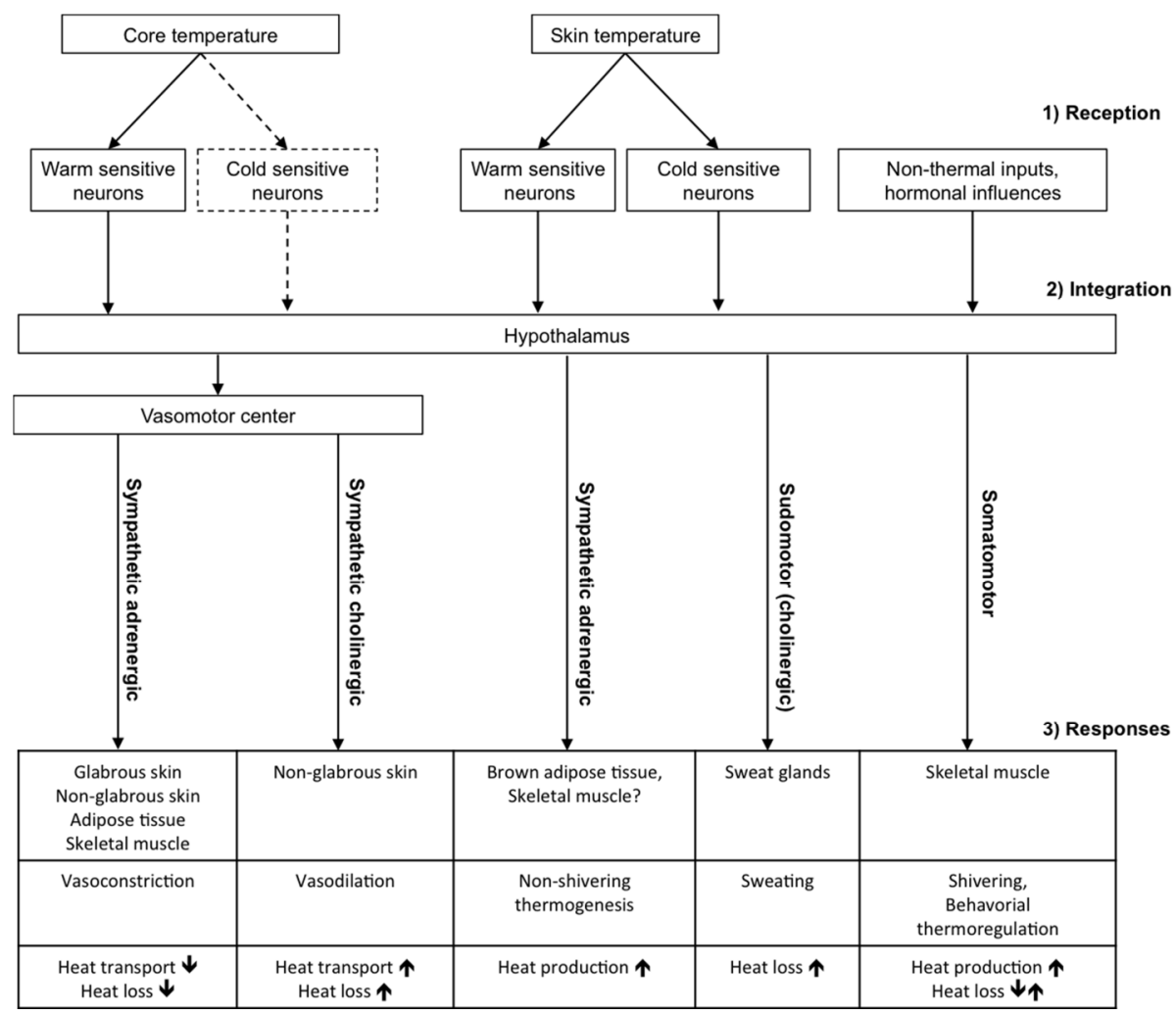

Figure 3: Schematic view of human thermoregulation. Temperature is sensed by neurons that send the afferent information to the hypothalamus, there the information is integrated and the appropriate efferent response is stimulated through separate nervous systems (depicted on the lines). Core temperature cold sensitive neurons are dashed because of low numbers in deep body tissues.

The thermoregulatory responses facilitate three concepts that are important in heat balance: 1) heat loss, 2) heat production and 3) heat transport (Figure 3). This thesis deals with the regulation of skin blood flow (heat transport) and non-shivering thermogenesis (heat production); both are stimulated by the sympathetic nervous system. The sympathetic nervous system is composed of adrenergic and cholinergic branches. Each branch has specific neurotransmitters and co-transmitters that are released from their nerve endings. For sympathetic adrenergic nerves, the main neurotransmitter is noradrenaline and for sympathetic cholinergic nerves, the main neurotransmitter is acetylcholine (12). Tissues that are innervated by these nerves contain receptors that respond to the specific neurotransmitters. For instance, blood vessels in the skin are densely innervated by sympathetic adrenergic nerves and contain many $\alpha$-adrenergic receptors, which, when stimulated by noradrenaline, cause vasoconstriction (i.e. the blood vessels decrease their inner diameter). 


\section{Mechanisms modulating heat loss}

All body heat loss takes place at the interfaces between body and the environment. The skin surface accounts for about $92 \%$ of total heat loss and the respiratory tract accounts for the remaining $8 \%(13)$. At proximal sites such as the abdomen and thorax body heat is transported to the skin by conduction from underlying heat producing organs and convection (i.e. blood flow). At distal areas such as the hands, most heat is transported to the skin by blood flow. Skin vasoconstriction reduces blood flow to the skin. Hence, less heat is transported from the body core to the skin. Under normothermic conditions, blood vessels are under a basal sympathetic tone. Any increase in sympathetic nerve activity induces vasoconstriction, and any decrease in sympathetic nerve activity induces passive vasodilation. Sympathetic adrenergic (vasoconstrictor) nerves innervate both glabrous skin (e.g. lips, forehead, palms and soles) and non-glabrous skin. Therefore all skin regions are able to modulate skin blood flow by vasoconstriction or passive vasodilation. Conversely, active vasodilation only occurs in non-glabrous skin, this is because sympathetic cholinergic (vasodilator) nerves innervate non-glabrous but not glabrous skin. It is not exactly known how neural vasodilation is mediated. However, experiments showed that acetylcholine released by cholinergic nerves is broken down by vessel endothelium (12). During this process nitric oxide is formed which is a powerful vasodilator. Release of acetylcholine also stimulates the production of sweat from sweat glands (i.e. sudomotor response). Therefore, the onsets of sweating and active vasodilation often coincide. In fact, it has been hypothesized that active vasodilation is actually a side effect of sudomotor control. Sweating is a powerful mechanism to increase heat loss; vaporization of $1 \mathrm{ml}$ sweat removes about $2.4 \mathrm{~kJ}$ of heat from the body. However, sweating is also costly because water is an invaluable resource for the body.

\section{Mechanisms modulating heat production}

Physiological mechanisms to increase heat production include non-shivering thermogenesis (NST) and shivering. NST likely takes place in brown adipose tissue and skeletal muscle (14). Specialized proteins in the cell mitochondria of these tissues enable the cell to reduce the efficiency of ATP production and release more heat. From animal studies it is known that NST is regulated by the sympathetic adrenergic nervous system. However, in humans this has not yet been confirmed. The increase in heat production by NST is around $+5 \%$ to $+20 \%$ of normal heat production (15). NST can be maintained for prolonged periods, unlike shivering which cannot be sustained longer than a few hours, but can increase heat production up to five times the normal value. 


\section{Modelling human thermoregulation}

Mathematical modelling of human thermoregulation involves both the physics of heat exchange and the physiology of thermoregulation. Before the existence of computers, calculations of heat balance were primarily used for analysis of experimental results and not for development or simulations (16). These latter functionalities emerged with the rise in computational power of computers from the 1960's onwards. Separate models were developed to simulate body heat balance during static (17) and dynamic environmental conditions (18-20). Since then, several researchers pioneered and enhanced more complex numerical models of human thermoregulation. The applications of these models vary widely from development of specialized clothing to comfort analyses in buildings, survival analysis and prediction of physiological responses during open-heart surgery $(8,21)$.

Nevertheless, these models still have room for improvements. Although the physics of heat exchange and modelling of body characteristics (i.e. passive model) are generally well understood, the actual dynamics of thermoregulatory responses (i.e. active model) are less clear. Modelers solved these knowledge-lacunae by iteratively adjusting thermoregulatory control parameters such that the error between simulations and measurements was minimized. This method is prone to errors because slight inaccuracies in the passive model may result in large deviations of the simulated thermoregulatory responses compared to the measured responses. A better approach would be to base thermoregulation models more on physiological regulation characteristics. In that case, thermoregulation models may be better applicable for testing temperature protocols for which the results are yet unknown. This thesis aims to further improve dynamic thermoregulation models, especially for ambient conditions close to the thermoneutrality. In the thermoneutral zone, skin blood flow is the major component for regulation of heat balance (22). Therefore, this thesis emphasizes on the physiology and mathematical modelling of thermoregulatory changes in skin blood flow.

\section{Outline of the thesis}

As stated above, this thesis aims to expand the synergy between physiology of thermoregulation and mathematical modelling. The thesis can be roughly split into two parts. The first part (i.e. Chapter 2 through Chapter 4) addresses the physiology of human thermoregulation and the second part (i.e. Chapter 5 and Chapter 6) focuses on the translation of these physiological concepts into a mathematical model. More specifically, in Chapter 2, the basics of heat balance and the thermoneutral zone are reviewed with special focus on how the thermoneutral zone is influenced by factors such as body composition, clothing, age and sex. In Chapter 3, age effects on control of skin blood flow during local cooling are studied. Chapter 4 focuses on 
age effects in thermoregulation during mild cold and rewarming and how this affects cardiovascular parameters such as systolic blood pressure. Chapter 5 describes the use of neurophysiology in mathematical modelling of skin blood flow. In Chapter 6 a novel approach to model thermal sensation, based on neurophysiology, is given. Finally, in Chapter 7, the results obtained in this thesis are discussed, techniques to gain knowledge about thermoregulation are reviewed, and implications and applications for future research are presented.

\section{References}

1. Burton, A.C. and O.G. Edholm, Man in a cold environment, 1955, London: Edward Arnold (Publishers) LTD.

2. White, C.R., N.F. Phillips, and R.S. Seymour, The scaling and temperature dependence of vertebrate metabolism. Biology letters, 2006. 2(1): p. 125-7.

3. Schellen, L., et al., Differences between young adults and elderly in thermal comfort, productivity, and thermal physiology in response to a moderate temperature drift and a steady-state condition. Indoor Air, 2010. 20(4): p. 273-83.

4. Johnson, F., et al., Could increased time spent in a thermal comfort zone contribute to population increases in obesity? Obes Rev, 2011.

5. Keith, S.W., et al., Putative contributors to the secular increase in obesity: exploring the roads less traveled. International journal of obesity, 2006. 30(11): p. 1585-94.

6. van Marken Lichtenbelt, W.D. and P. Schrauwen, Implications of non-shivering thermogenesis for energy balance regulation in humans. American journal of physiology. Regulatory, integrative and comparative physiology, 2011.

7. de Dear, R., Revisiting an old hypothesis of human thermal perception: alliesthesia. Building Research \& Information, 2011. 39(2): p. 108-117.

8. Fiala, D., et al., Physiological modeling for technical, clinical and research applications. Frontiers in bioscience, 2010. 2: p. 939-68.

9. Severens, N.M., Modelling Hypothermia in Patients Undergoing Surgery, in PhD-Thesis2008, Eindhoven University of Technology: Eindhoven.

10. Guyton, A.C. and J.E. Hall, Textbook of Medical Physiology. 10 ed2000, Philadelphia: W.B.Saunders Company.

11. Morrison, S.F., 2010 Carl Ludwig Distinguished Lectureship of the APS Neural Control \& Autonomic Regulation Section: Central Neural Pathways for Thermoregulatory Cold Defense. Journal of Applied Physiology, 2011.

12. Kellogg, D.L., Jr., In vivo mechanisms of cutaneous vasodilation and vasoconstriction in humans during thermoregulatory challenges. J Appl Physiol, 2006. 100(5): p. 1709-18.

13. Parsons, K., Human Thermal Environments. 2 ed, ed. K.C.Parsons2003: Taylor \& Francis (London). 
14. Wijers, S.L., W.H. Saris, and W.D. van Marken Lichtenbelt, Cold-Induced Adaptive Thermogenesis in Lean and Obese. Obesity (Silver Spring), 2010.

15. van Ooijen, A.M., et al., Cold-induced heat production preceding shivering. Br J Nutr, 2005. 93(3): p. 387-91.

16. Hardy, J.D. and E.F. Dubois, Basal metabolism, radiation, convection and vaporization at temperatures of 22 to 35C. The Journal of Nutrition, 1937. 15(5): p. 477-497.

17. Fanger, P.O., Thermal Comfort, 1970: Copenhagen: Danish Technical Press.

18. Stolwijk, J.A., A mathematical simulation model of the skin for evaluation of surface temperature gradients resulting from local variations in metabolism and blood flow. Bibl Radiol, 1975(6): p. 151-6.

19. Stolwijk, J.A., Mathematical models of thermal regulation. Annals of the New York Academy of Sciences, 1980. 335: p. 98-106.

20. Wissler, E.H., A Mathematical Model of the Human Thermal System. The Bulletin of mathematical biophysics, 1964. 26: p. 147-66.

21. Wissler, E.H., Probability of survival during accidental immersion in cold water. Aviation, space, and environmental medicine, 2003. 74(1): p. 47-55.

22. Brengelmann, G.L. and M.V. Savage, Temperature regulation in the neutral zone. Ann N Y Acad Sci, 1997. 813: p. 39-50. 


\section{CHAPTER 2}

\section{THE THERMONEUTRAL ZONE: IMPLICATIONS FOR METABOLIC STUDIES}




\begin{abstract}

\section{Background}

A thermoneutral environment is important for many human physiological studies. The thermoneutral zone (TNZ) is defined as the range of ambient temperatures without regulatory changes in metabolic heat production or evaporative heat loss. Many factors influence the thermoneutral zone, such as body composition, clothing, energy expenditure, age and gender. These factors have the potential to introduce bias in study results and therefore need to be taken into consideration in many metabolic studies or studies on obesity, medical conditions, thermal comfort or vigilance.
\end{abstract}

\title{
Aim
}

Given new developments on the TNZ combined with historical views the aim of this review is to 1) provide insight in how the human TNZ is affected by internal and external factors, 2) indicate how skin blood flow characteristics could be used as an objective criterion for determining whether someone is in the thermoneutral zone, 3) explain implications of the TNZ on metabolic studies and 4) indicate future directions to enhance understanding of the TNZ, especially for the elderly and obese. 


\section{Introduction}

In 1902, Max Rubner was the first to put forward notion of a thermoneutral environment in mammals (1); he realized that his experiments on energy balance in nutrition could only be reproduced when the environmental conditions were equal. The concept was later adopted and applied to humans by Hardy and Dubois (1937) (2). They defined the lower limit of the thermoneutral zone as: "the maximum gradient (Tskin - Tair) over which the body can maintain its temperature without increase in heat production". In nude subjects they found a maximum gradient of $4.7^{\circ} \mathrm{C}$ at the lower limit of the neutral zone. This corresponded to an air temperature of $28.5^{\circ} \mathrm{C}$. Below this limit heat loss regulation through vasoconstriction of the skin blood vessels was no longer sufficient to maintain body temperature $(2,3)$. Hardy and Dubois did not explicitly define an upper limit of the neutral zone, however their results indicated that evaporation was markedly increased at $32^{\circ} \mathrm{C}(2)$. An explicit upper limit of the thermoneutral zone was later defined using heat stress (heart rate) or increases in evaporative water loss as a criterion $(4,5)$.

Nowadays the definition of the thermoneutral zone is reformulated to: "the range of ambient temperature at which temperature regulation is achieved only by control of sensible (dry) heat loss, i.e. without regulatory changes in metabolic heat production or evaporative heat loss. The thermoneutral zone (TNZ) will therefore be different when insulation, posture or basal metabolism vary" (6). Here regulation of sensible heat loss refers to heat loss by conduction, convection or radiation (7). This means that thermoregulation in the thermoneutral zone only occurs through vasomotor control (8-10).

The concept of the thermoneutral zone is shown in Figure $1 \mathrm{~A}$. Below the lower critical temperature (LCT) of the TNZ heat balance can be achieved by upregulation of metabolic heat production (non-shivering thermogenesis and/or shivering). Above the upper critical temperature (UCT) heat balance can be achieved by increases in evaporation (sweating). In humans, the onset of sweating is accompanied with active vasodilation, which also contributes to the maintenance of heat balance by increasing heat transport from the body to the skin (11). Above the UCT heat production also increases due to increased blood circulation, activity of sweat glands and increased body temperature (12).

For this review we only focus on the thermoneutral zone. Note that there is a clear distinction between the thermoneutral zone and the core inter-threshold zone (CIZ). Both zones refer to a temperature range in which temperature regulation is achieved without increasing energy expenditure and without sweating. The difference between both zones is that the TNZ refers to the ambient temperature range, whereas the $\mathrm{CIZ}$ refers to the internal body temperature range (8). 


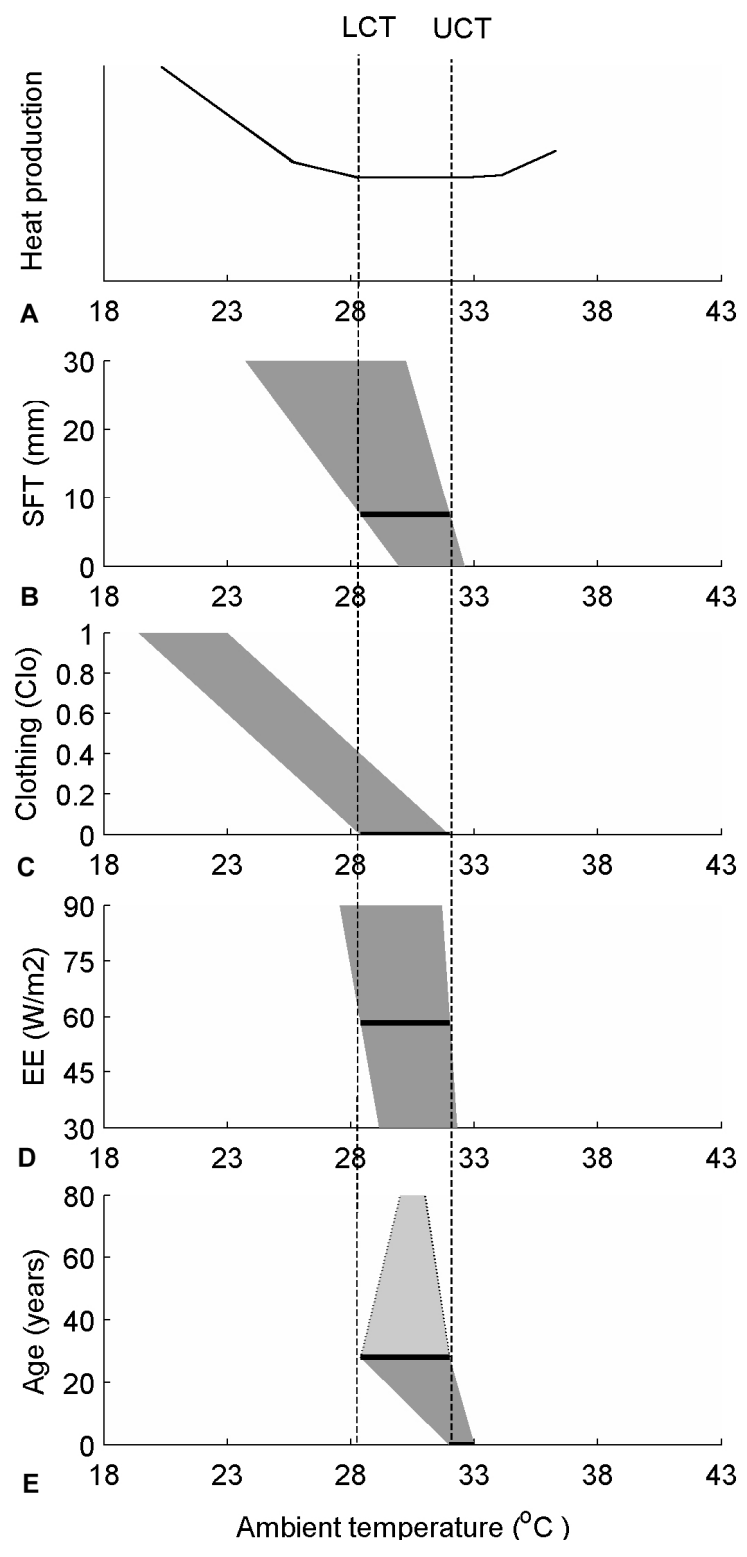

Figure 1: A) Thermoneutral zone (TNZ). The lower critical temperature (LCT) defines the lower bound of the TNZ. Below the LCT facultative heat production is increased to maintain thermal balance. The upper critical temperature (UCT) defines the upper bound of the TNZ. Above the UCT thermal balance is maintained by sweating. The solid horizontal line in subplots $B$ through $E$ indicates a reference TNZ as observed in experiments. B) Theoretical TNZ (gray area) over a range of subcutaneous fat thickness (SFT). C) TNZ (gray area) over a range clothing insulation. D) TNZ (gray area) over a range of energy expenditure. E) TNZ (gray area) over a range of age. Above 28 years (light gray area) the narrowing of the TNZ is not yet confirmed with experiments.

\section{Thermoneutral zone across studies}

The TNZ has mainly been studied in animals $(1,13-17)$, yet some studies exist that focus on the human $\operatorname{TNZ}(2,4,5,9,18)$. Hardy and Dubois are the first to describe the TNZ in men and women $(2,18)$, Craig and Dvorak defined a TNZ in water (4), Hey and Katz studied the TNZ in newborns (5) and Savage and Brengelmann studied skin blood flow in the TNZ (9). 
Research fields differ in defining the ambient temperature related to the TNZ. For instance, in the built environment operative temperature is used $(19,20)$, which is a weighted combination of air temperature and radiative temperature (21). Others use air (dry bulb) temperature (22-25) or control skin temperature directly by water immersion (26-30), or a water-perfused suit (31-34). Due to differences in thermal properties (i.e. mainly conduction) the thermoneutral zone in water is shifted upward compared to air $\left(33^{\circ} \mathrm{C}\right.$ to $35.5^{\circ} \mathrm{C}$ in water vs. $28.5^{\circ} \mathrm{C}$ to $32^{\circ} \mathrm{C}$ in air) $(2,4,9,10)$. In this review air temperature (i.e. dry bulb temperature) is used as the default TNZ medium.

\section{Heat balance in the thermoneutral zone}

In a steady state environment a subject can only be in the thermoneutral zone when heat production and heat loss are balanced. In classic textbooks on human thermoregulation heat balance is presented by the heat balance equation (35-37): $S=(M-W)-(E+C+R+B)$, where heat storage $(S)$ is defined as the difference between heat production (metabolism $M$ corrected for work $W$ ) and heat loss (evaporation $\mathrm{E}$, convection and conduction $\mathrm{C}$, radiation $\mathrm{R}$ and respiration $\mathrm{B}$ ).

\section{Heat production}

Total heat production can be categorized into obligatory and facultative components (38). Obligatory components include: basal metabolic rate (BMR), the obligatory part of diet-induced thermogenesis (ODIT) and involuntary physical activity (e.g. feeding, posture) (38). Facultative components include: the facultative part of diet induced thermogenesis (fDIT) and voluntary physical activity. Cold-induced thermogenesis is omitted here because it plays no role for subjects within the thermoneutral zone. BMR is the heat produced in an organism in a rested, awake, fasting and thermoneutral state and is needed to keep vital body processes functioning (6). In a resting sedentary male the energy expenditure is about $58 \mathrm{Wm}^{-2}(37)$. For comparison, typical values for energy expenditure in a reclining position or during sedentary activity are $46 \mathrm{Wm}^{-2}$ and $70 \mathrm{Wm}^{-2}$ respectively (21). Next, the obligatory part of DIT is necessary to process the food ingested. Note that DIT may also consist of a facultative part, i.e. burning excess calories, and is the focus of many studies on obesity (39). DIT is typically $10 \%$ to $15 \%$ of total daily heat production (40). Physical activity thermogenesis (both voluntary and involuntary) occurs when muscles perform work; approximately $65 \%$ to $80 \%$ of energy associated with work is released as heat $(41,42)$.

\section{Heat loss}

Body heat is lost at the skin surface and by respiration. Heat produced within the body is transported to the skin by conduction through tissues and by blood perfusion (convection) $(43,44)$. At skin in distal areas (hands and feet) the primary heat 
influx comes from blood flow, whereas at more proximal sites (torso) heat is also delivered through conduction from underlying metabolically active tissues (liver, gut, etc) (45). In the thermoneutral zone the regulation of skin blood flow is crucial to maintain thermal balance.

\section{Skin blood flow}

Total skin blood flow can vary from close to $0 \mathrm{~L} \mathrm{~min}^{-1}$ in a cool environment to as high as $7.8 \mathrm{~L} \mathrm{~min}^{-1}$ in a hot environment $(46,47)$. In the thermoneutral zone, the amount of heat transported from core to skin by blood flow is estimated between $19 \mathrm{Wm}^{-2}$ (near the LCT) and $218 \mathrm{Wm}^{-2}$ (near the UCT) $(9,48)$.

The majority of skin blood flow studies have been performed on the forearm. Extrapolation of blood flow data to whole body skin has to be performed with caution because of large regional differences $(45,49-51)$. For instance, skin of the head and hands only comprises about $13 \%$ of the total skin surface (112), yet between $25 \%$ and $27 \%$ of total skin blood flow occurs in these areas (52). Blood flow changes to environmental temperature variations also depend on the skin region. For example, during body heating of cooled subjects, total hand blood flow increased 29-fold, whereas forearm blood flow increased 3 -fold (50). With respect to reduction in heat loss through vasoconstriction, regional differences reported are about $-17 \%$ at the head and trunk, $-25 \%$ at the arms and legs and about $-50 \%$ at the hands and feet (53). These regional differences in skin blood flow and heat transport are attributed to arterio venous anastomoses (AVAs). AVAs are only present in glabrous skin (palms, ventral region of fingers, soles, forehead and lips) $(45,48)$. When these AVAs are opened, they form a bypass for blood from arterioles to venules, whereas the blood otherwise would only flow through high resistance capillaries at the skin surface. Hence, opening of AVAs greatly increases heat transport to the skin $(45,54$, 55). In a thermoneutral environment blood flow in AVA rich glabrous skin has a characteristic fluctuation with 2 to 3 vasoconstrictions per minute (56). This property, which is found in glabrous skin alone, can be used to measure whether a subject is within the TNZ (see practical considerations) (57).

Overall, the ability of skin to control heat loss is influenced by the vascular anatomy, flow rate, regulation of skin blood flow and the exposure to the environment. For reviews on skin blood flow regulation see Kellogg (2006) and Johnson and Kellogg $(2010)(11,58)$. Although the area of glabrous skin is small relative to the entire body surface, its importance for heat loss regulation is large. This is due to the above-mentioned AVA's and because glabrous skin areas are normally the skin areas that are actually exposed to the environment. Clothing covers most other parts of the skin. Therefore, in clothed humans, glabrous skin areas are considered as major contributors to heat regulation in the thermoneutral zone (59). 


\section{Modulating factors}

The thermoneutral zone is influenced by several internal and external factors. Here the modulating effect of body composition, clothing, energy expenditure, age and gender on the TNZ is addressed. In Figure 1 the influences of these factors on the TNZ are shown. For comparisons the standard TNZ $\left(\mathrm{LCT}_{0}=28.6^{\circ} \mathrm{C}\right.$ and $\left.\mathrm{UCT}_{0}=32.0^{\circ} \mathrm{C}\right)$ was taken from a 28 years old nude male subject with standard basal metabolic rate $\left(\mathrm{BMR}_{0}=58 \mathrm{~W} / \mathrm{m}^{2}\right)$ and subcutaneous fat thickness $\left(\mathrm{SFT}_{0}=7.5 \mathrm{~mm}\right)$. The subscript " 0 " was used to denote the value of the standard, or reference subject. Where possible temperature data from literature was used, otherwise the theoretical influence was calculated as described in the corresponding sections.

\section{Body composition}

Insulation of tissues can be viewed as a series of thermal resistances (inverse of conductivity) of muscle and subcutaneous fat (60). The thermal resistance of tissues is a function of both the conductivity and blood perfusion (see for an overview of heat conductivities of tissues refs. (61) and (62)). In general fat mass is positively related to tissue insulation (63). For limb muscle the story is more complicated. In resting conditions, limb muscle tissue is a major factor of the insulative capacity of the body explaining up to $70 \%$ of the total insulation $(28,60,64)$. However, the insulative effect of limb muscle is only present with reduction of blood flow. During exercise in cold conditions blood flow is maintained in limb muscle, which prevents insulation (60). Under resting conditions, subjects with higher limb muscle mass also have a higher volume of blood -and corresponding heat transport- flowing from the body to the limbs. Therefore, limb muscle mass is negatively associated with tissue insulation (63).

Tissue insulation is also influenced by the subcutaneous fat layer, which serves as an insulating layer between muscle and skin $(25,63-65)$. The thickness of the subcutaneous fat layer is by far the most important factor for the lower critical temperature when subjects are immersed in water (60). For reviews on the influence of tissue type on tissue insulation and temperature regulation see Rennie (1988) (60) and Anderson (1999) (64).

Rennie (1988) showed that the lower critical water temperature of the TNZ can be expressed as a function of the thickness of the subcutaneous fat + skin layer (SFT) (i.e. for subjects with equal heat production and muscle mass) (60). Here we use the same approach to show the influence of sub cutaneous fat thickness on the air TNZ (Figure 1B). The LCT and UCT were calculated relative to the standard subject as follows: $\mathrm{LCT}=\mathrm{LCT}_{0}+\mathbf{0 . 9 2} \cdot \mathrm{BMR}_{0} \cdot\left(\left(\mathrm{SFT}_{0}-\mathrm{SFT}\right) / \mathrm{K}_{\mathrm{LCT}}\right)$ and $\mathrm{UCT}=\mathrm{UCT}_{0}+$ 0.92 $\cdot \mathrm{BMR}_{0} \cdot\left(\left(\mathrm{SFT}_{0}-\mathrm{SFT}\right) / \mathrm{k}_{\mathrm{UCT}}\right)$, where, $\mathrm{k}\left(\mathrm{Wm}^{-1}{ }^{\circ} \mathrm{C}^{-1}\right)$ is the conductivity of the subcutaneous fat + skin layer. The factor 0.92 is used to correct for respiratory heat loss, i.e. $8 \%$ of total heat production (60). Near the LCT the thermal conductivity of subcuta- 
neous fat and skin is lowest due to vasoconstriction $\left(\mathrm{k}_{\mathrm{LCT}}=0.28 \mathrm{Wm}^{-1} \mathrm{C}^{-1}\right.$ from (28)). Near the UCT the thermal conductivity of subcutaneous fat and skin is higher due increased blood flow ( $\mathrm{k}_{\mathrm{UCT}}=0.73 \mathrm{Wm}^{-1} \mathrm{C}^{-1}$ from (28)).

Although the calculation above does not account for regional differences in adiposity and other complexities, it does illustrate the impact of the subcutaneous fat layer on the thermoneutral zone. For instance, a subcutaneous fat thickness of $40 \mathrm{~mm}$ (quite common in obesity (66)) results in a LCT of $22^{\circ} \mathrm{C}$. Note that LCT of $22^{\circ} \mathrm{C}$ is for a nude subject. Inclusion of light clothing $(0.5 \mathrm{clo})$ lowers the LCT further to about $18^{\circ} \mathrm{C}$. With a lower LCT compared to a lean subject, an obese subject may have a reduced need for cold-induced increases in energy expenditure, which in turn increases the likelihood of sustained overweight (67). Indeed, studies indicate that subjects with increased fat mass (both subcutaneous fat thickness and whole body fat percentage) are capable of enduring lower ambient temperatures without significantly increasing heat production $(60,68)$, or that the cold induced heat production is negatively related to the thickness of subcutaneous fat $(25,65,69)$. In relation to the UCT, no study directly measured the UCT in obese subjects. Yet, it has been suggested that obese may have increased sweat gland activity at normal room temperature $\left(\mathrm{T}_{\mathrm{air}}=20-22^{\circ} \mathrm{C}\right)$ relative to lean subjects (70).

Body composition also influences the distribution of heat loss. Increased body fat is associated with decreased proximal temperatures (trunk) and increased distal skin temperatures (hands and feet) $(71,72)$, thereby decreasing heat loss from proximal sites and increasing heat loss from distal sites. This is of special relevance when thermoneutrality is obtained by means of local cooling (e.g. automotive industry). For instance, in obese more body heat can be extracted by hand cooling than in lean subjects.

\section{Clothing}

One of the functions of clothing is to keep the microclimate around the body comfortable for a range of ambient temperatures. Factors that influence the insulation of clothing are: dry resistance, evaporative resistance, compression from wind and movements (37). Extensive databases on the thermal properties of clothing are available (73). The unit used to express the insulation value of clothing is the "Clo" ( $1 \mathrm{Clo}=0.155 \mathrm{~m}^{2 \circ} \mathrm{CW}^{-1}=$ equivalent to a business suit). A simplified example of the impact of clothing on our thermal environment shows that in a steady state environment of a sedentary resting subject, clothing of 1 Clo lowers required ambient temperature by $9.7^{\circ} \mathrm{C}\left(0.92 \times 58 \mathrm{Wm}^{-2} \times\left(0.155 \mathrm{~m}^{2 \circ} \mathrm{CW}^{-1}+\left(7.5 \times 10^{-3} \mathrm{~m} / 0.28 \mathrm{Wm}^{-1} \mathrm{C}^{-1}\right)\right) \approx\right.$ $9.7^{\circ} \mathrm{C}$; again the factor 0.92 is used to correct metabolic heat production for respiratory heat loss). Hence, relative to a nude subject, the ambient temperature of the thermoneutral zone is shifted downward by $9.7^{\circ} \mathrm{C}$, which results in a thermoneutral temperature of around $20.3^{\circ} \mathrm{C}\left(30.0^{\circ} \mathrm{C}-9.7^{\circ} \mathrm{C}=20.3^{\circ} \mathrm{C}\right)$. In summary, the ambient 
temperature of the TNZ is lowered according to the insulation provided by clothing (Figure 1C).

\section{Energy Expenditure}

In resting conditions energy expenditure is influenced by factors such as diet, circadian rhythm, posture and acclimatization. These factors may cause a shift in the potential for temperature regulation by sensible heat loss, which may introduce a bias in studies on metabolism, skin blood flow, vigilance and thermal comfort.

Thermal balance can only be maintained when heat production is equal to heat loss. Therefore the TNZ is shifted to lower temperatures when energy expenditure increases $(57,74)$. Vice versa, the TNZ shifts to higher temperatures when energy expenditure decreases (see Figure 1D). The LCT and UCT were calculated relative to the standard subject as follows: $\mathbf{L C T}=\mathbf{L C T}_{\mathbf{0}}+\mathbf{0 . 9 2} \cdot\left(\mathrm{BMR}_{\mathbf{0}}-\mathrm{BMR}\right) \cdot\left(\mathrm{SFT}_{\mathbf{0}} / \mathbf{K}_{\mathrm{LCT}}\right)$ and $\mathrm{UCT}$ $=\mathrm{UCT}_{0}+\mathbf{0 . 9 2} \cdot\left(\mathrm{BMR}_{\mathbf{0}}-\mathrm{BMR}\right) \cdot\left(\mathrm{SFT}_{\mathbf{0}} / \mathrm{k}_{\mathrm{UCT}}\right)$.

Digestion of nutrients is associated with an increase in metabolic rate between $+10 \%$ to $+15 \%$ of total daily energy expenditure depending on the nutrients ingested $(40,75)$. However, the acute thermogenic effect of diet can be much higher (+25\%) (76). To maintain thermal balance, heat loss should also increase with $25 \%$ and therefore the TNZ shifts to lower temperatures.

With respect to the influence of circadian rhythm on the TNZ: over the course of a day body temperature naturally follows both heat production and heat loss (77-80). Heat production is phase shifted approximately $1.2 \mathrm{~h}$ ahead of heat loss, with a maximum at noon ( $+10 \%$ of mean $24 \mathrm{~h}$ heat production) and a minimum at night $(-6 \%$ of mean $24 \mathrm{~h}$ heat production) $(77,78)$. On top of this circadian redistribution of skin blood flow (i.e. from trunk to the extremities) causes minimum internal heat conductance at day ( $-9 \%$ of mean $24 \mathrm{~h}$ internal heat conduction) and maximum heat conductance at night ( $+5 \%$ of mean $24 \mathrm{~h}$ internal heat conduction) (79). Therefore, the TNZ is lowest at noon and highest at night.

Posture affects both heat production and heat loss (81-83). In supine position heat production is decreased in muscles that are used during upright position (about $-2 \%$ heat produced in thermoneutral conditions and about $-19 \%$ heat produced in cool conditions) (82). As a consequence the TNZ in supine position is shifted upward relative to the TNZ in upright position. Furthermore, arterial baroreceptor reflexes that accompany a supine position cause vasodilatation both in muscle and skin tissue ( $+57 \%$ blood flow in femoral artery), which decreases insulation and contributes to the upward shift of the TNZ in supine vs. upright position (84).

Another factor that influences the TNZ is acclimatization. Relative to nonacclimatized people, those that are acclimatized to cold conditions maintain a significantly greater BMR (i.e. under thermoneutral conditions) (85). As a consequence, the TNZ is shifted downward in cold acclimatized vs. non-acclimatized subjects. The acclimatization can be induced by geography (e.g. tropic vs. arctic regions), altitude 
and by season (e.g. summer vs. winter in non-equatorial latitudes). With respect to seasonal acclimatization, increased BMR and increased sleeping metabolic rate have been measured in winter $\left(+6 \%\right.$ heat production for a $10^{\circ} \mathrm{C}$ decrease in air temperature) $(86,87)$. Thus, depending on the season-induced acclimatization, the TNZ in winter is shifted to lower temperatures relative to the summer TNZ. However, in developed countries there is a continuing trend of increasing indoor temperatures, which reduces seasonal cold acclimatization and may have a causal relation to the increases in obesity prevalence (67). Moreover, obese subjects have a lower LCT due to increased insulation, which may further reduce the need for cold acclimatization and in turn may contribute to sustained overweight.

\section{Age}

In neonates the thermoneutral zone depends greatly on the birth weight and ranges between $35.0^{\circ} \mathrm{C}$ to $35.5^{\circ} \mathrm{C}$ in $1 \mathrm{~kg}$ babies and $33.8^{\circ} \mathrm{C}$ to $34.5^{\circ} \mathrm{C}$ in $2 \mathrm{~kg}$ babies (5). Within about a month the TNZ ranges from $32.0^{\circ} \mathrm{C}$ to $34.0^{\circ} \mathrm{C}$. Until adulthood the TNZ continues to decrease to the range from $28.6^{\circ} \mathrm{C}$ to $32.0^{\circ} \mathrm{C}$. With further increasing age, changes occur in various factors that affect thermoregulation. With respect to body composition, lean mass is in general decreased in elderly, whereas fat mass is increased, and subcutaneous fat mass is decreased (88). Secondly, elderly show decreased temperature sensitivity $(89,90)$ and impaired neural control of vasoconstriction $(10,23,25,91-93)$. On top of that, results suggest that control of skin blood flow in elderly is not able to maintain thermal balance in the same skin temperature range as young adults (10). However, vasoconstriction might not be affected by age in all skin regions $(31,94,95)$, and there are indications that the blunting effects of ageing on thermoregulation can partly be compensated for by physical fitness (31, $96,97)$. Nevertheless, age is associated with impaired thermoregulation even during mild thermal challenges (23).

Although the majority of studies that describe age effects on thermoregulation relate to the internal temperature range for thermoregulation and not to the ambient temperature range, it does indicate that elderly have an impaired ability to maintain thermal balance in the cold and in the heat compared to young adults (23, $25,98,99)$. Elderly either fail to sense the thermal imbalance and/or they fail to respond appropriately (80). In conclusion, on average, elderly respond slower to slight disturbances in thermal balance and are not able to maintain thermal balance with vasomotor responses in the same temperature range as young adults. Consequently, the thermoneutral zone for elderly is narrower than for young adults, although the exact range has not yet been determined (Figure 1E).

\section{Gender}

Gender differences in thermoregulation are mainly explained by the differences in body characteristics and endocrinal physiology $(26,100)$. In general, yet with large 
individual differences, women have a larger surface to mass ratio, which implies that women are more prone to heat loss (100). On the other hand, women have a higher whole body and subcutaneous fat content than men, which in turn increases insulation $(26,64)$. Interestingly, in men, increased body fat is associated with lower proximal skin (torso and abdomen) temperatures and higher distal (hand and foot) temperatures $(71,72)$. In contrast, women are known to have colder skin at distal areas, despite the increased body fat content relative to men (101). Aside from differences in metabolic heat production, part of this effect can be attributed to reproductive hormones and the menstrual phase (102). Progesterone levels increase during the luteal phase, and cause an increased internal threshold temperature for vasodilation and sweating $(102,103)$. As a consequence, the extremities remain colder, more body heat is preserved and core body temperature rises. Vice versa, increased estrogen during the follicular phase decreases the threshold for vasodilatation, which causes increased distal temperature and lowers core temperature.

Unfortunately these shifts in $\mathrm{ClZ}$ cannot be directly translated to shifts in the TNZ. A longitudinal study showed that in lightly dressed early pregnant women (i.e. prolonged high threshold for vasodilation) their TNZ was not statistically different from their post-partum follicular-phase (low threshold for vasodilation) TNZ (57). This suggests that there is no shift in the TNZ due to a change in sex hormones. However, during pregnancy, as the metabolic rate of the fetus and mother increased, there was a marked decrease in ambient temperature to reach TNZ $\left(26.64^{\circ} \mathrm{C} \pm 0.64^{\circ} \mathrm{C}\right.$ at week 8 vs. $22.67^{\circ} \mathrm{C} \pm 0.58^{\circ} \mathrm{C}$ at week 36$)$.

Relative to men, thermoregulatory responses to cold and heat are shifted to higher body temperatures (104). Also women are reported to initiate sweating at higher heat loads than males $(105,106)$. Because of intrinsic gender related differences in body characteristics these internal temperature thresholds cannot be translated directly into changes within the TNZ. Nevertheless, semi-nude women are reported to increase metabolic heat production already when air temperature is decreased below $31^{\circ} \mathrm{C}$, whereas in men the LCT was $28.5^{\circ} \mathrm{C}(18)$. Thus in general, relative to men, the thermoneutral zone of women is shifted upward. It is not yet known whether the width of the TNZ is affected.

\section{Practical considerations and future directions}

Due to the complex interactions of factors that influence the TNZ it is often difficult to make an a priori definition of the thermoneutral zone for any individual subject. When designing an experiment it would be much more practical to define an approximate thermoneutral environment based on the average subject characteristics (e.g. slightly warmer environment for women than for men), and actually measure during a test whether a subject is indeed within the thermoneutral zone. The environmental conditions can then be adjusted to the needs of the individual subject. 
This concept is used in some human studies $(56,57)$ and also in animal (rat) thermophysiology $(13,17)$. For instance, the study of Hartgill et al. (2011) was conducted in a climatic chamber, which allowed for temperature adjustment to each subject. However, most metabolic studies do not use this concept, which might significantly affect the outcome of experiments. For instance, in nutrition it has been reported that resting metabolic rate (while in fasting condition) of clothed female subjects (wearing a thin cotton trouser suit) was higher at $22^{\circ} \mathrm{C}$ than at $28^{\circ} \mathrm{C}(4.329 \pm 0.152 \mathrm{~kJ}$ $\mathrm{min}^{-1}$ vs. $3.899 \pm 0.122 \mathrm{~kJ} \mathrm{~min}^{-1}$ respectively). However, after consumption of a meal no difference in resting metabolic rate was observed anymore (107). The author reasoned that before the meal, part of the capacity for diet-induced thermogenesis (DIT) was already used to maintain thermal balance at $22^{\circ} \mathrm{C}$ (i.e. cold induced thermogenesis). Further, after the meal, the full capacity for facultative thermogenesis was reached both at $22^{\circ} \mathrm{C}$ and $28^{\circ} \mathrm{C}$. Calculation of DIT is performed relative to the baseline resting energy expenditure. Hence, when only measurements at $22^{\circ} \mathrm{C}$ would have been observed, there would have been a significant underestimation of the diet-induced thermogenesis. Since most metabolic studies do not incorporate the effects of TNZ-shifts, part of the high variability observed in diet-induced thermogenesis may be attributed to these temperature artifacts.

Relatively simple techniques exist to measure whether a subject is in its TNZ. The basic assumption is that in the TNZ the skin alternates between states of net vasodilation and net vasoconstriction, yet neither state dominates. In a thermoneutral environment blood flow in AVA rich glabrous skin has a characteristic fluctuation with 2 to 3 vasoconstrictions per minute (56). These fluctuations are directly observable by measuring skin blood flow (e.g. by Laser Doppler flowmetry, see Figure 2) or skin surface temperature (13). The major advantage of adopting these criteria for thermoneutrality in humans is that one has an objective criterion to determine whether an individual subject is in the TNZ.

In summary, to study temperature-induced responses in different groups (male vs. female; lean vs. obese), both groups should be relatively equidistant from their thermoneutral zone.

Further research is warranted to measure the effects of age, gender and obesity on the TNZ. The practical impact of these studies can be widespread from individual health to increased productivity and energy conservation in buildings. For instance, in elderly even a mild cold environment can contribute to health problems (108, 109). The same accounts for elderly in warm conditions (110). Precise knowledge of the TNZ is therefore especially important for those elderly that live in care houses. Although there is some evidence that the lower critical temperature (LCT) of the TNZ is shifted upward in females vs. males, it is not known whether the UCT is also shifted upward. This is important to know, because TNZ differences between males and females could contribute to large variations observed in metabolic or nutritional studies $(1,107)$. 


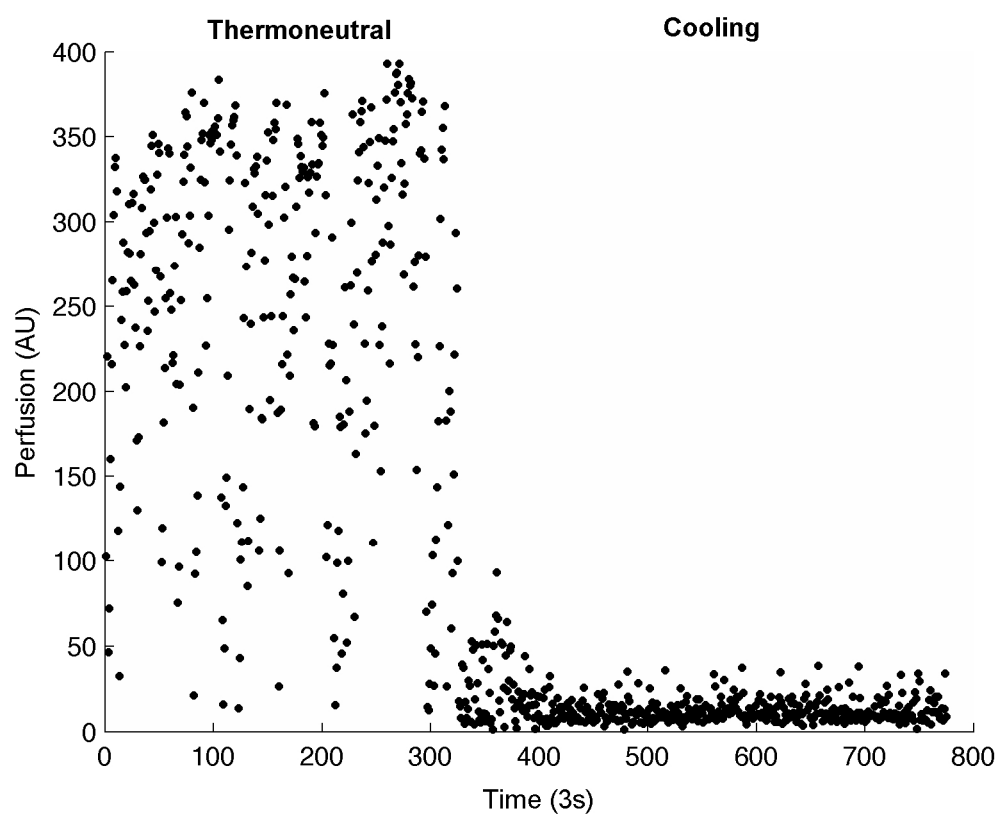

Figure 2: Recording of skin perfusion at glabrous skin of the hand (palm). In thermoneutral conditions perfusion fluctuates between vasoconstriction and vasodilation, yet neither state dominates. In a cool condition vasoconstriction dominates.

For obese subjects experimental results showed that the LCT is lowered with increased adiposity (60). Recently it has been suggested that effects of cold exposure on body weight could be studied in context of possible health strategies to tackle obesity (67). For such studies, precise knowledge of the TNZ is warranted. Moreover, since ambient temperature greatly influences the productivity of workers, with an optimum productivity in the TNZ (111), obese subjects might need cooler temperatures for optimal performance relative to their lean counterparts.

\section{Conclusions}

For each individual the thermoneutral zone is influenced by factors such as body composition, clothing, energy expenditure, age and gender. Therefore, the thermoneutral zone varies between conditions and between individual subjects. Metabolic studies in which thermoregulatory responses affect the outcome should incorporate individual variations of the thermoneutral zone in study designs. Otherwise, biased study results may cause invalid conclusions. This implies that for sound comparison between subjects, the environmental conditions should be attuned to each individual. Characteristic fluctuations in glabrous skin blood flow can be further explored as an objective criterion to measure whether a subject is within the thermoneutral zone. Already slight deviations from the thermoneutral zone may affect 
health and productivity. Therefore further research on the thermoneutral zone is warranted, especially for the obese and elderly.

\section{References}

1. M. Rubner: The laws of energy conservation in nutrition. Academic Press, INC. (London) LTD., London (1982)

2. J. D. Hardy and E. F. Dubois: Basal metabolism, radiation, convection and vaporization at temperatures of 22 to 35C. The Journal of Nutrition, 15(5), 477-497 (1937) 3. J. D. Hardy and E. F. Dubois: Regulation of Heat Loss from the Human Body. Proc Natl Acad Sci U S A, 23(12), 624-31 (1937)

4. A. B. Craig, Jr. and M. Dvorak: Thermal regulation during water immersion. J Appl Physiol, 21(5), 1577-85 (1966)

5. E. N. Hey and G. Katz: The optimum thermal environment for naked babies. Arch Dis Child, 45(241), 328-34 (1970)

6. T. C. IUPS: Glossary of terms for thermal physiology. Third edition. Revised by The Commission for Thermal Physiology of the International Union of Physiological Sciences (IUPS Thermal Commission). The Japanese Journal of Physiology, 51(2), 245-80 (2001)

7. F. P. Incropera, D. P. DeWitt, T. L. Bergman and S. A. Lavine: Introduction to Heat Transfer. John Wiley \& Sons, Inc., (2007)

8. I. B. Mekjavic and O. Eiken: Contribution of thermal and nonthermal factors to the regulation of body temperature in humans. J Appl Physiol, 100(6), 2065-72 (2006)

9. M. V. Savage and G. L. Brengelmann: Control of skin blood flow in the neutral zone of human body temperature regulation. J Appl Physiol, 80(4), 1249-57 (1996)

10. G. L. Brengelmann and M. V. Savage: Temperature regulation in the neutral zone. Ann N Y Acad Sci, 813, 39-50 (1997)

11. D. L. Kellogg, Jr.: In vivo mechanisms of cutaneous vasodilation and vasoconstriction in humans during thermoregulatory challenges. J Appl Physiol, 100(5), 1709-18 (2006)

12. C. F. Consolazio, L. R. Matoush, R. A. Nelson, J. B. Torres and G. J. Isaac: Environmental temperature and energy expenditures. Journal of Applied Physiology, 18, 65-8 (1963)

13. A. A. Romanovsky, A. I. Ivanov and Y. P. Shimansky: Selected contribution: ambient temperature for experiments in rats: a new method for determining the zone of thermal neutrality. J Appl Physiol, 92(6), 2667-79 (2002)

14. D. P. Clarkson, C. L. Schatte and J. P. Jordan: Thermal neutral temperature of rats in helium-oxygen, argon-oxygen, and air. Am J Physiol, 222(6), 1494-8 (1972)

15. K. Morgan: Thermoneutral zone and critical temperatures of horses. Journal of Thermal Biology, 23(1), 59-61 (1998) 
16. Y. Smith and O. B. Kok: A Suggested Thermoneutral Zone for African Lions (Panthera leio Linnaeus, 1758) in the Southwestern Kalahari, Namibia. Pakistan Journal of Biological Sciences, 9(13), 2535-2537 (2006)

17. M. C. Almeida, A. A. Steiner, N. C. Coimbra and L. G. Branco: Thermoeffector neuronal pathways in fever: a study in rats showing a new role of the locus coeruleus. J Physiol, 558(Pt 1), 283-94 (2004)

18. J. D. Hardy and E. F. Du Bois: Differences between Men and Women in Their Response to Heat and Cold. Proc Natl Acad Sci U S A, 26(6), 389-98 (1940)

19. P. O. Fanger: Assessment of man's thermal comfort in practice. Br J Ind Med, 30(4), 313-24 (1973)

20. L. Schellen, W. D. van Marken Lichtenbelt, M. G. Loomans, J. Toftum and M. H. de Wit: Differences between young adults and elderly in thermal comfort, productivity, and thermal physiology in response to a moderate temperature drift and a steady-state condition. Indoor Air, 20(4), 273-83 (2010)

21. ISOTC159: Ergonomics of the thermal environmet - Analytical determination and interpretation of thermal comfort using calculation of the PMV and PPD indices and local thermal comfort criteria (ISO 7730:2005,IDT). ISO copyright office, Geneva (2005)

22. H. A. Daanen, E. van de Vliert and X. Huang: Driving performance in cold, warm, and thermoneutral environments. Appl Ergon, 34(6), 597-602 (2003

23. D. W. deGroot and W. L. Kenney: Impaired defense of core temperature in aged humans during mild cold stress. Am J Physiol Regul Integr Comp Physiol, 292(1), R103-8 (2007)

24. W. D. van Marken Lichtenbelt, J. W. Vanhommerig, N. M. Smulders, J. M. Drossaerts, G. J. Kemerink, N. D. Bouvy, P. Schrauwen and G. J. Teule: Cold-activated brown adipose tissue in healthy men. N Engl J Med, 360(15), 1500-8 (2009)

25. G. M. Budd, J. R. Brotherhood, A. L. Hendrie and S. E. Jeffery: Effects of fitness, fatness, and age on men's responses to whole body cooling in air. J Appl Physiol, 71(6), 2387-93 (1991)

26. P. Tikuisis, I. Jacobs, D. Moroz, A. L. Vallerand and L. Martineau: Comparison of thermoregulatory responses between men and women immersed in cold water. J Appl Physiol, 89(4), 1403-11 (2000)

27. A. Veicsteinas, G. Ferretti and D. W. Rennie: Superficial shell insulation in resting and exercising men in cold water. J Appl Physiol, 52(6), 1557-64 (1982)

28. M. B. Ducharme and P. Tikuisis: In vivo thermal conductivity of the human forearm tissues. J Appl Physiol, 70(6), 2682-90 (1991)

29. Y. S. Park, D. W. Rennie, I. S. Lee, Y. D. Park, K. S. Paik, D. H. Kang, D. J. Suh, S. H. Lee, S. Y. Hong and S. K. Hong: Time course of deacclimatization to cold water immersion in Korean women divers. J Appl Physiol, 54(6), 1708-16 (1983) 
30. A. C. Burton and H. C. Bazett: A study of the average temperature of the tissues, of the exchanges of heat and vasomotor responses in man by means of a bath calorimeter. Am. J. Physiol, 117, 36-54 (1936)

31. B. R. Kingma, A. J. Frijns, W. H. Saris, A. A. van Steenhoven and W. D. van Marken Lichtenbelt: Cold-induced vasoconstriction at forearm and hand skin sites: the effect of age. Eur J Appl Physiol, 109(5), 915-21 (2010)

32. P. E. Pergola, D. L. Kellogg, Jr., J. M. Johnson and W. A. Kosiba: Reflex control of active cutaneous vasodilation by skin temperature in humans. Am J Physiol, 266(5 Pt 2), H1979-84 (1994)

33. J. M. Johnson, P. E. Pergola, F. K. Liao, D. L. Kellogg, Jr. and C. G. Crandall: Skin of the dorsal aspect of human hands and fingers possesses an active vasodilator system. J Appl Physiol, 78(3), 948-54 (1995)

34. C. S. Thompson and W. L. Kenney: Altered neurotransmitter control of reflex vasoconstriction in aged human skin. J Physiol, 558(Pt 2), 697-704 (2004

35. A. C. Burton and O. G. Edholm: Man in a cold environment, . Edward Arnold (Publishers) LTD., London (1955)

36. C. Gisolfi and F. Mora: The Hot Brain: Survival, Temperature and the Human Body. Cambridge, MIT Press, (2000)

37. K. Parsons: Human Thermal Environments. Taylor \& Francis, (2003)

38. W. D. van Marken Lichtenbelt and P. Schrauwen: Implications of Non-shivering Thermogenesis for Energy Balance Regulation in Humans (2011)

39. S. L. Wijers, W. H. Saris and W. D. van Marken Lichtenbelt: Individual thermogenic responses to mild cold and overfeeding are closely related. J Clin Endocrinol Metab, 92(11), 4299-305 (2007)

40. N. R. Stob, C. Bell, M. A. van Baak and D. R. Seals: Thermic effect of food and beta-adrenergic thermogenic responsiveness in habitually exercising and sedentary healthy adult humans. J Appl Physiol, 103(2), 616-22 (2007)

41. G. A. Gaesser and G. A. Brooks: Muscular efficiency during steady-rate exercise: effects of speed and work rate. J Appl Physiol, 38(6), 1132-9 (1975)

42. D. C. Poole, G. A. Gaesser, M. C. Hogan, D. R. Knight and P. D. Wagner: Pulmonary and leg VO2 during submaximal exercise: implications for muscular efficiency. J Appl Physiol, 72(2), 805-10 (1992)

43. H. H. Pennes: Analysis of tissue and arterial blood temperatures in the resting human forearm. J Appl Physiol, 1(2), 93-122 (1948)

44. E. H. Wissler: Pennes' 1948 paper revisited. J Appl Physiol, 85(1), 35-41 (1998)

45. I. Roddie: Circulation to skin and adipose Tissue. In: Handbook of Physiology, A critical, comprehensive presentation of physiological knowledge and concepts. Ed J. T. Shepherd, F. M. Abboud\&S. R. Geiger. American Physiological Society, Bethesda, Maryland (1983) 
46. J. D. Hardy and G. F. Soderstrom: Heat loss from the nude body and peripheral blood flow at temperatures of $22 \mathrm{C}$ to 35C. Journal of Nutrition, 16(5), 494-510 (1938)

47. L. B. Rowell: Human cardiovascular adjustments to exercise and thermal stress. Physiol Rev, 54(1), 75-159 (1974)

48. J. M. Johnson, G. L. Brengelmann, J. R. Hales, P. M. Vanhoutte and C. B. Wenger: Regulation of the cutaneous circulation. Fed Proc, 45(13), 2841-50 (1986)

49. R. Thauer: Circulatory adjustments to climatic requirements. In: Handbook of Physiology. Ed W. F. Hamilton\&P. Dow. American Phsyiological Society, Washington DC (1965)

50. I. C. Roddie, J. T. Shepherd and R. F. Whelan: The contribution of constrictor and dilator nerves to the skin vasodilatation during body heating. J Physiol, 136(3), 48997 (1957)

51. E. Tur, M. Tur, H. I. Maibach and R. H. Guy: Basal perfusion of the cutaneous microcirculation: measurements as a function of anatomic position. J Invest Dermatol, 81(5), 442-6 (1983)

52. A. B. Hertzman and W. C. Randall: Regional differences in the basal and maximal rates of blood flow in the skin. J Appl Physiol, 1(3), 234-41 (1948)

53. D. I. Sessler, A. Moayeri, R. Stoen, B. Glosten, J. Hynson and J. McGuire: Thermoregulatory vasoconstriction decreases cutaneous heat loss. Anesthesiology, 73(4), 656-60 (1990)

54. H. V. Sparks: Skin and Muscle. In: Peripheral Circulation. Ed C. P. Johnson. John Wiley \& Sons, Inc., New York (1978)

55. D. Grahn and H. Craig Heller: Heat Transfer in Humans: Lessons from Large Hibernators. In: Life in the Cold: Evolution, Mechanisms, Adaptation, and Application. Ed B. M. Barnes\&H. V. Carey. Biological papers of the University of Alaska, (2004)

56. T. K. Bergersen: A search for arteriovenous anastomoses in human skin using ultrasound Doppler. Acta Physiol Scand, 147(2), 195-201 (1993)

57. T. W. Hartgill, T. K. Bergersen and J. Pirhonen: Core body temperature and the thermoneutral zone: a longitudinal study of normal human pregnancy. Acta Physiol (Oxf) (2011)

58. J. M. Johnson and D. L. Kellogg, Jr.: Thermoregulatory and thermal control in the human cutaneous circulation. Front Biosci (Schol Ed). 1(2), 825-53 (2010)

59. E. J. Van Someren: Thermoregulation and aging. Am J Physiol Regul Integr Comp Physiol, 292(1), R99-102 (2007)

60. D. W. Rennie: Tissue heat transfer in water: lessons from the Korean divers. Med Sci Sports Exerc, 20(5 Suppl), S177-84 (1988)

61. H. F. Bowman, E. G. Cravalho and M. Woods: Theory, measurement, and application of thermal properties of biomaterials. Annu Rev Biophys Bioeng, 4(00), 43-80 (1975) 
62. A. Shitzer: Heat transfer in medicine and biology: analysis and applications. Plenum Press, London (1985)

63. D. W. deGroot, G. Havenith and W. L. Kenney: Responses to mild cold stress are predicted by different individual characteristics in young and older subjects. J Appl Physiol, 101(6), 1607-15 (2006)

64. G. S. Anderson: Human morphology and temperature regulation. Int J Biometeorol, 43(3), 99-109 (1999)

65. M. G. Hayward and W. R. Keatinge: Roles of subcutaneous fat and thermoregulatory reflexes in determining ability to stabilize body temperature in water. J Physiol, 320, 229-51 (1981)

66. J. Wang, B. Laferrere, J. C. Thornton, R. N. Pierson, Jr. and F. X. Pi-Sunyer: Regional subcutaneous-fat loss induced by caloric restriction in obese women. Obesity research, 10(9), 885-90 (2002)

67. F. Johnson, A. Mavroggiani, M. Ucci, A. Vidal-Puig and J. Wardle: Could increased time spent in a thermal comfort zone contribute to population increases in obesity? Obes Rev (2011)

68. S. L. Wijers, W. H. Saris and W. D. van Marken Lichtenbelt: Cold-Induced Adaptive Thermogenesis in Lean and Obese. Obesity (Silver Spring) (2010)

69. P. Tikuisis, D. G. Bell and I. Jacobs: Shivering onset, metabolic response, and convective heat transfer during cold air exposure. J Appl Physiol, 70(5), 1996-2002 (1991)

70. H. Loffler, J. U. Aramaki and I. Effendy: The influence of body mass index on skin susceptibility to sodium lauryl sulphate. Skin Res Technol, 8(1), 19-22 (2002)

71. D. M. Savastano, A. M. Gorbach, H. S. Eden, S. M. Brady, J. C. Reynolds and J. A. Yanovski: Adiposity and human regional body temperature. Am J Clin Nutr, 90(5), 1124-31 (2009)

72. A. M. Claessens-van Ooijen, K. R. Westerterp, L. Wouters, P. F. Schoffelen, A. A. van Steenhoven and W. D. van Marken Lichtenbelt: Heat production and body temperature during cooling and rewarming in overweight and lean men. Obesity (Silver Spring), 14(11), 1914-20 (2006)

73. ASHRAE: ASHRAE handbook, fundamentals. Atlanta (2005)

74. A. Meltzer: Thermoneutral zone and resting metabolic rate of broilers. Br Poult Sci, 24(4), 471-6 (1983)

75. I. Macdonald: Differences in dietary-induced thermogenesis following the ingestion of various carbohydrates. Ann Nutr Metab, 28(4), 226-30 (1984)

76. R. Swaminathan, R. F. King, J. Holmfield, R. A. Siwek, M. Baker and J. K. Wales: Thermic effect of feeding carbohydrate, fat, protein and mixed meal in lean and obese subjects. Am J Clin Nutr, 42(2), 177-81 (1985)

77. K. Krauchi and A. Wirz-Justice: Circadian rhythm of heat production, heart rate, and skin and core temperature under unmasking conditions in men. Am J Physiol, 267(3 Pt 2), R819-29 (1994) 
78. K. Krauchi: How is the circadian rhythm of core body temperature regulated? Clin Auton Res, 12(3), 147-9 (2002)

79. J. Aschoff: Circadian control of body temperature. J. therm. Biol, 8, 143 to 147 (1983)

80. E. J. Van Someren, R. J. Raymann, E. J. Scherder, H. A. Daanen and D. F. Swaab: Circadian and age-related modulation of thermoreception and temperature regulation: mechanisms and functional implications. Ageing Res Rev, 1(4), 721-78 (2002)

81. P. Tikuisis and M. B. Ducharme: The effect of postural changes on body temperatures and heat balance. Eur J Appl Physiol Occup Physiol, 72(5-6), 451-9 (1996)

82. G. C. Donaldson, M. Scarborough, K. Mridha, L. Whelan, M. Caunce and W. R. Keatinge: Effect of posture on body temperature of young men in cold air. Eur J Appl Physiol Occup Physiol, 73(3-4), 326-31 (1996)

83. S. Aizawa and M. Cabanac: The influence of temporary semi-supine and supine postures on temperature regulation in humans. Journal of Thermal Biology, 27, 109114 (2002)

84. H. Edfeldt and J. Lundvall: Sympathetic baroreflex control of vascular resistance in comfortably warm man. Analyses of neurogenic constrictor responses in the resting forearm and in its separate skeletal muscle and skin tissue compartments. Acta Physiol Scand, 147(4), 437-47 (1993)

85. W. R. Leonard, M. V. Sorensen, V. A. Galloway, G. J. Spencer, M. J. Mosher, L. Osipova and V. A. Spitsyn: Climatic influences on basal metabolic rates among circumpolar populations. Am J Hum Biol, 14(5), 609-20 (2002)

86. S. Osiba: The seasonal variation of basal metabolism and activity of thyroid gland in man. Jpn J Physiol, 7(4), 355-65 (1957)

87. G. Plasqui, A. D. Kester and K. R. Westerterp: Seasonal variation in sleeping metabolic rate, thyroid activity, and leptin. Am J Physiol Endocrinol Metab, 285(2), E338-43 (2003)

88. G. A. Borkan, D. E. Hults, S. G. Gerzof, A. H. Robbins and C. K. Silbert: Age changes in body composition revealed by computed tomography. J Gerontol, 38(6), 673-7 (1983)

89. H. W. Huang, W. C. Wang and C. C. Lin: Influence of age on thermal thresholds, thermal pain thresholds, and reaction time. J Clin Neurosci, 17(6), 722-6

90. J. Smolander: Effect of cold exposure on older humans. Int J Sports Med, 23(2), 86-92 (2002)

91. C. S. Thompson-Torgerson, L. A. Holowatz, N. A. Flavahan and W. L. Kenney: Rho kinase-mediated local cold-induced cutaneous vasoconstriction is augmented in aged human skin. Am J Physiol Heart Circ Physiol, 293(1), H30-6 (2007)

92. C. S. Thompson-Torgerson, L. A. Holowatz and W. L. Kenney: Altered mechanisms of thermoregulatory vasoconstriction in aged human skin. Exerc Sport Sci Rev, 36(3), 122-7 (2008) 
93. F. Khan, V. A. Spence and J. J. Belch: Cutaneous vascular responses and thermoregulation in relation to age. Clin Sci (Lond), 82(5), 521-8 (1992)

94. J. A. Wagner and S. M. Horvath: Influences of age and gender on human thermoregulatory responses to cold exposures. J Appl Physiol, 58(1), 180-6 (1985)

95. T. E. Wilson, K. D. Monahan, D. S. Short and C. A. Ray: Effect of age on cutaneous vasoconstrictor responses to norepinephrine in humans. Am J Physiol Regul Integr Comp Physiol, 287(5), R1230-4 (2004)

96. W. L. Kenney and C. G. Armstrong: Reflex peripheral vasoconstriction is diminished in older men. J Appl Physiol, 80(2), 512-5 (1996)

97. R. J. Petrella, D. A. Cunningham, P. M. Nichol and R. Thayer: Cardiovascular responses to facial cooling are age and fitness dependent. Med Sci Sports Exerc, 31(8), 1163-8 (1999)

98. C. G. Armstrong and W. L. Kenney: Effects of age and acclimation on responses to passive heat exposure. J Appl Physiol, 75(5), 2162-7 (1993)

99. A. Dufour and V. Candas: Ageing and thermal responses during passive heat exposure: sweating and sensory aspects. Eur J Appl Physiol, 100(1), 19-26 (2007) doi:10.1007/s00421-007-0396-9

100. H. Kaciuba-Uscilko and R. Grucza: Gender differences in thermoregulation. Curr Opin Clin Nutr Metab Care, 4(6), 533-6 (2001)

101. J. M. Stocks, N. A. Taylor, M. J. Tipton and J. E. Greenleaf: Human physiological responses to cold exposure. Aviat Space Environ Med, 75(5), 444-57 (2004)

102. N. Charkoudian: Influences of female reproductive hormones on sympathetic control of the circulation in humans. Clin Auton Res, 11(5), 295-301 (2001)

103. M. A. Kolka and L. A. Stephenson: Control of sweating during the human menstrual cycle. Eur J Appl Physiol Occup Physiol, 58(8), 890-5 (1989)

104. D. J. Cunningham, J. A. Stolwijk and C. B. Wenger: Comparative thermoregulatory responses of resting men and women. J Appl Physiol, 45(6), 908-15 (1978)

105. G. P. Kenny and O. Jay: Evidence of a greater onset threshold for sweating in females following intense exercise. Eur J Appl Physiol, 101(4), 487-93 (2007)

106. T. Ichinose-Kuwahara, Y. Inoue, Y. Iseki, S. Hara, Y. Ogura and N. Kondo: Sex differences in the effects of physical training on sweat gland responses during a graded exercise. Exp Physiol, 95(10), 1026-32

107. M. J. Dauncey: Influence of mild cold on $24 \mathrm{~h}$ energy expenditure, resting metabolism and diet-induced thermogenesis. Br J Nutr, 45(2), 257-67 (1981)

108. K. L. Hess, T. E. Wilson, C. L. Sauder, Z. Gao, C. A. Ray and K. D. Monahan: Aging affects the cardiovascular responses to cold stress in humans. J Appl Physiol, 107(4), 1076-82 (2009)

109. P. Wilkinson, S. Pattenden, B. Armstrong, A. Fletcher, R. S. Kovats, P. Mangtani and A. J. McMichael: Vulnerability to winter mortality in elderly people in Britain: population based study. BMJ, 329(7467), 647 (2004) 
110. R. Basu: High ambient temperature and mortality: a review of epidemiologic studies from 2001 to 2008. Environ Health, 8, 40 (2009)

111. O. Seppanen, W. J. Fisk and . Indoor climate and productivity. Rehva J, 3, 811 (2005)

112. Tikuisis, P., P. Meunier, and C.E. Jubenville, Human body surface area: measurement and prediction using three dimensional body scans. European journal of applied physiology, 2001. 85(3-4): p. 264-71. 



\section{CHAPTER 3}

\section{LOCAL SKIN BLOOD FLOW CONTROL: THE EFFECT OF AGE}

The contents of this chapter are published in Kingma BRM, Frijns AJH, Saris WHM, van Steenhoven AA, and van Marken Lichtenbelt WD. Cold induced vasoconstriction at forearm and hand skin sites: the effect of age. Eur J Appl Physiol 109: 915-921, 2010. 


\begin{abstract}

\section{Background}

During mild cold exposure elderly are at risk of hypothermia. In humans, glabrous skin at the hands is well adapted as a heat exchanger. Evidence exists that elderly show equal vasoconstriction to local cooling at the ventral forearm, yet no age effects on vasoconstriction at hand skin have been studied. Here, we tested the hypotheses that at hand sites (a) elderly show equal vasoconstriction to local cooling and (b) elderly show reduced response to noradrenergic stimuli.
\end{abstract}

\title{
Methods
}

Skin perfusion and mean arterial pressure were measured in 16 young adults ( $\mathrm{Y}: 18$ 28 years) and 16 elderly (E: 68-78 years). To study the effect of local vasoconstriction mechanisms local sympathetic nerve terminals were blocked by bretylium (BR). Baseline local skin temperature was clamped at $33^{\circ} \mathrm{C}$. Next, local temperature was reduced to $24^{\circ} \mathrm{C}$. After 15 minutes of local cooling noradrenalin (NA) was administered to study the effect of neural vasoconstriction mechanisms.

\section{Results}

No significant age effect was observed in vasoconstriction to local cooling at BR sites. After NA vasoconstriction at the forearm showed a significant age effect, however no significant age effect was found at the hand sites. [Change in CVC (\% from baseline): Forearm $Y-76 \pm 3$ vs. E $-60 \pm 5(p<0.01)$, dorsal hand $Y-74 \pm 4$ vs. E $72 \pm 4$ (n.s.), ventral hand $Y-80 \pm 7$ vs. $E-70 \pm 11$ (n.s.)].

\section{Conclusion}

In conclusion contrasting to results from the ventral forearm, elderly did not show a blunted response to local cooling and noradrenalin at hand skin sites. This indicates that at hand skin the noradrenergic mechanism of vasoconstriction is maintained with age. 


\section{Introduction}

With advancing age, thermoregulatory defense mechanisms may be impaired. Recent studies indicate that even during mild cold exposure elderly are predisposed to risk of hypothermia (1). Skin blood flow is a major effector of heat loss in humans, as it transports heat from the body core to the skin. DeGroot and Kenney (2007) report a reduced vasoconstrictor response in elderly subjects compared to young adults. However, their biophysical analysis could not explain why elderly failed to defend their core temperature. In his editorial response van Someren proposed (2) that there might be an underestimation in calculations of the actual heat loss, because the regions rich in arterio venous anastomoses (AVA) are generally not taken into account. AVA's are predominantly found in glabrous skin such as palms, fingers, soles and forehead (3-6). Together with their relatively large surface-to-volumeratio and high sensitivity to thermal changes (7), these locations are ideally adapted as heat exchangers with the environment $(2,8,9)$. Hence, a blunted perfusion response in elderly in these skin areas might explain why elderly fail to maintain their core temperature when exposed to cold (10). Clothing provides insulative protection to most of the body surface. Therefore, the initial defense to cold might be related to local cooling of exposed areas, which in fact are mainly glabrous skin sites (forehead and hands). Age effects on mechanisms of mediating local cold induced vasoconstriction are well documented for non-glabrous human forearm skin, yet no information is available for glabrous (hand) skin.

Neurally mediated vasoconstriction works primarily through sympathetic adrenergic axon reflexes and alpha ${ }_{2}$-adrenergic receptors (11-13). However, in vitro research does not support findings of increased cold related axonal release of sympathetic adrenergic agents (14). Therefore non-neural mechanisms are likely involved. Nonneural mechanisms include the rho-kinase pathway, and removal of nitric oxide (15, 16). Experimental evidence indicates that the early phase of vasoconstriction to local cooling is mainly dependent on neural regulation and that late phase vasoconstriction relies more on non-neural mechanisms (13).

From literature it is known that during local cooling, young adults and elderly show a similar level of vasoconstriction at the ventral forearm $(17,18)$. Interestingly, the actual mechanisms by which the vasoconstriction is mediated are different. Elderly show a reduced response to noradrenergic agents (17), yet this is compensated by an increased vasoconstriction through non-adrenergic mechanisms (18). It is unclear whether young and elderly show different vasoconstriction to local cooling at other skin sites than the forearm, such as glabrous and non-glabrous skin of the hand. Many studies describe that innervation and topology of cutaneous microcirculation is not homogenous $(4,12,19-22)$. For instance glabrous skin (palms, fingers, soles, lips) is innervated mostly by sympathetic noradrenergic nerves and is rich in AVA's $(4,12,22-24)$. Studies by Ekenvall et al. have shown that vascular responses to local 
cooling and noradrenalin in human finger skin (glabrous) are primarily mediated through alpha ${ }_{2}$-adrenergic receptors $(25,26)$. In contrast to glabrous skin, nonglabrous skin has no AVA's and is innervated by both noradrenergic and cholinergic nerves (12).

In this study we are interested in age related differences in perfusion in response to cooling at the hand sites. No data on age effects on vasoconstriction to local cooling at hand skin and mechanisms that mediate it is available in literature. Therefore, we tested the hypotheses that at hand sites (a) elderly show equal vasoconstriction to local cooling and (b) elderly show reduced perfusion response to neuronal (noradrenergic) stimuli.

\section{Methods}

\section{Ethical approval}

The medical ethical committee of Maastricht University Medical Center + approved the study. Each subject gave verbal and written informed consent prior to participation in the study. All procedures conformed the standards of the Declaration of Helsinki.

\section{Subjects}

Sixteen young adults ( 18 to $28 \mathrm{yrs} ; 8 \mathrm{M}, 8 \mathrm{~F}$ ) and sixteen elderly ( 68 to 78 yrs, $8 \mathrm{M}, 8$ F) were included (characteristics in Table 1). All subjects were healthy, non-obese, nonsmokers and not taking medications. All young females were tested during the early follicular phase of their menstrual cycle. Subjects refrained from caffeinated or alcoholic beverages in the morning prior to the test, but were allowed to eat a small breakfast.

\section{Protocol}

Because of increased sympathetic vascular tone in the morning (27) experiments were conducted in the afternoon. After subjects were seated skin sites were cleaned with alcohol and air-dried. The studied skin sites were the dorsal side of the hand between the $2^{\text {nd }}$ and $3^{\text {rd }}$ metacarpal, the ventral hand at the base of the thumb and the ventral forearm halfway the wrist and inner side of the elbow. To reduce the influence of age differences in systemic sympathetic adrenergic tone (28) bretylium tosylate (10mM, Bio-Connect, the Netherlands), diluted in glycol propylene, was delivered via iontophoresis (Perlont, Sweden). Iontophoresis is a noninvasive method of delivering a drug through the skin using a small electric charge. Bretylium (BR) is a positively charged drug, which is propelled through the cutaneous barrier by the anode of the iontophoretic chamber. Glycol propylene was chosen as a carrier as it is non-conducting by itself; hence it does not interfere with the drug delivery (29). Bretylium is known to selectively block local endogenous release of noradrenergic neurotransmitters (29). Because of inherent differences in skin 
permeability between glabrous and non-glabrous skin, iontophoresis characteristics were modified between sites to deliver a dose that caused a similar physiologic effect. Aging per se may affect the cutaneous barrier properties (30). Thus, the iontophoresis dose scheme was set at a level to be maximally effective for both groups. From literature $(13,19,20,29)$ and a pilot study it was concluded that for effective bretylium treatment, different duration and current strength of iontophoresis was needed for different sites, as shown in Table 2.

Table 1: Subject characteristics. Values are presented as mean $\pm S E$

\begin{tabular}{|c|c|c|c|}
\hline & $Y(n=16)$ & $E(n=16)$ & p-value \\
\hline Age, yr & $23.19 \pm 0.73$ & $71.33 \pm 0.61^{*}$ & $p<0.01$ \\
\hline Gender, Male/Female & $8 / 8$ & $8 / 8$ & \\
\hline Height, m & $1.74 \pm 0.02$ & $1.67 \pm 0.02^{*}$ & $p<0.04$ \\
\hline Mass, kg & $64.36 \pm 2.32$ & $65.77 \pm 2.29$ & N.S. \\
\hline BMI, kg/m² & $21.25 \pm 0.73$ & $23.42 \pm 0.53^{*}$ & $p<0.01$ \\
\hline Systolic BP, mmHg & $119.00 \pm 2.69$ & $129.47 \pm 3.63^{*}$ & $p<0.03$ \\
\hline Diastolic BP, mmHg & $66.38 \pm 1.17$ & $69.07 \pm 2.28$ & N.S. \\
\hline Mean $\mathrm{BP}, \mathrm{mmHg}$ & $83.92 \pm 1.24$ & $89.20 \pm 2.12^{*}$ & $p<0.04$ \\
\hline Mean skin temp. ${ }^{\circ} \mathrm{C}$ & $33.74 \pm 0.04$ & $32.9^{\circ} \mathrm{C} \pm 0.06^{*}$ & $P<0.01$ \\
\hline Whole body fat, $\%$ & $22.48 \pm 2.00$ & $27.40 \pm 1.81$ & N.S. \\
\hline Leisure Activity Level & $3.31 \pm 0.12$ & $3.55 \pm 0.11$ & N.S. \\
\hline
\end{tabular}

Y: young adults. E: elderly. BP: blood pressure. ${ }^{*} p<0.05$ vs. young adult.

Control measurements (BR-) of perfusion response to local cooling were performed ipselateral to the locations treated with bretylium $(B R+)$. After iontophoresis of bretylium, sites were given $1 \mathrm{~h}$ for hyperemia to subside and sympathetic blocking to take effect. Skin temperature was measured in one minute intervals using iButtons (type DS1921H; Maxim/Dallas Semiconductor Corp., USA) (31) at the 14 positions of the adapted Mitchel/Wyndham equation for mean skin temperature (32). Next, subjects were dressed in a water-perfused suit (TUBEsuit, DTI) to control whole body skin temperature (Blanketrol II, Cincinnati Sub-zero). The effectiveness of the bretylium treatment was tested via whole body cooling by setting the temperature of the water perfused suit to $26^{\circ} \mathrm{C}$. Whole body cooling elicits reflex vasoconstriction through release of noradrenalin and cotransmitters from sympathetic nerve terminals; effective blockade of presynaptic nerve terminals abolishes the response, while at non-treated sites perfusion drops (29). During the rest of the experiment, subjects remained in thermal comfort, by perfusing the suit with water at $33^{\circ} \mathrm{C}(33)$. Room temperature was kept at $24^{\circ} \mathrm{C}$. Laser Doppler flowmetry 
(Perimed PF5000, Sweden) was used for measurement of skin perfusion. Custom made Peltier elements in the casing of the probes allowed for local temperature control of skin sites at $24^{\circ} \mathrm{C}$ and $33^{\circ} \mathrm{C}$. Measurements were divided in three phases (see Table 3).

Table 2: Current and duration of iontophoresis $(0.5 \mathrm{~cm} 2)$ and concentration of drugs at treated skin sites.

\begin{tabular}{|c|c|c|c|}
\hline & Current $[\mathrm{mA}]$ & $\mathrm{t}[\mathrm{min}]$ & Concentration [mM] \\
\hline \multicolumn{4}{|l|}{ Bretylium } \\
\hline Dorsal hand & 0.24 & 15 & 10 \\
\hline Ventral hand & 0.30 & 25 & 10 \\
\hline \multirow[t]{2}{*}{ Ventral forearm } & 0.24 & 10 & 10 \\
\hline & Current $[\mathrm{mA}]$ & $\mathrm{t}[\mathrm{min}]$ & Concentration [mM] \\
\hline \multicolumn{4}{|l|}{ Noradrenalin } \\
\hline Dorsal hand & 0.24 & 1 & 2.5 \\
\hline Ventral hand & 0.30 & 5 & 5.0 \\
\hline Ventral forearm & 0.24 & 1 & 2.5 \\
\hline
\end{tabular}

Table 3: Timeline of measure protocol repeated at each skin site. Blood pressure was measured at start of baseline and at end of noradrenalin (NA) phase.

\begin{tabular}{|c|c|c|c|}
\hline & Baseline & Local Cooling & Local NA \\
\hline Suit & $33^{\circ} \mathrm{C}$ & $33^{\circ} \mathrm{C}$ & $33^{\circ} \mathrm{C}$ \\
\hline Probe & $33^{\circ} \mathrm{C}$ & $24^{\circ} \mathrm{C}$ & $24^{\circ} \mathrm{C}$ \\
\hline Duration & 30 minutes & 15 minutes & 10 minutes \\
\hline
\end{tabular}

After a 30 -minute baseline period at $33^{\circ} \mathrm{C}$, skin sites were cooled to $24^{\circ} \mathrm{C}\left(-5^{\circ} \mathrm{C} / \mathrm{min}\right)$ for 15 minutes, until perfusion reached a nadir. Next noradrenalin, diluted in glycol propylene (Bio-Connect, the Netherlands), was delivered transcutaneously via iontophoresis to simulate maximal response to noradrenergic stimulation (details in Table 2, example recording in Figure 1).

A study by Thompson (17) has shown that local cooling of skin and local administration of NA does not alter mean arterial pressure (MAP). Therefore, and to minimalize the influence of the blood pressure (BP) measurement itself to the perfusion, $\mathrm{BP}$ measurement was restricted to before baseline and after administration of noradrenalin via digital blood pressure monitoring (CRESTA, Taiwan). Cutaneous vascular conductance (CVC) was calculated as perfusion divided by mean arterial pressure $(\mathrm{MAP}=1 / 3$ systolic $\mathrm{BP}+2 / 3$ diastolic $\mathrm{BP})$. Whole body fat percentage was measured 
through Dual-X-ray Absorptiometry (DXA, HOLOGIC, USA). Daily leisure activity of subjects was measured through a Baecke (34) questionnaire.

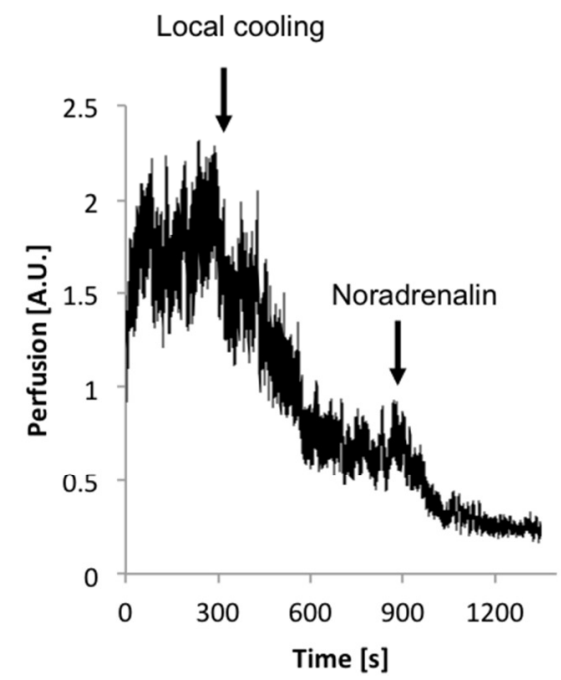

Figure 1: Individual recording of skin perfusion. Local skin temperature was $33^{\circ} \mathrm{C}$ during baseline, $24^{\circ} \mathrm{C}$ during cooling and administration of noradrenalin.

\section{Data analysis}

Perfusion data was sampled at $8 \mathrm{~Hz}$. Baseline values of CVC were obtained by averaging 3 minutes of perfusion data at baseline. Vasoconstriction measures were obtained by averaging 3 minutes during local cooling or after administration of noradrenalin. Data for local cooling alone were normalized to baseline, total vasoconstriction responses (local cooling+NA) were also normalized to baseline. SPSS16.0 for Mac was used for statistics. Subject characteristics were tested for differences via Student-t testing. A MANOVA was used to test for differences in $\% \triangle C V C$ among age and gender groups. Data were presented as mean \pm SE unless stated otherwise. Statistical significance level was set at $p<0.05$.

\section{Results}

Elderly subjects differed significantly from young adult subjects in BMI, baseline mean arterial pressure (MAP) and mean skin temperature $(p<0.05)$ (Table 1$)$. Since no significant gender differences were evident, data of both males and females were pooled. Daily leisure activity did not differ significantly between both age groups. Because BMI, baseline MAP and mean skin temperature showed no significant relation to vasoconstriction measures and leisure activity was equal over age groups, we assumed that observed effects were mainly related to age. 
Due to technical malfunction during iontophoresis testing on $n=3$ young adults and $\mathrm{n}=1$ elderly was aborted.

To test the effectiveness of the bretylium treatment, whole body rapid cooling was applied. This resulted in a decrease of perfusion units (PU) at control sites, but not at bretylium treated sites for both age groups (young control $-73 \% \pm 4 \%$; young bretylium $-8 \% \pm 6 \%$; elderly control $-65 \% \pm 4 \%$; elderly bretylium $-5 \% \pm 3 \%$ ).

At bretylium treated sites baseline CVC values did not differ significantly between age groups. Control sites also showed no age effect except for the ventral hand (young adults $0.66 \pm 0.12 \mathrm{PU} / \mathrm{mmHg}$ vs. elderly $0.31 \pm 0.04 \mathrm{PU} / \mathrm{mmHg} ; \mathrm{p}<0.02$ ).

\section{Non-noradrenalin treated skin sites.}

Bretylium treated sites at the ventral forearm and dorsal side of the hand (nonglabrous skin) showed a significantly smaller percentage change in CVC to local cooling than non-treated sites (see Table 4, NA-). At the glabrous skin site (ventral hand) vasoconstriction to local cooling at $B R+$ sites was not significantly different than vasoconstriction at BR- sites, indicating that local mechanisms dominated. At bretylium treated sites no significant age effect to local cooling was found. At control sites (BR-), only the ventral forearm showed reduced vasoconstriction in elderly $(p<0.05)$.

\section{Noradrenalin treated skin sites.}

After iontophoresis of a supra-physiological dose of noradrenalin perfusion decreased significantly at all measurement sites (table 4, NA+). The change in CVC was significantly smaller in elderly as compared to young adults at the bretylium treated sites of the ventral forearm $(p<0.01)$, indicating a reduced response to noradrenalin in elderly. However, at the ventral and dorsal side of the hand no significant age effect was found. The effect of noradrenalin at control (BR-) compared to bretylium treated $(\mathrm{BR}+)$ sites was not significantly different at the hand sites, but smaller at the ventral forearm (Table 4, denoted with \#).

\section{Discussion}

This study explored age effects in vasoconstriction during local cooling at three different sites of the skin. For the first time, the dorsal and ventral sides of the hand were measured, in addition to the ventral forearm that is traditionally studied. The primary findings of this study are:

1. There was no significant age effect on vasoconstrictor response to local cooling at both glabrous and non-glabrous skin of the hand.

2. In contrast to the results from the ventral forearm skin, elderly did not show a blunted response to noradrenalin during local cooling at hand skin sites. This indicates that at hand skin the noradrenergic mechanism of vasoconstriction is maintained with age. 
Table 4: Change in skin perfusion to local cooling (in \% from baseline) at the ventral forearm, dorsal hand and ventral hand.

\begin{tabular}{|c|c|c|c|c|}
\hline Forearm & $B R+N A-$ & $B R-N A-$ & $B R+N A+$ & $B R-N A+$ \\
\hline $\begin{array}{l}\text { Young } \\
\text { adults }\end{array}$ & $-22 \pm 7$ & $-46 \pm 5 *$ & $-76 \pm 3 *$ & $-57 \pm 6 \#$ \\
\hline Elderly & $-14 \pm 4$ & $-33 \pm 3 *$ & $-60 \pm 5 *$ & $-45 \pm 4 \#$ \\
\hline Age effect & N.S. & $p<0.05$ & $\mathrm{p}<0.05$ & N.S. $(p<0.07)$ \\
\hline \multicolumn{5}{|l|}{ Dorsal Hand } \\
\hline $\begin{array}{l}\text { Young } \\
\text { adults }\end{array}$ & $-32 \pm 5$ & $-49 \pm 6 *$ & $-74 \pm 4 *$ & $-71 \pm 4$ \\
\hline Elderly & $-27 \pm 5$ & $-45 \pm 5 *$ & $-72 \pm 4 *$ & $-65 \pm 3$ \\
\hline Age effect & N.S. & N.S. & N.S. & N.S. \\
\hline \multicolumn{5}{|l|}{ Ventral Hand } \\
\hline $\begin{array}{l}\text { Young } \\
\text { adults }\end{array}$ & $-35 \pm 14$ & $-49 \pm 6$ & $-80 \pm 7 *$ & $-63 \pm 3$ \\
\hline Elderly & $-37 \pm 11$ & $-59 \pm 5$ & $-70 \pm 11 *$ & $-67 \pm 5$ \\
\hline Age effect & N.S. & N.S. & N.S. & N.S. \\
\hline
\end{tabular}

BR-: Control site (no bretylium); BR+: Bretylium treated skin; NA-: Before local administration of noradrenalin; NAt: After local administration of noradrenalin. *: significant difference in vasoconstriction compared to $B R+N A-(p<0.05)$; \#: significant difference in vasoconstriction compared to $B R+N A+(p<0.05)$

\section{Ventral forearm}

Studies by Thompson et al. $(17,18)$ have shown that at the ventral forearm vasoconstrictor response to local cooling is not different between young adults and elderly. However, the mechanisms that mediate vasoconstriction are different. Elderly have a decreased noradrenergic vasoconstriction response, which is compensated by increased vasoconstriction through local mechanisms. In the present study, however, we observed a blunted vasoconstriction in elderly to local cooling at the control skin site (Table 4, BR-NA-, p<0.05). On the other hand, our observation that the neural (noradrenergic) response is reduced in elderly was in line with earlier studies that also indicate reduced sensitivity to noradrenalin at the ventral forearm $(17,35)$. This was strengthened by the result that the vasoconstriction response of noradrenalin at bretylium treated skin (BR+NA+), was significantly smaller in the elderly. Overall, these results suggest that the elderly in this study did not show increased vasoconstriction through local mechanisms at the ventral forearm. Indeed, skin that had sympathetic blockade showed no age effect in vasoconstriction to local cooling (BR+NA-), which indicates that the elderly did not increase vasoconstriction through local mechanisms.

\section{Dorsal hand}

The dorsal hand (non-glabrous skin) showed no age effect of vasoconstriction to local cooling at both bretylium treated and control sites. Even the application of exogenous noradrenalin did not result in an age effect. Both in young adults and elderly the bretylium treated skin sites showed a significantly smaller vasoconstrictor effect to local cooling alone than the control site. This indicates that at the dor- 
sal hand, similar to the ventral forearm, vasoconstriction during early phase local cooling was obtained through noradrenergic and non-adrenergic pathways. In combination with the absence of an age effect during local cooling alone at the control site, this indicates that aging per se does not alter noradrenergic sensitivity. This was strengthened by the results that no age effect is found after administration of noradrenalin $(\mathrm{BR}+\mathrm{NA}+)$.

\section{Ventral hand}

The ventral hand, like the dorsal hand, showed no age effect of vasoconstriction neither to local cooling nor to vasoconstriction after administration of noradrenalin. Glabrous skin consists of capillaries and arterio-venous anastomoses (AVA). Nonglabrous skin only has capillaries. These AVA's, which are solely innervated by sympathetic adrenergic nerves, are capable of shunting blood directly from the arteriole to the venous bed, thereby bypassing the capillaries and drastically reducing cutaneous blood flow (12). Suprisingly, despite greater sympathetic innervation at glabrous skin sites (7) no significant difference in vasoconstriction was observed between the BR+ and BR- site during local cooling. This indicates that at the ventral hand vasoconstriction by local mechanisms was able to compensate for lack of vasoconstriction by noradrenergic mechanisms. An interesting parallel may be drawn with another study by Wilson et al. (21), who found that glabrous skin with sympathetic blockade was still able to autoregulate flow during blood pressure variations, whereas non-glabrous skin lost its capability of autoregulation.

From a functional perspective of thermoregulation, the ventral side of the hand, as compared to the dorsal side and the ventral forearm, is most adapted as a heat exchanger through the abundance of $\operatorname{AVA}^{\prime} s(1,2,9)$ and high sensitivity to temperature changes (7). Various studies underscore the importance of glabrous skin areas $(8,10,36)$. Therefore, maintaining the functionality as heat exchanger of these skin areas is more important than for instance at the less exposed forearm. Analogous to the beneficial effects of physical exercise on vascular reactivity (6), naturally occurring exposure to cold of the hands might keep the skin of elderly "fit" to respond to daily changes in environmental temperatures.

\section{Limitations}

Other studies on local regulation of skin perfusion cited in this article in general used $34^{\circ} \mathrm{C}$ for baseline whole body mean skin temperature and local skin temperature. Although we used bretylium to avoid effects of systemic sympathetic tone, this may still have influenced results on non-treated sites. Furthermore relatively fit and healthy elderly were selected. Despite age in years was indicative of senescence, the biological age could have been much younger. Therefore, subject selection based on biological age would make sense. Yet, the difficulty remains how to define the biological age. Since the majority of elderly in western societies are taking drugs 
that effect blood pressure (69.6\% of aged over 65 years in the Netherlands (37)). It may be interesting to study whether these elderly, whose biological age might better reflect their age in years, do show a greater effect of age in vascular responses. Furthermore, the delivery of drugs through iontophoresis might induce a vasodilator response, by stimulating c-fibers, which has to be overcome before actual vasoconstriction is measured (38). In this study no age effect was found for the small iontophoretic vasodilation at any of the measured locations. Furthermore, despite differences in protocols, vasoconstriction values found in our study matched that of Thompson et al. (17) with respect to vasoconstrictor response to noradrenalin imposed on local cooling.

In summary there was no significant age effect on vasoconstrictor response to local cooling at both glabrous and non-glabrous skin of the hand. This is in line with the results from earlier studies on the ventral forearm. Contrary to earlier studies, elderly did not show a blunted response to noradrenalin during local cooling. This indicates that at hand skin sites the noradrenergic (neural) mechanism of vasoconstriction is maintained with age.

\section{Conclusion}

In contrast to the results from literature covering ventral forearm studies, our study on hand skin sites shows that upon cooling both local (non-neural) and noradrenergic (neural) mechanisms of vasoconstriction are maintained in the elderly.

\section{References}

1. deGroot, D.W. and W.L. Kenney, Impaired defense of core temperature in aged humans during mild cold stress. Am J Physiol Regul Integr Comp Physiol, 2007. 292(1): p. R103-8.

2. Van Someren, E.J., Thermoregulation and aging. Am J Physiol Regul Integr Comp Physiol, 2007. 292(1): p. R99-102.

3. Bergersen, T.K., M. Eriksen, and L. Walloe, Local constriction of arteriovenous anastomoses in the cooled finger. Am J Physiol, 1997. 273(3 Pt 2): p. R880-6.

4. Donadio, V., et al., Skin sympathetic adrenergic innervation: an immunofluorescence confocal study. Ann Neurol, 2006. 59(2): p. 376-81.

5. Gorgas, K., et al., The fine structure of human digital arterio-venous anastomoses (Hoyer-Grosser's organs). Anat Embryol (Berl), 1977. 150(3): p. 269-89.

6. Lenasi, $H$. and M. Strucl, Effect of regular physical training on cutaneous microvascular reactivity. Med Sci Sports Exerc, 2004. 36(4): p. 606-12.

7. Defrin, R., L. Petrini, and L. Arendt-Nielsen, Spatial summation of thermal sensations depends on skin type and skin sensitivity. Exp Brain Res, 2009.

8. Grahn, D. and H. Craig Heller, Heat Transfer in Humans: Lessons from Large Hibernators, in Life in the Cold: Evolution, Mechanisms, Adaptation, and Application, 
B.M. Barnes and H.V. Carey, Editors. 2004, Biological papers of the University of Alaska.

9. Grahn, D.A., J.L. Dillon, and H.C. Heller, Heat loss through the glabrous skin surfaces of heavily insulated, heat-stressed individuals. J Biomech Eng, 2009. 131(7): p. 071005.

10. Gilbert, S.S., et al., Peripheral heat loss: a predictor of the hypothermic response to melatonin administration in young and older women. Physiol Behav, 1999. 66(2): p. $365-70$.

11. Hodges, G.J., et al., Role of sensory nerves in the cutaneous vasoconstrictor response to local cooling in humans. Am J Physiol Heart Circ Physiol, 2007. 293(1): p. H784-9.

12. Kellogg, D.L., Jr., In vivo mechanisms of cutaneous vasodilation and vasoconstriction in humans during thermoregulatory challenges. J Appl Physiol, 2006. 100(5): p. 1709-18.

13. Pergola, P.E., et al., Role of sympathetic nerves in the vascular effects of local temperature in human forearm skin. Am J Physiol, 1993. 265(3 Pt 2): p. H785-92.

14. Johnson, J.M., Mechanisms of vasoconstriction with direct skin cooling in humans. Am J Physiol Heart Circ Physiol, 2007. 292(4): p. H1690-1.

15. Thompson-Torgerson, C.S., et al., Cold-induced cutaneous vasoconstriction is mediated by Rho kinase in vivo in human skin. Am J Physiol Heart Circ Physiol, 2007. 292(4): p. H1700-5.

16. Hodges, G.J., et al., The involvement of nitric oxide in the cutaneous vasoconstrictor response to local cooling in humans. J Physiol, 2006. 574(Pt 3): p. 849-57.

17. Thompson, C.S., L.A. Holowatz, and W.L. Kenney, Attenuated noradrenergic sensitivity during local cooling in aged human skin. J Physiol, 2005. 564(Pt 1): p. 3139.

18. Thompson-Torgerson, C.S., et al., Rho kinase-mediated local cold-induced cutaneous vasoconstriction is augmented in aged human skin. Am J Physiol Heart Circ Physiol, 2007. 293(1): p. H30-6.

19. Johnson, J.M., et al., Skin of the dorsal aspect of human hands and fingers possesses an active vasodilator system. J Appl Physiol, 1995. 78(3): p. 948-54.

20. Yamazaki, F. and R. Sone, Different vascular responses in glabrous and nonglabrous skin with increasing core temperature during exercise. Eur J Appl Physiol, 2006. 97(5): p. 582-90.

21. Wilson, T.E., et al., Dynamic autoregulation of cutaneous circulation: differential control in glabrous versus nonglabrous skin. Am J Physiol Heart Circ Physiol, 2005. 289(1): p. H385-91.

22. Krogstad, A.L., et al., Arteriovenous anastomoses and the thermoregulatory shift between cutaneous vasoconstrictor and vasodilator reflexes. J Auton Nerv Syst, 1995. 53(2-3): p. 215-22. 
23. Alvarez, G.E., et al., Relative roles of local and reflex components in cutaneous vasoconstriction during skin cooling in humans. J Appl Physiol, 2006. 100(6): p. 20838.

24. Charkoudian, N., Skin blood flow in adult human thermoregulation: how it works, when it does not, and why. Mayo Clin Proc, 2003. 78(5): p. 603-12.

25. Ekenvall, L., et al., alpha-Adrenoceptors and cold-induced vasoconstriction in human finger skin. Am J Physiol, 1988. 255(5 Pt 2): p. H1000-3.

26. Lindblad, L.E., L. Ekenvall, and C. Klingstedt, Neural regulation of vascular tone and cold induced vasoconstriction in human finger skin. J Auton Nerv Syst, 1990. 30(2): p. 169-73.

27. Panza, J.A., S.E. Epstein, and A.A. Quyyumi, Circadian variation in vascular tone and its relation to alpha-sympathetic vasoconstrictor activity. N Engl J Med, 1991. 325(14): p. 986-90.

28. Wilson, T.E., et al., Effect of age on cutaneous vasoconstrictor responses to norepinephrine in humans. Am J Physiol Regul Integr Comp Physiol, 2004. 287(5): p. R1230-4.

29. Kellogg, D.L., Jr., J.M. Johnson, and W.A. Kosiba, Selective abolition of adrenergic vasoconstrictor responses in skin by local iontophoresis of bretylium. Am J Physiol, 1989. 257(5 Pt 2): p. H1599-606.

30. Carmeli, E., H. Patish, and R. Coleman, The aging hand. J Gerontol A Biol Sci Med Sci, 2003. 58(2): p. 146-52.

31. van Marken Lichtenbelt, W.D., et al., Evaluation of wireless determination of skin temperature using iButtons. Physiol Behav, 2006. 88(4-5): p. 489-97.

32. Choi, J.K., et al., Evaluation of mean skin temperature formulas by infrared thermography. Int J Biometeorol, 1997. 41(2): p. 68-75.

33. Parsons, K., Human Thermal Environments. 2 ed, ed. K.C.Parsons2003: Taylor \& Francis.

34. Baecke, J.A., J. Burema, and J.E. Frijters, A short questionnaire for the measurement of habitual physical activity in epidemiological studies. Am J Clin Nutr, 1982. 36(5): p. 936-42.

35. Thompson, C.S., L.A. Holowatz, and W.L. Kenney, Cutaneous vasoconstrictor responses to norepinephrine are attenuated in older humans. Am J Physiol Regul Integr Comp Physiol, 2005. 288(5): p. R1108-13.

36. Krauchi, K. and A. Wirz-Justice, Circadian rhythm of heat production, heart rate, and skin and core temperature under unmasking conditions in men. Am J Physiol, 1994. 267(3 Pt 2): p. R819-29.

37. CBS, Zelfgerapporteerde medische consumptie, gezondheid en leefstijl, in Centraal Bureau voor de Statistiek2009.

38. Drummond, P.D. and D.M. Lipnicki, Noradrenaline provokes axon reflex hyperaemia in the skin of the human forearm. J Auton Nerv Syst, 1999. 77(1): p. 3944. 



\section{CHAPTER 4}

\section{INCREASED SYSTOLIC BLOOD PRESSURE AFTER MILD COLD AND REWARMING: RELATION TO COLD-INDUCED THERMOGENESIS AND AGE}




\begin{abstract}

\section{Background}

Higher winter mortality in elderly has been associated with augmented systolic blood pressure (SBP) response and with impaired defense of core temperature. Here we investigated whether the augmented SBP upon mild cold exposure remains after a rewarming period, and whether SBP changes are linked to thermoregulation. Therefore, we tested the following hypotheses: cold-induced increase in SBP a) remains augmented after rewarming in elderly compared to young adults $b$ ) is related to non-shivering thermogenesis upon mild cold $c$ ) is related to vasoconstriction upon mild cold.
\end{abstract}

\title{
Methods
}

$\mathrm{BP}$, energy expenditure (EE), skin and core temperature, skin perfusion (abdomen, forearm, both sides of hand) and \% body fat were measured in 12 young adults ( $Y$ ) and 12 elderly (E). Supine subjects were exposed to a thermoneutral baseline $0.5 \mathrm{~h}$ $\left(T_{\text {air }}=30.1^{\circ} \mathrm{C}\right), 1 \mathrm{~h}$ mild cold $\left(\mathrm{T}_{\text {air }}=20.7^{\circ} \mathrm{C}\right), 1 \mathrm{~h}$ rewarming $\left(\mathrm{T}_{\text {air }}=34.8^{\circ} \mathrm{C}\right)$ and $1 \mathrm{~h}$ baseline $\left(\mathrm{T}_{\mathrm{air}}=30.5^{\circ} \mathrm{C}\right)$.

\section{Results}

Upon mild cold only the young adults showed significant non-shivering thermogenesis (NST) $\left(\mathrm{Y}:+2.5 \pm 0.6 \mathrm{~W} / \mathrm{m}^{2}, \mathrm{p}<0.05\right)$. No significant age effects in vasoconstriction were observed. After rewarming $\% \triangle \mathrm{SBP}$ remained significantly increased in both age groups and was augmented in elderly $(\mathrm{Y}:+5.0 \% \pm 1.2 \% \mathrm{vs} . \mathrm{E}:+14.7 \% \pm 3.1 \%, \mathrm{p}<0.05)$. Regression analysis revealed that $\% \triangle \mathrm{SBP}$ significantly related to $\triangle \mathrm{EE}$ upon mild cold $\left(p<0.01, r^{2}=0.35\right)$ and in elderly also to \%body fat $\left(p<0.02, r^{2}=0.57\right)$.

\section{Conclusion}

Individual changes in SBP after rewarming correlate negatively to non-shivering thermogenesis (NST). Elderly did not show NST, which explains the greater SBP increase in this group. In elderly a relatively large \%body fat protected against the adverse effects of mild cold. 


\section{Introduction}

During winter there is a higher mortality rate in elderly than in young adults (1). This higher seasonal mortality has been associated with augmented systolic blood pressure response $(2,3)$ and with impaired defense of core temperature during cold exposure (4). These studies indicated that cold exposures do not need to be severe or long lasting to reveal age effects in changing blood pressure or body temperature. Indeed, a greater increase in systolic blood pressure in elderly compared to young adults is already observed after a 20-minute mild cold exposure ( $T_{\text {water- }}$ suit $=18^{\circ} \mathrm{C}$ ) (2). Also, contrary to young adults, elderly failed to defend their core temperature during a $2 \mathrm{~h}$ mild cold exposure (progressive cooling from $\mathrm{T}_{\text {air }}=26.5^{\circ} \mathrm{C}$ to $\mathrm{T}_{\text {air }}$ $\left.=17^{\circ} \mathrm{C}\right)(4)$.

During severe cold exposure (i.e. $2 \mathrm{~h}$ in $\mathrm{T}_{\text {air }}=6^{\circ} \mathrm{C}$ ), the increase in systolic blood pressure is significantly associated with body core temperature changes (both in young adults and elderly) (5).

Heat loss is one of the primary mechanism dictating internal temperature, the other being heat production. Upon mild cold exposure vasoconstriction is a thermoregulatory mechanism to decrease heat loss $(6,7)$. Hence, impaired capacity for vasoconstriction in elderly could explain their inability to defend core temperature $(4,8)$.

With respect to heat production, in young adults mild cold induced thermogenesis (i.e. non-shivering thermogenesis) has been observed $(9,10)$. Both skeletal muscle and brown adipose tissue (BAT) have been proposed as tissues capable of increasing heat production through mitochondrial uncoupling upon cold $(11,12)$. However, there are indications that BAT or mitochondrial function decreases with advancing age (13-15). Therefore, impaired defense of core temperature in elderly might also be caused by reduced non-shivering thermogenesis (NST).

The studies described above indicate that mild cold poses elderly to a greater risk for health problems than young adults. It is impractical to completely protect elderly from cold exposure, yet a rewarming period after mild cold exposure could be part of a treatment. Rewarming is expected to induce recovery of body temperature and consequently result in restoration of blood pressure to baseline levels. To our knowledge no other study has investigated this before.

In this study we investigate whether the age related augmented systolic blood pressure response upon mild cold exposure remains after a rewarming period, and whether systolic blood pressure changes are linked to the thermoregulatory responses. Therefore we tested the following hypotheses following mild cold exposure:

1. Increase in systolic blood pressure after rewarming remains significantly augmented in elderly compared to young adults

2. Change in systolic blood pressure after rewarming is significantly related to change in energy expenditure during cooling. 
3. Change in systolic blood pressure after rewarming is significantly related to vasoconstriction during cooling.

\section{Methods}

\section{Subjects}

Twelve young adult males (18 to $31 \mathrm{yrs}$ ) and twelve elderly males (66 to $78 \mathrm{yrs}$ ) were included. For this study, only males were selected to avoid interference from sex and menstrual cycle temperature variations in females (16). All subjects were healthy, non-obese and non-smokers. Subjects were measured in fasting state and they refrained from caffeinated or alcoholic beverages for $8 \mathrm{~h}$ prior to the test. The medical ethical committee of Maastricht University Medical Centre+ approved the study. Each subject gave verbal and written informed consent prior to participation in the study. All procedures conformed the standards of the Declaration of Helsinki.

\section{Protocol and Materials}

Subjects visited the laboratory during winter (January-March 2010, average outside temperature ranged from $-0.5^{\circ} \mathrm{C}$ to $\left.6.4^{\circ} \mathrm{C}(17)\right)$. After arrival at $8: 30 \mathrm{am}$ subjects swallowed a telemetric pill (CoreTemp HT150002, USA) for core temperature measurement. Next subjects were placed in a tent (Colorado altitude training, model king size, USA), which served as a climate room. Initial air temperature was $30^{\circ} \mathrm{C}$. In order not to cool the subjects before measurements started, they undressed themselves in the tent. During tests subjects were dressed in underwear only (briefs; 0.04 clo). Subsequently, ibuttons (Maxim integrated, USA) were placed at the 14 ISOdefined skin sites for measurement of mean skin temperature $(18,19)$; additional ibuttons were placed at the ventral forearm and both sides of the hand. Ibuttons were attached with semi-permeable tape (Fixomull, Germany). Furthermore a pressure cuff (Cresta, Taiwan) was placed around the left upper arm for automated blood pressure recordings. Thereafter, subjects were placed in supine position on a stretcher (Model Campart Rome-XL), which allowed for ventilation at the dorsal side of the body. After subjects were comfortably positioned on the stretcher, a mask was placed over mouth and nose for indirect calorimetry (Omnical 2, The Netherlands). Indirect calorimetry was used to measure energy expenditure (i.e. heat production (20)). Skin blood flow was measured by laser Doppler flowmetry at the dorsal side of the hand between the $2^{\text {nd }}$ and $3^{\text {rd }}$ metacarpal, at the ventral side of the hand at the base of the thumb (Perimed PF5000, Sweden), at the ventral side of the forearm halfway between the elbow and the wrist and at the abdomen halfway between the umbilicus and the right lateral side of the body (Perimed PF4000, Sweden). Inspection for shivering was performed by visual recognition and every 10 minutes subjects were asked to state their thermal sensation and thermal comfort. 
Table 1: Baseline subject characteristics. Data are mean \pm SE and [range]. Three elderly subjects shivered during mild cold exposure and were excluded from the analysis.

\begin{tabular}{|c|c|c|}
\hline & Young adults & Elderly \\
\hline N & 12 & 9 \\
\hline Age (year) & $24.9 \pm 1.0[19.0-31.0]$ & $71.4 \pm 1.5[66.0-78.0]$ \\
\hline Height (m) & $1.80 \pm 0.02[1.67-1.90]$ & $1.74 \pm 0.02[1.67-1.86]^{*}$ \\
\hline Mass (kg) & $76.1 \pm 3.3[57.9-92.5]$ & $79.6 \pm 2.9$ [69.6-101.0] \\
\hline BMI $\left(\mathrm{kg} / \mathrm{m}^{2}\right)$ & $23.4 \pm 0.9[18.3-27.9]$ & $26.4 \pm 0.8[22.9-29.2]^{*}$ \\
\hline Body Fat (\%) & $16.7 \pm 1.4[10.1-24.4]$ & $26.7 \pm 0.8[23.7-31.7] *$ \\
\hline Area $\left(m^{2}\right)$ & $1.89 \pm 0.05[1.64-2.22]$ & $1.95 \pm 0.05[1.79-2.28]$ \\
\hline Mass/Area $\left(\mathrm{kg} / \mathrm{m}^{2}\right)$ & $40.1 \pm 0.9[35.1-44.1]$ & $40.7 \pm 0.9[36.1-44.4]$ \\
\hline Systolic BP (mmHg) & $120.7 \pm 2.9[101-134]$ & $142.2 \pm 7.4[122-157]^{*}$ \\
\hline Diastolic BP (mmHg) & $61.6 \pm 2.0[53-76]$ & $72.3 \pm 1.8[61-78]^{*}$ \\
\hline MAP (mmHg) & $81.3 \pm 1.9[74.7-92.7]$ & $95.6 \pm 2.0[85.3-104.3]^{*}$ \\
\hline Heart rate (bpm) & $55.5 \pm 2.0[44.9-70.4]$ & $63.3 \pm 3.3[52.2-82.6]^{*}$ \\
\hline $\mathrm{CVC}_{\text {abdomen }}(\mathrm{PU} / \mathrm{mmHg})$ & $0.11 \pm 0.02[0.06-0.25]$ & $0.11 \pm 0.01[0.07-0.14]$ \\
\hline $\mathrm{CVC}_{\text {forearm ventral }}(\mathrm{PU} / \mathrm{mmHg})$ & $0.14 \pm 0.02[0.09-0.28]$ & $0.16 \pm 0.03[0.08-0.32]$ \\
\hline $\mathrm{CVC}_{\text {hand dorsal }}(\mathrm{PU} / \mathrm{mmHg})$ & $0.27 \pm 0.05[0.12-0.69]$ & $0.25 \pm 0.04[0.16-0.45]$ \\
\hline $\mathrm{CVC}_{\text {hand ventral }}(\mathrm{PU} / \mathrm{mmHg})$ & $1.36 \pm 0.26[0.21-3.60]$ & $1.41 \pm 0.25[0.23-2.65]$ \\
\hline
\end{tabular}

BP: blood pressure; MAP: mean arterial pressure; PU: perfusion unit; CVC: cutaneous vascular conductance.

\section{Protocol}

The measurements lasted 3.5 hours. The protocol started with a 30 min thermoneutral baseline period (air temperature $=30.1{ }^{\circ} \mathrm{C} \pm 0.1^{\circ} \mathrm{C}$ ). Whether subjects were in their thermoneutral zone was confirmed by characteristic skin perfusion variations at the ventral side of the hand ( 2 to 3 vasoconstrictions per minute $(6,21,22)$ ). This was followed by $1 \mathrm{~h}$ of mild cold exposure (air temperature $=20.7^{\circ} \mathrm{C} \pm 0.2^{\circ} \mathrm{C}$ ), and $1 \mathrm{~h}$ of rewarming (air temperature $=34.8^{\circ} \mathrm{C} \pm 0.1^{\circ} \mathrm{C}$ ). Finally, subjects were exposed again to baseline conditions for $1 \mathrm{~h}\left(30.5^{\circ} \mathrm{C} \pm 0.1^{\circ} \mathrm{C}\right)$.

On a separate occasion body composition was determined with dual x-ray absorptiometry (Hologic Discovery A, TBAR1209). Body surface area was calculated from measurements of the length and circumference of different parts of the body. The body parts were: head, neck, chest, abdomen, upper arms, lower arms, hands, thighs, upper legs, lower legs and feet.

\section{Data acquisition and analysis}

Temperature, energy expenditure, skin perfusion and heart rate data were sampled on a 1-minute base and averaged to 10-minute values. Blood pressure was recorded 
three times every ten minutes; the average of these three measurements was used. Mean arterial blood pressure (MAP) was calculated as MAP $=1 / 3$ Systolic pressure + 2/3 Diastolic pressure. Cutaneous vascular conductance (CVC) was calculated as CVC = perfusion/MAP. Reported changes in energy expenditure, temperature, cutaneous vascular conductance, heart rate and blood pressure are relative to baseline. Data handling was performed using Matlab2010a for Mac. Statistical analysis was performed using SPSS18.0 for Mac. Subject characteristics were tested by student-t statistic. Independent samples t-test on the difference between systolic blood pressure at baseline and at the end of the protocol was used to test whether increase in systolic blood pressure after rewarming remains significantly augmented in elderly compared to young adults (hypothesis a). Regression analysis was used to test correlates between change in systolic blood pressure after rewarming and nonshivering thermogenesis (hypothesis b) or vasoconstriction (hypothesis $\mathrm{c}$ ) upon mild cold. Time series were analyzed by mixed model analysis with "age group", "time" and "time * age group" as fixed factors and fat percentage as covariate. The percentage change was used for analyses when baseline values differed significantly between age groups. The absolute change was used for analyses when baseline data did not differ significantly between age groups. Data are presented as mean \pm standard error (SE). Statistical significance level was set at $p<0.05$.

\section{Results}

In three elderly subjects cooling caused shivering. Therefore, these individuals were excluded from further analyses. The remaining elderly $(n=9)$ had a significantly higher percentage body fat than the young adults, yet the body mass to surface area ratio was not significantly different (characteristics in Table 1).

Baseline blood pressure and heart rate were significantly higher in elderly than in young adults, but baseline cutaneous vascular conductance did not differ significantly between age groups (Table 1). Furthermore, baseline energy expenditure, core temperature and mean skin temperature did not differ significantly between age groups (Figure 1).

\section{Systolic blood pressure}

Upon mild cold systolic blood pressure (SBP) increased in both age groups. The percent increase in systolic blood pressure was significantly smaller in young adults than in elderly (Figure $2 \mathrm{~A}$ ).

During rewarming the percent change in systolic blood pressure (\% $\triangle \mathrm{SBP}$ ) showed signs of recovery, but remained significantly augmented in elderly compared to young adults (Figure $2 \mathrm{~A}$ ).

Upon return to baseline conditions \% $\triangle \mathrm{SBP}$ increased again to the level during mild cold exposure in both groups. At the end of the protocol \% $\triangle \mathrm{SBP}$ still was significant- 
ly higher in elderly compared to young adults $(+14.7 \% \pm 3.1 \%$ vs. $5.0 \% \pm 1.2 \%$ resp., $\mathrm{p}<0.05$, Figure $2 \mathrm{~A}$ ).

A)

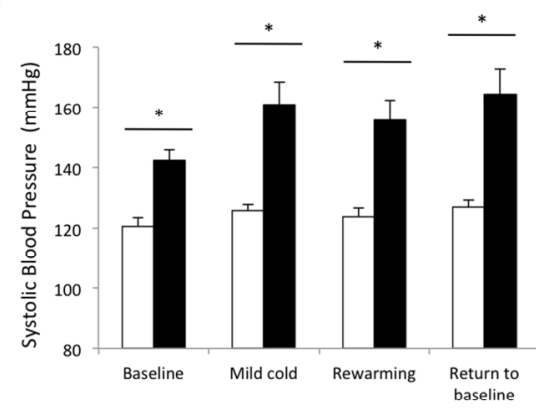

C)

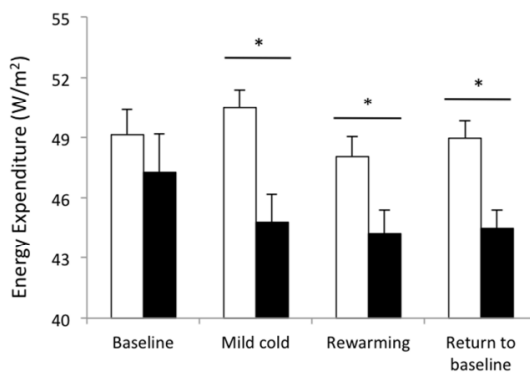

B)

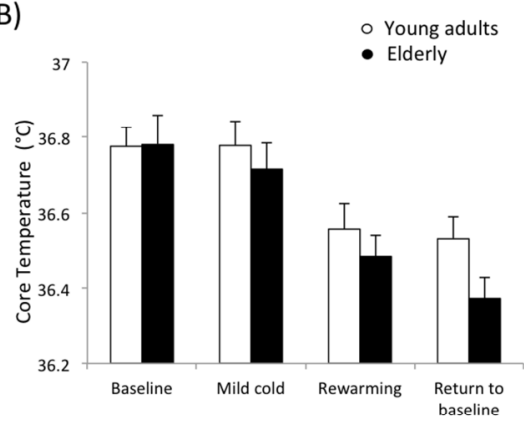

D)

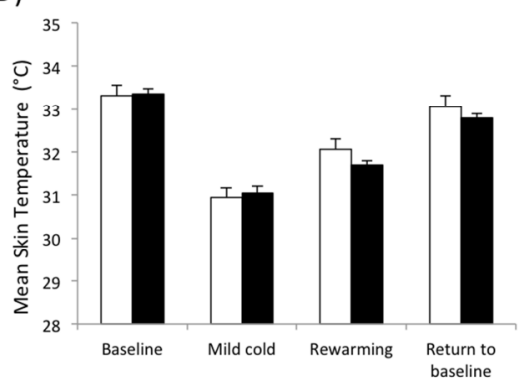

Figure 1: A) Average systolic blood pressure in young adults and elderly. Data are averaged over the entire protocol phase (baseline, mild cold, rewarming and return to baseline) $B$ ) Average core temperature in young adults and elderly. C) Average energy expenditure in young adults and elderly. D) Average mean skin temperature in young adults and elderly. Error bars denote SE. *: age effect $(p<0.05)$.

\section{Core temperature}

In the cold the core temperature of the young adults did not change significantly (Figure 2B). However, mild cold induced a significant drop in core temperature in elderly ( $\left.t=85 \mathrm{~min}:-0.09^{\circ} \mathrm{C} \pm 0.04^{\circ} \mathrm{C}, \mathrm{p}<0.05\right)$.

During rewarming core temperature decreased significantly below baseline in young adults, and in elderly core temperature continued to decrease.

Upon return to baseline core temperature stabilized significantly below baseline in both age groups. Relative to baseline, the decrease in core temperature was significantly smaller in young adults than in elderly $\left(\mathrm{t}=205 \mathrm{~min}:-0.24^{\circ} \mathrm{C} \pm 0.04^{\circ} \mathrm{C}\right.$ vs. $0.41^{\circ} \mathrm{C} \pm 0.06^{\circ} \mathrm{C}$ resp., $\mathrm{p}<0.05$, Figure $2 \mathrm{~B}$ )

\section{Energy Expenditure}

During mild cold exposure the change in energy expenditure ( $\Delta \mathrm{EE})$ differed significantly between young adults and elderly (Figure $2 \mathrm{C}$ ). Young adults significantly in- 
creased energy expenditure above baseline ( $\left.t=85 \mathrm{~min}:+2.5 \mathrm{~W} / \mathrm{m}^{2} \pm 0.6 \mathrm{~W} / \mathrm{m}^{2}, p<0.05\right)$, whereas elderly decreased energy expenditure significantly below baseline ( $\left.t=85 \mathrm{~min}:-2.5 \mathrm{~W} / \mathrm{m}^{2} \pm 1.1 \mathrm{~W} / \mathrm{m}^{2}, \mathrm{p}<0.05\right)$.

Rewarming caused energy expenditure to revert to baseline level in young adults, yet $\Delta \mathrm{EE}$ remained significantly below baseline in elderly $\left(\mathrm{t}=145 \mathrm{~min}:-3.3 \mathrm{~W} / \mathrm{m}^{2} \pm\right.$ $\left.1.0 \mathrm{~W} / \mathrm{m}^{2}, \mathrm{p}<0.05\right)$.

Upon return to baseline conditions $\Delta \mathrm{EE}$ of young adults remained significantly above that of elderly (Figure $2 \mathrm{C}$ ). Nevertheless, $\Delta \mathrm{EE}$ in elderly did not significantly differ from baseline anymore.

\section{Skin temperature}

During mild cold exposure, mean skin temperature decreased significantly below baseline in both age groups (Figure 2D). No age effect in change of mean skin temperature $(\Delta T s k)$ was observed.

Upon rewarming mean skin temperature increased again yet remained significantly below baseline in both age groups. Nevertheless, $\Delta$ Tsk in young adults was significantly above $\Delta$ Tsk in elderly (Figure $2 \mathrm{D}$ ).

Upon return to baseline conditions $\Delta$ Tsk stabilized significantly below baseline in both age groups. However, $\Delta$ Tsk in young adults remained significantly above $\Delta$ Tsk in elderly ( $\mathrm{t}=205 \mathrm{~min}$ : $-0.25^{\circ} \mathrm{C} \pm 0.08^{\circ} \mathrm{C}$ vs. $-0.57^{\circ} \mathrm{C} \pm 0.13^{\circ} \mathrm{C}$ resp., $\mathrm{p}<0.05$, Figure $2 \mathrm{D}$ ). Although $\Delta$ Tsk differed significantly between age groups, no age effect was observed in mean skin temperature itself ( $t=205 \mathrm{~min}$ : young adults: $33.06^{\circ} \mathrm{C} \pm 0.26^{\circ} \mathrm{C}$ vs. elderly: $-32.78^{\circ} \mathrm{C} \pm 0.10^{\circ} \mathrm{C}$, $\left.\mathrm{p}>0.35\right)$.

\section{Heart rate}

During mild cold exposure heart rate decreased below baseline both young adults ($3.1 \% \pm 1.3 \%, p<0.05)$ and in elderly $(-7.0 \% \pm 2.4 \%, p<0.05)$. In young adults the percent change in heart rate $(\% \Delta \mathrm{HR})$ was significantly smaller than in their older counterparts (Figure $2 \mathrm{E}$ ),

During rewarming $\% \Delta \mathrm{HR}$ stabilized in elderly. In young adults, $\% \Delta \mathrm{HR}$ continued to decrease during the first $20 \mathrm{~min}$. Thereafter $\% \Delta \mathrm{HR}$ increased again to baseline level. Upon return to baseline conditions $\% \Delta H R$ did not significantly differ from baseline in both age groups. However, $\% \Delta \mathrm{HR}$ remained significantly below that of young adults (Figure 2E). 
A)

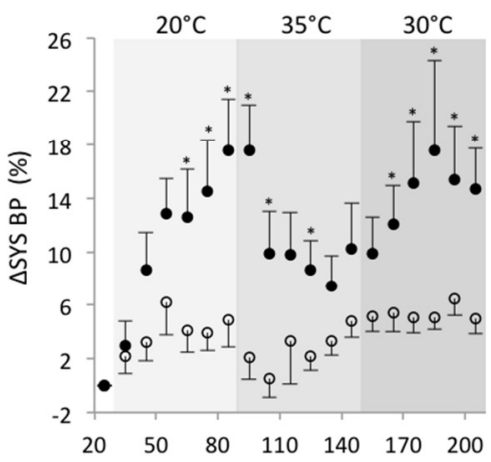

C)

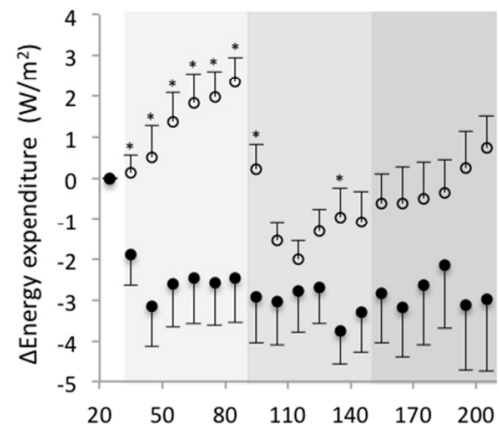

B)

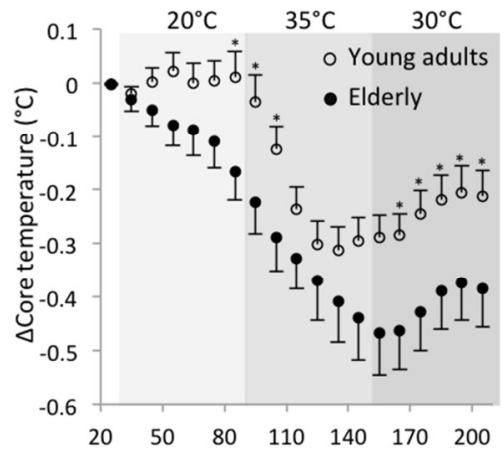

D)

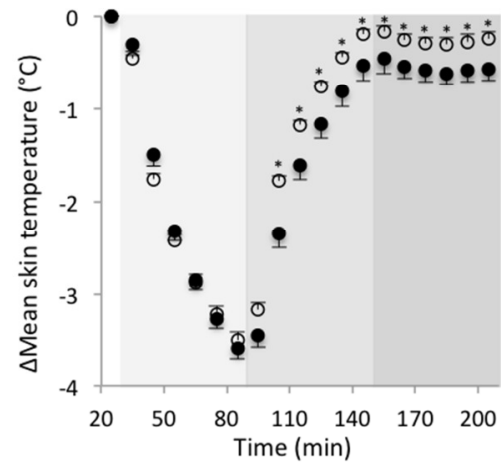

E)

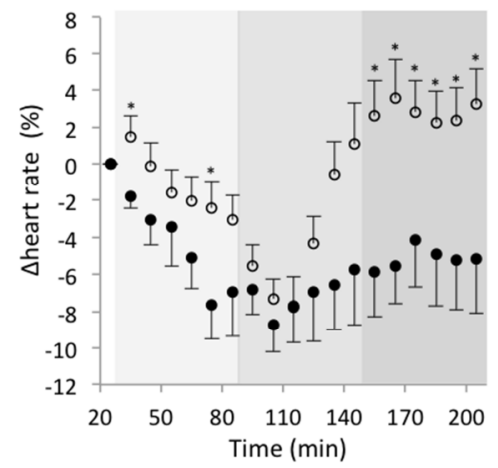

Figure 2: A) Average percent change in systolic blood pressure vs. time in young adults (open circles) and elderly (closed circles). Background shades of gray denote separate phases: mild cold (lightest gray), rewarming (light gray), and return to baseline (gray). B) Average change in core temperature vs. time in young adults and elderly. C) Average change in energy expenditure vs. time in young adults and elderly. D) Average change in mean skin temperature $v$ s. time in young adults and elderly. E) Average percent change in heart rate vs. time in young adults and elderly. Error bars represent SE. *: age effect ( $p<0.05)$ 


\section{Cutaneous Vascular Conductance}

Upon mild cold cutaneous vascular conductance decreased significantly below baseline at all measured positions. No significant age effects in vasoconstriction were observed (Figure 3).

During rewarming $\triangle C V C$ at the abdomen did not significantly differ from baseline in both age groups. However, $\triangle C V C$ at the abdomen in young adults was significantly above $\triangle C V C$ in elderly (Figure $3 \mathrm{~A}$ ). $\triangle \mathrm{CVC}$ at the forearm and hand skin sites remained significantly below baseline.

Upon return to baseline $\triangle C V C$ at the abdomen was at baseline level in both age groups. At other sites, $\triangle \mathrm{CVC}$ remained significantly below baseline.
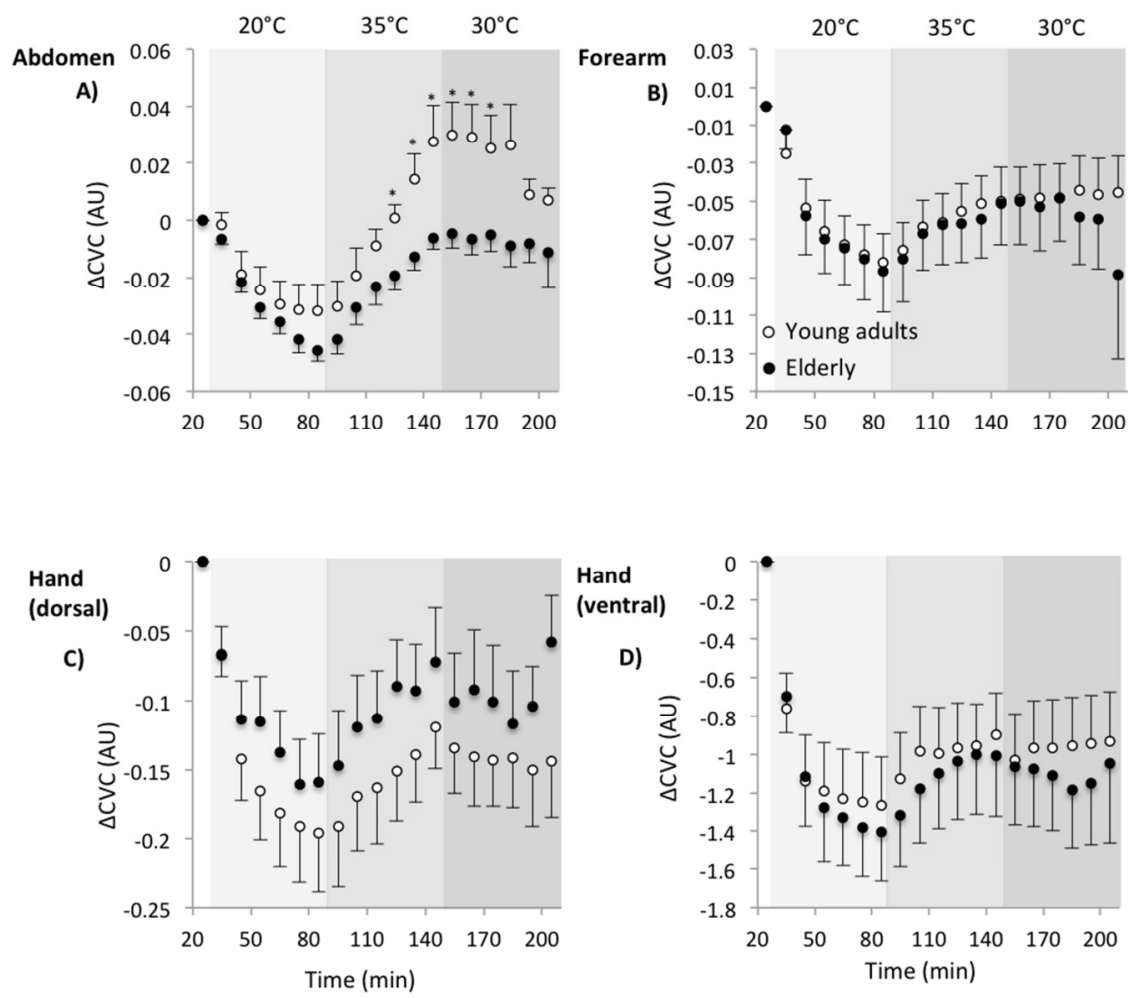

Figure 3: A) Average change in cutaneous vascular conductance ( $\triangle C V C$ ) at abdomen vs. time in young adults (open circles) and elderly (closed circles). Background shades of gray denote separate phases: mild cold (lightest gray), rewarming (light gray), and return to baseline (gray). B) Average $\triangle C V C$ at ventral forearm vs. time in young adults and elderly. C) Average $\triangle C V C$ at dorsal hand vs. time in young adults and elderly. D) Average $\triangle C V C$ at ventral hand vs. time in young adults and elderly. Error bars represent SE. *: age effect $(p<0.05)$

\section{Thermoregulation and systolic blood pressure}

The percent change in systolic blood pressure $(\% \triangle \mathrm{SBP})$ at the end of the protocol was significantly negatively related to the change in energy expenditure $(\Delta \mathrm{EE})$ upon 
mild cold $\left(p<0.01\right.$ and $r^{2}=0.35$, Figure $\left.5 A\right)$. In elderly $\% \triangle S B P$ was also significantly negatively related to the percent body fat $\left(\% \Delta \mathrm{SBP}_{\text {elderly }}=105.2-3.4 \% \mathrm{Fat}_{\text {body; }}\right.$; $p<0.01$ and $r^{2}=0.57$, Figure 5B).

The change in energy expenditure was not significantly related to the percent body fat $(p>0.05)$. Percent change in systolic blood pressure was not significantly related to the changes in cutaneous vascular conductance at the measured positions (p>0.05).
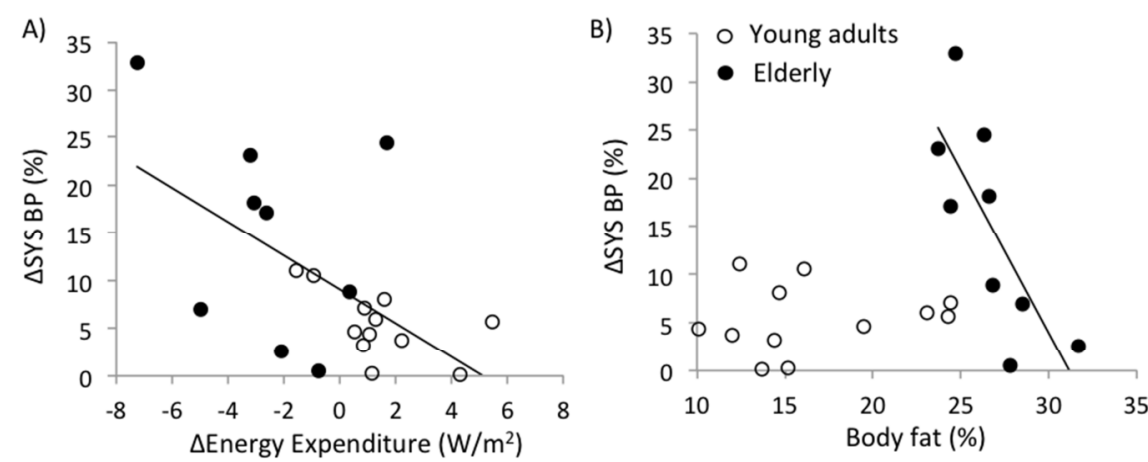

Figure 4: A) Percent change in systolic blood pressure after rewarming vs. percent change in energy expenditure upon mild cold exposure. Linear relation between both variables is significant $(p<0.01, r 2=0.35)$. B) Percent change in systolic blood pressure vs. percent body fat. In young adults the relation is not significant. In elderly the relation is significant $(p<0.02$, $r 2=0.57)$.

\section{Discussion}

This study shows that, even after a one-hour rewarming period, the mild coldinduced increase in systolic blood pressure is maintained in both age groups and is augmented in elderly. Interestingly, increased systolic blood pressure was related to the mild cold induced change in energy expenditure. The results also indicate that in elderly, body fat protects from mild cold induced increases in systolic blood pressure.

These findings contribute to existing knowledge by showing that cold-induced elevation in systolic blood pressure is negatively related to cold-induced thermogenesis. Also, in elderly increase in systolic blood pressure related negatively to percent body fat. Furthermore, these findings are of clinical relevance by showing that especially lean elderly require extra attention for their ambient environment.

Our results thus indicate that increases in systolic blood pressure relate negatively to cold-induced changes in thermogenesis. One possible mechanism behind this phenomenon is that the heat debt, which increases during cold exposure, differs between subjects. A large heat debt means that after cold exposure more energy is 
needed to restore tissue temperature. Therefore, the effects of cold exposure may last longer in those that experience a larger heat debt. To defend the heat balance upon mild cold two main strategies can be applied: 1. Increase heat production. 2 . Decrease heat loss (i.e. increase insulation). In practice, subjects will apply both strategies, yet there is a large individual variation between those that rely more on heat production or those that rely more on decreasing heat loss (van Ooijen et al, 2005). Shutting down heat transfer from the body core to the periphery through vasoconstriction effectively decreases heat loss $(23,24)$. A consequence of the second strategy is that the heat debt in peripheral tissue increases. Therefore, in relation to increased systolic blood pressure, the increased heat production strategy is advantageous over the reduction of heat loss strategy, because, with a smaller heat debt body temperature and related systolic blood pressure may restore quicker.

It is remarkable that the elderly showed a significant decrease in energy expenditure upon cold exposure. In fact, elderly are handicapped from the perspective of heat production compared to young adults. Human non-shivering thermogenesis (NST) can be mediated by mitochondrial uncoupling in brown adipose tissue and skeletal muscle $(9,25,26)$. The absence of NST in elderly points to an age-associated loss of ability of increasing mitochondrial uncoupling in those tissues. Indeed, age is associated with reduced amount of mitochondria in muscle cells (14). However, reduced amounts of mitochondria still do not explain why heat production decreased in elderly. This observation, however, may be explained by temperatureinduced changes on metabolic rates of tissues, also known as Arrhenius' law or the $\mathrm{Q}_{10}$-effect $(27,28)$. For example, given a frequently used $\mathrm{Q}_{10}$ factor $\left(\mathrm{Q}_{10}=2.3\right)$, metabolism drops by $57 \%$ for each $10^{\circ} \mathrm{C}$ drop in tissue temperature. A drop of $8 \%$ would therefore only require a $1.0^{\circ} \mathrm{C}$ temperature drop in metabolically active tissue (e.g. peripheral muscle). In this study we did not measure peripheral muscle temperature. Nevertheless, other studies reported a persistent thermal gradient of approximately $3^{\circ} \mathrm{C}$ between muscle and skin tissue $(29,30)$. Given these previous observations, in combination with an observed $3.5^{\circ} \mathrm{C}$ drop in mean skin temperature in this study, it is plausible that peripheral muscle temperature dropped approximately $1.0^{\circ} \mathrm{C}$. In that case, the $\mathrm{Q}_{10}$-effect could well explain the drop in energy expenditure in elderly. Moreover, the described $\mathrm{Q}_{10}$-effect also holds for young adults. This implies that some of the cold-induced non-shivering thermogenesis may be obscured by decreased thermogenesis in cooled peripheral (including skeletal muscle) tissues. A future study could shed light on this by comparing whole body change in energy expenditure with local tissue change in energy expenditure upon mild cold.

With respect to regulation of heat loss, there were no age effects in vasoconstriction, which contradicts previous observations $(4,31)$. The difference in observation could be explained by the rate of cooling. This study used a sudden ambient 
temperature drop (i.e. $30^{\circ} \mathrm{C}$ to $20^{\circ} \mathrm{C}$ reached within 10 minutes), whereas deGroot and Kenney used a more graded decrease temperature (i.e. $26.5^{\circ} \mathrm{C}$ to $17^{\circ} \mathrm{C}$ within 120 minutes). Nevertheless, the elderly in this study did show impaired nonshivering thermogenesis. In both studies, the result is failure to maintain thermal balance in elderly and therefore impaired defense of core temperature compared to young adults.

With the data of subjects combined, vasoconstriction, as marker for insulation did not significantly correlate to increases in systolic blood pressure. Nevertheless, data from the elderly show a significant negative relation between the change in systolic blood pressure and percent body fat (another marker for insulation) (Figure 4B). Body fat, i.e. fat tissue insulation, thus seems to protect against the cold and as a consequence to protect against persistent high blood pressure after cold exposure and rewarming. With respect to heat debt, fat tissue may have prevented heat debt in those tissues that are relevant to increase blood pressure. Notwithstanding the fact that increased adiposity is associated with increased peripheral arterial stiffness (32), its insulative properties can thus protect elderly from the adverse effects of mild cold.

\section{Limitations}

This study included only male subjects. Future studies could identify whether findings from this study can be generalized to both sexes. Furthermore, inspection for shivering was performed by visual recognition and every 10 minutes subjects were asked to state their thermal sensation and thermal comfort. Shivering is usually detected by electromyograms (EMG), and detection of shivering by visual recognition may lack sensitivity.

In summary, this study shows that even mild cold causes a long lasting increased systolic blood pressure that is augmented in elderly compared to young adults and is maintained in both groups after a one-hour rewarming period. There was a marked relation between change in energy expenditure upon mild cold and the maintained increase in systolic blood pressure after rewarming. With respect to heat production, young adults showed significant non-shivering thermogenesis upon mild cold, whereas the elderly decreased energy expenditure. With respect to heat loss, the elderly with a higher percent body fat had a lower increase in systolic blood pressure. Hence, despite an impaired thermoregulatory response, the insulating effect of body fat can protect the elderly from the adverse effects of mild cold.

\section{Conclusion}

This study shows that even after a one-hour rewarming period, the mild coldinduced increase in systolic blood pressure remains in young adults and elderly and is augmented in the latter. Furthermore, the increase in systolic blood pressure 
related negatively to cold induced changes in thermogenesis. Also, in elderly increase in systolic blood pressure related negatively to percent body fat. These findings are of clinical relevance by showing that: 1 ) impaired cold-induced thermogenesis renders elderly more vulnerable to mild thermal challenges than young adults; 2 ) especially lean elderly require extra attention for their ambient environment.

\section{References}

1. Wilkinson, P., et al., Vulnerability to winter mortality in elderly people in Britain: population based study. BMJ, 2004. 329(7467): p. 647.

2. Hess, K.L., et al., Aging affects the cardiovascular responses to cold stress in humans. J Appl Physiol, 2009. 107(4): p. 1076-82.

3. Collins, K.J., et al., Circadian body temperatures and the effects of a cold stress in elderly and young subjects. Age Ageing, 1995. 24(6): p. 485-9.

4. deGroot, D.W. and W.L. Kenney, Impaired defense of core temperature in aged humans during mild cold stress. Am J Physiol Regul Integr Comp Physiol, 2007. 292(1): p. R103-8.

5. Collins, K.J., et al., Effects of age on body temperature and blood pressure in cold environments. Clin Sci (Lond), 1985. 69(4): p. 465-70.

6. Hartgill, T.W., T.K. Bergersen, and J. Pirhonen, Core body temperature and the thermoneutral zone: a longitudinal study of normal human pregnancy. Acta Physiol (Oxf), 2011.

7. Savage, M.V. and G.L. Brengelmann, Control of skin blood flow in the neutral zone of human body temperature regulation. J Appl Physiol, 1996. 80(4): p. 124957.

8. Holowatz, L.A., C. Thompson-Torgerson, and W.L. Kenney, Aging and the control of human skin blood flow. Front Biosci, 2010. 15: p. 718-39.

9. van Marken Lichtenbelt, W.D., et al., Cold-activated brown adipose tissue in healthy men. N Engl J Med, 2009. 360(15): p. 1500-8.

10. van Ooijen, A.M., et al., Cold-induced heat production preceding shivering. $\mathrm{Br} J$ Nutr, 2005. 93(3): p. 387-91.

11. Wijers, S.L., et al., Human skeletal muscle mitochondrial uncoupling is associated with cold induced adaptive thermogenesis. PLOS ONE, 2008. 3(3): p. e1777.

12. Wijers, S.L., et al., \{beta\}-Adrenergic Receptor Blockade Does Not Inhibit ColdInduced Thermogenesis in Humans: Possible Involvement of Brown Adipose Tissue. The Journal of clinical endocrinology and metabolism, 2011. 96(4): p. E598-605.

13. Heaton, J.M., The distribution of brown adipose tissue in the human. Journal of anatomy, 1972. 112(Pt 1): p. 35-9.

14. Conley, K.E., et al., Mitochondrial dysfunction: impact on exercise performance and cellular aging. Exercise and sport sciences reviews, 2007. 35(2): p. 43-9. 
15. Zingaretti, M.C., et al., The presence of UCP1 demonstrates that metabolically active adipose tissue in the neck of adult humans truly represents brown adipose tissue. The FASEB journal : official publication of the Federation of American Societies for Experimental Biology, 2009. 23(9): p. 3113-20.

16. Kaciuba-Uscilko, H. and R. Grucza, Gender differences in thermoregulation. Curr Opin Clin Nutr Metab Care, 2001. 4(6): p. 533-6.

17. KNMI, Maandoverzicht van het weer in Nederland, 2010.

18. Parsons, K., Human Thermal Environments. 2 ed, ed. K.C.Parsons2003: Taylor \& Francis.

19. van Marken Lichtenbelt, W.D., et al., Evaluation of wireless determination of skin temperature using iButtons. Physiol Behav, 2006. 88(4-5): p. 489-97.

20. Brouwer, E., On simple formulae for calculating the heat expenditure and the quantities of carbohydrate and fat oxidized in metabolism of men and animals, from gaseous exchange (Oxygen intake and carbonic acid output) and urine-N. Acta physiologica et pharmacologica Neerlandica, 1957. 6: p. 795-802.

21. Bergersen, T.K., A search for arteriovenous anastomoses in human skin using ultrasound Doppler. Acta Physiol Scand, 1993. 147(2): p. 195-201.

22. Thoresen, M. and L. Walloe, Skin blood flow in humans as a function of environmental temperature measured by ultrasound. Acta Physiol Scand, 1980. 109(3): p. 333-41.

23. Sessler, D.I., et al., Thermoregulatory vasoconstriction decreases cutaneous heat loss. Anesthesiology, 1990. 73(4): p. 656-60.

24. Rennie, D.W., Tissue heat transfer in water: lessons from the Korean divers. Med Sci Sports Exerc, 1988. 20(5 Suppl): p. S177-84.

25. Wijers, S.L., W.H. Saris, and W.D. van Marken Lichtenbelt, Cold-Induced Adaptive Thermogenesis in Lean and Obese. Obesity (Silver Spring), 2010.

26. Astrup, A., Thermogenesis in human brown adipose tissue and skeletal muscle induced by sympathomimetic stimulation. Acta Endocrinol Suppl (Copenh), 1986. 278: p. 1-32.

27. Gisolfi, C. and F. Mora, The Hot Brain: Survival, Temperature and the Human Body2000: Cambridge, MIT Press.

28. Lemieux, H., P.U. Blier, and J.C. Tardif, Does membrane fatty acid composition modulate mitochondrial functions and their thermal sensitivities? Comp Biochem Physiol A Mol Integr Physiol, 2008. 149(1): p. 20-9.

29. Pennes, H.H., Analysis of tissue and arterial blood temperatures in the resting human forearm. J Appl Physiol, 1948. 1(2): p. 93-122.

30. Severens, N.M., et al., Effect of forced-air heaters on perfusion and temperature distribution during and after open-heart surgery. Eur J Cardiothorac Surg, 2007. 32(6): p. 888-95.

31. Thompson, C.S. and W.L. Kenney, Altered neurotransmitter control of reflex vasoconstriction in aged human skin. J Physiol, 2004. 558(Pt 2): p. 697-704. 
32. Snijder, M.B., et al., Regional body composition as a determinant of arterial stiffness in the elderly: The Hoorn Study. J Hypertens, 2004. 22(12): p. 2339-47. 


\section{CHAPTER 5}

\section{INCORPORATING NEUROPHYSIOLOGICAL CONCEPTS IN MATHEMATICAL THERMOREGULATION MODELS}




\begin{abstract}

\section{Background}

Skin blood flow (SBF) is a key player in human thermoregulation during mild thermal challenges. Various numerical models of SBF regulation exist. However, none explicitly incorporates the neurophysiology of thermal reception. This study tested a new SBF model that is in line with experimental data on thermal reception and the neurophysiological pathways involved in thermoregulatory SBF control. Additionally, a numerical thermoregulation model was used as a platform to test the function of the neurophysiological SBF model for skin temperature simulation.
\end{abstract}

\title{
Methods
}

The prediction-error of the SBF-model was quantified by mean-squared-residual (MSR) between simulations and experimental measurement data. Measurement data consisted of SBF (abdomen, ventral forearm, dorsal and ventral hand), core and skin temperature recordings of 12 young males during two transient thermal challenges (development and validation). Additionally, ThermoSEM, a thermoregulation model, was used to simulate body temperatures using the new neurophysiological SBF-model. The square root MSR between simulated and measured mean skin temperature was used to validate the model.

\section{Results}

The neurophysiological model predicted SBF with reasonable accuracy (MSR<0.01). Also, Tskin simulation results were within acceptable range (square root $\left.\mathrm{MSR}<0.37^{\circ} \mathrm{C}\right)$.

\section{Conclusion}

This study shows that 1 ) thermal reception and neurophysiological pathways involved in thermoregulatory SBF control can be captured in a mathematical model and 2) human thermoregulation models can be equipped with skin blood flow control functions that are based on neurophysiology without loss of performance. 


\section{Introduction}

Skin blood flow is a major thermoregulatory mechanism to control body heat loss (1). Under most living circumstances ambient temperature is below skin temperature. In that case, when skin blood flow is reduced, skin temperature drops and heat loss decreases. Vice versa, when skin blood flow is increased, skin temperature rises and heat loss increases. In the thermoneutral zone, skin blood flow is the sole thermoregulatory mechanism through which body temperature is regulated (2). Therefore, only when body temperature regulation by skin blood flow modulation alone is insufficient other mechanisms start to play a role, such as: non-shivering thermogenesis, shivering and sweating.

Models of human thermoregulation simulate the thermoregulatory mechanisms that regulate body temperature. However, since it is common to start simulations in thermoneutral conditions the overall quality of these models depends for a great deal on their ability to predict skin blood flow. Practical applications of thermoregulation models are found in various fields such as: biometeorology, the built environment, clothing research, car industry and clinics (3). Moreover, these models also provide a platform to test hypotheses on control of thermoregulatory mechanisms.

Over time several models for skin blood flow regulation have been developed (4-8). Most of these models incorporate concepts of physiological regulation of skin blood flow to some degree. For instance, the models contain functions that resemble the stimulation of the sympathetic adrenergic (i.e. for vasoconstriction) and sympathetic cholinergic (i.e. for vasodilation) nervous system $(1,9)$. However, none of them directly incorporate the neurophysiology of thermal reception (i.e. transduction of temperature to neuron fire rate) and neural pathways including neural inhibition and excitation. The idea of neurophysiological control in thermoregulation has been around for some time (10-14). However, only a few explored neurophysiology as an alternative approach for mathematical modeling of human thermoregulation (15, 16).

In this study a new skin blood flow model was developed in line with experimental data on thermal reception and the neurophysiological pathways involved in thermoregulatory SBF control. We hypothesized that the model is able to predict skin blood flow at least as good as traditional models.

To test this hypothesis, two models of skin blood flow (SBF) predictions were validated using an independent data set with varying environmental temperatures. One model is Fiala's skin blood flow model (the reference SBF-model). The other model is the neurophysiological model developed in this study.

Additionally, ThermoSEM, a model based on the Fiala thermoregulation model (6, 17), was used to simulate body temperatures. ThermoSEM was equipped with 1) the neurophysiological SBF model or 2) with the reference SBF model. Both model 
variations were validated using the square root mean squared residual (SRMSR) between simulated and experimentally measured mean skin temperatures.

\section{Methods}

\section{Experimental data}

The neurophysiological skin blood flow model was developed and validated by using two experimental datasets. The datasets included measurements of skin blood flow, core temperature and skin temperature on 12 young males from a study performed in our laboratory (described in Chapter 4). Skin blood flow was measured with laser Doppler flowmetry at the abdomen, the ventral side of the forearm and both the dorsal and ventral side of the hand (Perimed, Sweden). Core temperature was measured with an ingested telemetric pill (CoreTemp, USA) and skin temperature was measured with iButtons (Maxim, USA) at the 14 ISO positions for mean skin temperature $(18,19)$.

Subjects were exposed to two protocols. In both protocols subjects were in supine position and dressed in shorts only $(0.04 \mathrm{Clo})$. Subjects were first exposed to baseline air-temperature $\left(30^{\circ} \mathrm{C}, 0.5 \mathrm{~h}\right)$. Next, in protocol 1 , they were exposed to warm conditions, followed by a mild cold condition $\left(35^{\circ} \mathrm{C}, 1 \mathrm{~h} ; 20^{\circ} \mathrm{C}, 1 \mathrm{~h}\right)$, and finally subjects were exposed to baseline conditions again for $1 \mathrm{~h}$. On another day, in protocol 2, subjects were first exposed to a mild cold condition, followed by a warm condition $\left(20^{\circ} \mathrm{C}, 1 \mathrm{~h} ; 35^{\circ} \mathrm{C}, 1 \mathrm{~h}\right)$, and thereafter 1 hour baseline conditions again (20).

\section{Skin blood flow model}

The neurophysiological skin blood flow model simulates five phases of the thermoregulatory tract (16). First, the model transduces local skin temperatures into the dynamic fire rates of both warm and cold temperature sensitive neurons according to Mekjavic and Morrison (15) (see Figure 1, for equations see below).

Second, the peripheral (skin) neuron fire rates are integrated according to the neurophysiological pathways reported by Nakamura and Morrison $(22,23)$. Their experiments showed that the neuron fire rate of peripheral warm and cold sensitive neurons project to neurons at the spine (see $P_{\text {warm }}$ and $P_{\text {cold }}$ in Figure 2 ).

Third, via secondary neurons at the dorsal horn, the (integrated) peripheral warm and cold sensing pathways project to the medial pre-optic area (MPO) of the hypothalamus where they respectively excite and inhibit local warm sensitive neurons (12). The neuron fire rate of warm sensitive neurons at the MPO is calculated separately (depicted as $\mathrm{H}_{\text {warm }}$ in Figure 2, for equations see below).

Fourth, the neurons of the MPO inhibit neurons of the ventromedial medulla. This inhibition is proportional to the activity of the neurons at the MPO and associated weights ( $\gamma_{2}$ and $\gamma_{3}$ in Figure 2 ). 
Fifth, from the ventromedial medulla, efferent neurons control skin blood flow. Local skin blood flow is calculated by multiplication of the integrated neural signal with basal perfusion and the $\mathrm{Q}_{10}$-factor for local thermoregulation (7). The neurophysiological pathways are also under influence of other non-thermal inputs (e.g. hormones, blood pressure or anesthesia) (24). The model incorporates these nonthermal influences with a constant ( $\boldsymbol{\gamma}_{1}$ in Figure 2 ).

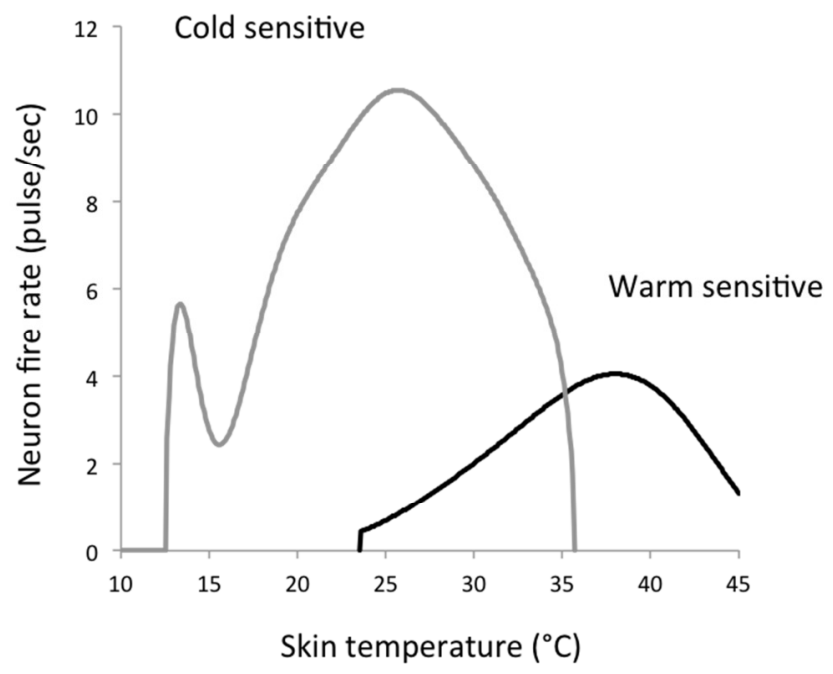

Figure 1: Steady state neuron fire rate vs. skin temperature for cold sensitive (gray line) and warm sensitive (black line) neurons (after $(15,21)$ )

The neurophysiological approach for skin blood flow regulation was implemented as:

$$
\beta_{i}=\beta_{i, b a s} \times N \times Q_{10}
$$

Here, $\beta_{i}$ is the heat equivalent of blood flow, $Q_{10}=2^{\frac{\left(T_{i}-T_{i, b a s}\right)}{10}}$ accounts for the local regulation (i.e. $Q_{10}$ effect) of skin blood flow, and $N$ is the neural regulation signal for skin blood flow. $N$ is calculated as:

$$
N=\gamma_{1}-\gamma_{2}\left(H_{\text {warm }}-P_{\text {cold }}\right)-\gamma_{3}\left(H_{\text {warm }}+P_{\text {warm }}\right)
$$




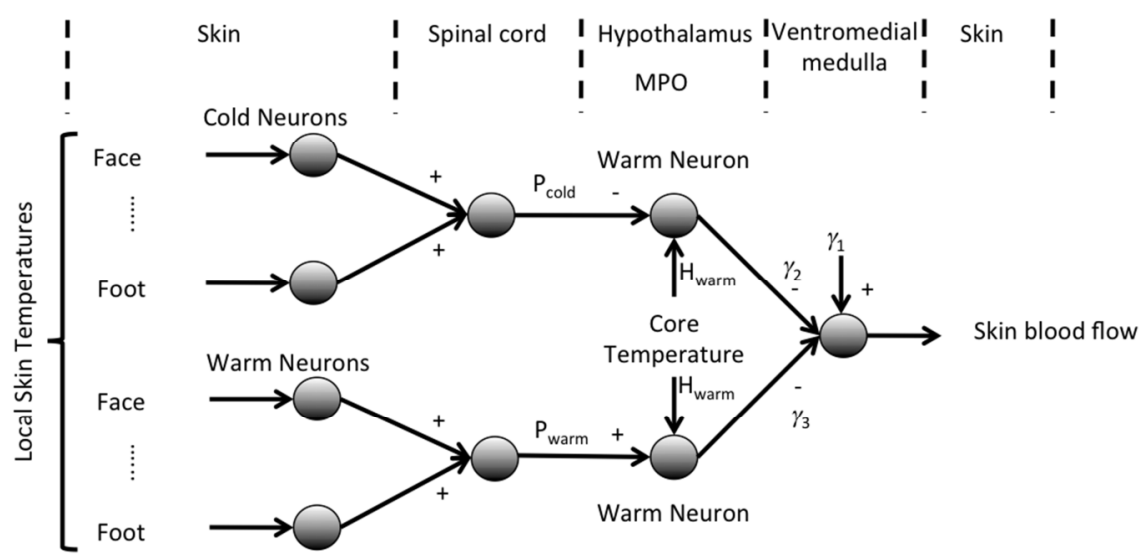

Figure 2: Schematic of neuronal model for control of skin blood flow. + and - denote excitatory or inhibitory pathways; $\gamma 1$ denotes the averaged non-thermal effects on skin blood flow; $\gamma 2$ denotes weighing of the ventromedial medulla inhibition by warm sensitive neurons in the hypothalamus that are under influence of skin cold reception (Pcold) and $\gamma 3$ weighing of the ventromedial medulla inhibition by warm sensitive neurons in the hypothalamus that are under influence of skin warm reception (Pwarm).

Here $H_{\text {warm }}$ is the neuron fire rate of temperature sensitive neurons in the hypothalamus $H_{\text {warm }}, P_{\text {cold }}$ is the peripheral cold stimulus and $P_{\text {warm }}$ is the peripheral warm stimulus. $\gamma_{1}$ is the model constant which represents the averaged combined effect of non-thermal factors that affect skin blood flow (e.g. blood pressure) and $\gamma_{2}$ and $\gamma_{3}$ (given in Table 5 of the appendix) define the inhibition strength of the hypothalamus on the vasomotor center.

The afferent peripheral cold and warm stimuli are calculated as the mean neuron fire rate of skin temperature sensitive neurons:

$$
\begin{aligned}
P_{\text {cold }} & =\frac{1}{n} \sum_{i=1}^{n} f_{s k, \text { cold }} \\
P_{\text {warm }} & =\frac{1}{n} \sum_{n=1}^{n} f_{s k, \text { warm }}
\end{aligned}
$$

Here, $f_{s k \text {,cold }}$ and $f_{s k \text {,warm }}$ are the fire rate of a skin cold and warm sensitive neuron respectively, and, for completeness, $H_{\text {warm }}=f_{\text {hy,warm }}$. The fire rate of temperature sensitive neurons is composed of steady state fire rate and dynamic response to temperature changes and is calculated according to Mekjavic and Morrison (15): 
$f=\frac{1}{\Delta t} \sum_{j=0}^{j=\Delta t-1} S_{t-1}+\left(G_{0}\left(1-e^{-j / K}\right)+D \cdot G\left(e^{-j / K_{e x c}}-e^{-j / K_{i n h}}\right)\right)$

Here $S_{t-1}$ is the steady state neuron fire rate at $t=t-1, G_{0}$ and $G$ are gain factors that depend on the difference of steady state fire rates between two moments of time $\left(G_{0}=S_{t-1}-S_{t}\right.$ and $\left.G=5.0 \cdot S_{t-1} \cdot\left|G_{0}\right|\right) \cdot K=5.5, K_{\text {exc }}=5.5$ and $K_{i n h}=3.3$ are static, excitatory and inhibitory gain factors respectively. $D$ is a sign operator indicating an excitatory or inhibitory response. When cold sensitive neurons are heated $D$ is negative, when the same neurons are cooled, $D$ is positive and vice versa for warm sensitive neurons. The steady state fire rate of neurons is calculated as:

$$
S_{t}=\sum_{j} s_{j} T_{i}^{j}
$$

Where $s_{j}$ is the $j$-th order coefficient as given in Table 6 of the appendix and $T_{i}^{j}$ is the local temperature. The steady state response of core temperature neurons is also calculated according to Mekjavic and Morrison by shifting core temperature by $-2^{\circ} \mathrm{C}(15)$.

The neurophysiological skin blood flow model was validated using a modified $k$-fold cross validation scheme (25) (see also Figure 3). Protocol 1 served as a development dataset and protocol 2 served as a validation dataset. The development of the model was carried out as follows. K-fold cross validation allowed iterative model development, where each iteration the model parameters $\left(\gamma_{1}, \gamma_{2}\right.$ and $\left.\gamma_{3}\right)$ were fitted against the experimental data of eleven $(n-1=11)$ subjects (protocol 1$)$. Note that skin blood flow measurements were first corrected for local regulation by dividing by the local $\mathrm{Q}_{10}$-factor and then normalized to baseline values. In this manner, each cycle yielded a new set of $\gamma$ s, and each time a unique subject was left out of the development dataset. This unique subject was then selected and skin blood flow was predicted using skin and core temperature from the validation dataset (protocol 2). The mean squared residual (MSR) between simulated and measured skin blood flow of the validation dataset was used as a measure of prediction quality. Hence, after the procedure the neurophysiological SBF-model was validated on each subject and twelve MSR's were obtained for each skin site. For the thermoregulation model, the $\gamma$ sets obtained in the development phase were averaged to define a final $\gamma$ set for each skin site. 


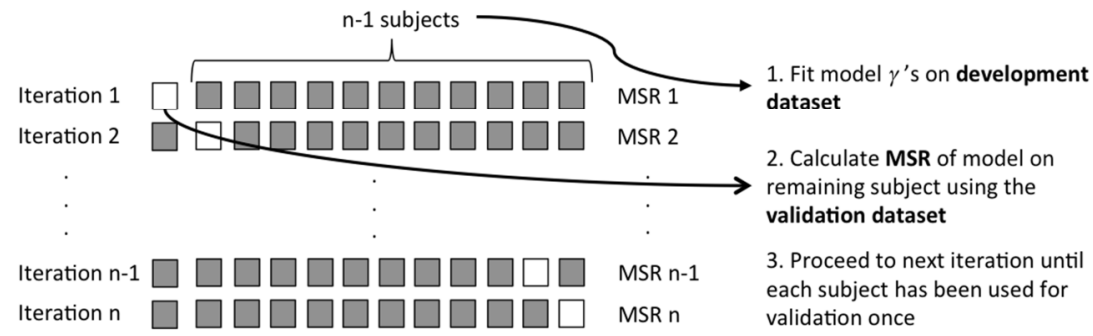

Figure 3: Schematic view of neurophysiological skin blood flow model development and validation. In each row the gray boxes denote the subjects on which the neurophysiological model parameters were fitted using the development dataset and the white box denotes the individual subject on the model was validated using the validation dataset. The mean squared residual (MSR) between model prediction and experimental measurement was used to quantify the prediction error.

The reference skin blood flow model predictions were also compared to the validation dataset for each individual. Hence, in total 48 MSR's were obtained for both models ( 12 subjects and 4 skin sites).

To test whether skin blood flow predictions by the reference and neurophysiological model differed significantly, a paired samples t-test was conducted on the MSR data of both models. The test statistic was corrected for multiple testing using Bonferroni's method (26). The alpha level for significance was set at 0.05 . All calculations were performed with Matlab R2010a.

\section{Thermoregulation model}

ThermoSEM, a numerical thermoregulation model, was used for simulations. ThermoSEM is a descendant of the Fiala thermoregulation model $(6,17)$. In the passive part, ThermoSEM differs slightly from Fiala's model in that the arms and legs are split in upper and lower parts and that the skin perfusion (inner skin) is corrected for tissue volume $(27,28)$. In the active part, no adjustments were performed aside from the skin blood flow model presented in this manuscript.

Similar to the Fiala thermoregulation model, ThermoSEM does not define skin blood flow control for the dorsal and ventral hand side of the hand separately. Therefore, the ventral hand $\gamma$ set of the neurophysiological SBF-model was assigned to the entire hand. The reason for this choice is that in contrast to the dorsal hand, skin at the ventral side of the hand contains many arterio venous anastomoses (AVAs) (29). When opened, the AVAs shunt blood flow directly from arterioles to venules, thereby bypassing low capacity capillaries and drastically increasing skin blood flow (30). Since AVAs have such a pronounced effect of skin blood flow the ventral hand $\gamma$-set was assigned to both sides of the hand (see appendix, Table 6). 


\section{Simulation of thermoregulation}

Body temperatures were simulated with ThermoSEM, using either the reference SBF-model for skin blood flow or the neurophysiological SBF-model. The prediction quality of mean skin temperature in the simulations was tested by calculation of the mean squared residual between mean skin temperature measurement and simulation. Mean skin temperature was calculated as the area-weighted average of skin sites with thermometers (iButtons) attached during experiments.

For the simulation of the thermoregulation response, and resulting body temperatures, the environmental conditions were set as the averaged air and wall temperatures and averaged relative humidity and wind speed as measured during the experiments of protocol 2 (see Figure 4, relative humidity and wind speed are given in Table 1). The humanoid used for the simulation was based on the Fiala model (17) (height $=1.73 \mathrm{~m}$; Dubois area $=1.85 \mathrm{~m}^{2}$, weight $=73.4 \mathrm{~kg}$, fat percentage $=14.4 \%$, metabolic rate $=87 \mathrm{~W}$ and cardiac output $=4.9 \mathrm{~L} / \mathrm{min}$ ).

Table 1: Relative humidity and wind speed of the surrounding air as prescribed in the model simulation

\begin{tabular}{llll}
\hline Epoch $(\min )$ & Relative humidity $(\%)$ & & Wind speed $(\mathrm{m} / \mathrm{s})$ \\
1 to 30 & 27 & 38 & 0.09 \\
31 to 90 & 20 & 0.12 \\
91 to 150 & 20 & 0.10 \\
151 to 210 & & 0.10 \\
\hline
\end{tabular}

\section{Results}

\section{Validation of skin blood flow models}

An example of the perfusion prediction of the neurophysiological and the reference SBF-model is given in Figure 5. At the ventral forearm, the predictions of the neurophysiological model are close to experimentally measured values for the entire simulation, whereas the reference model shows a large overestimation of vasoconstriction.

The validation of the SBF-models at the abdomen, forearm, dorsal side of the hand and ventral side of the hand is summarized in Figure 6 . The neurophysiological SBFmodel performed significantly better at all measured positions, except at the ventral hand, where the model performance is not significantly different from the reference SBF model. Moreover, the averaged MSRs of the neurophysiological model is comparable over all 4 positions, while the reference model shows a large variation in averaged MSR between positions, indicating a greater robustness of the neurophysiological model. 


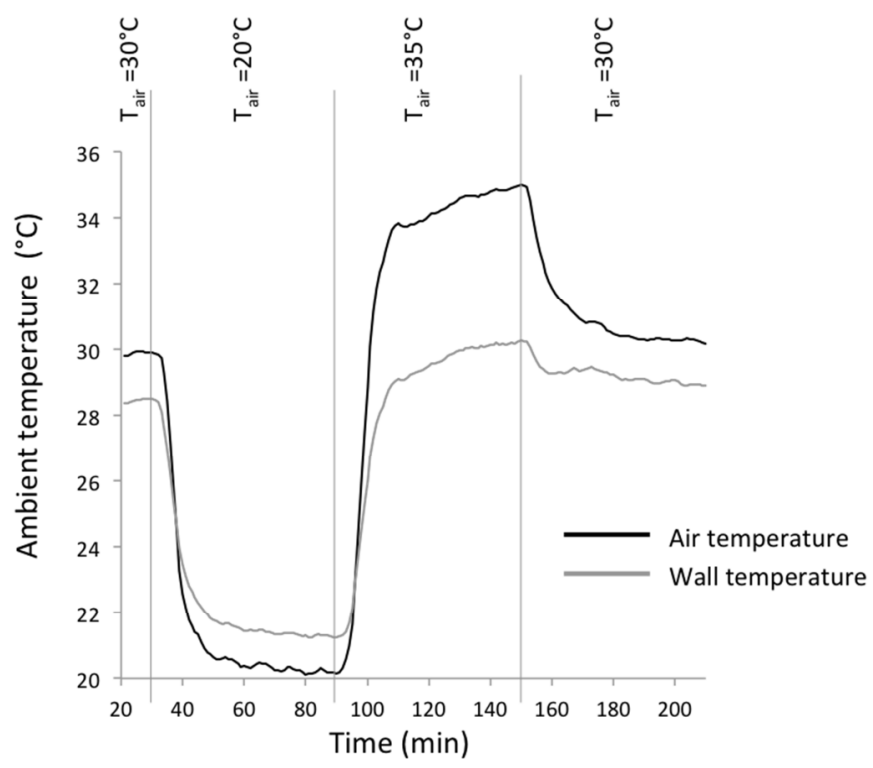

Figure 4: Averaged measured air and wall temperature as prescribed in the model simulation.

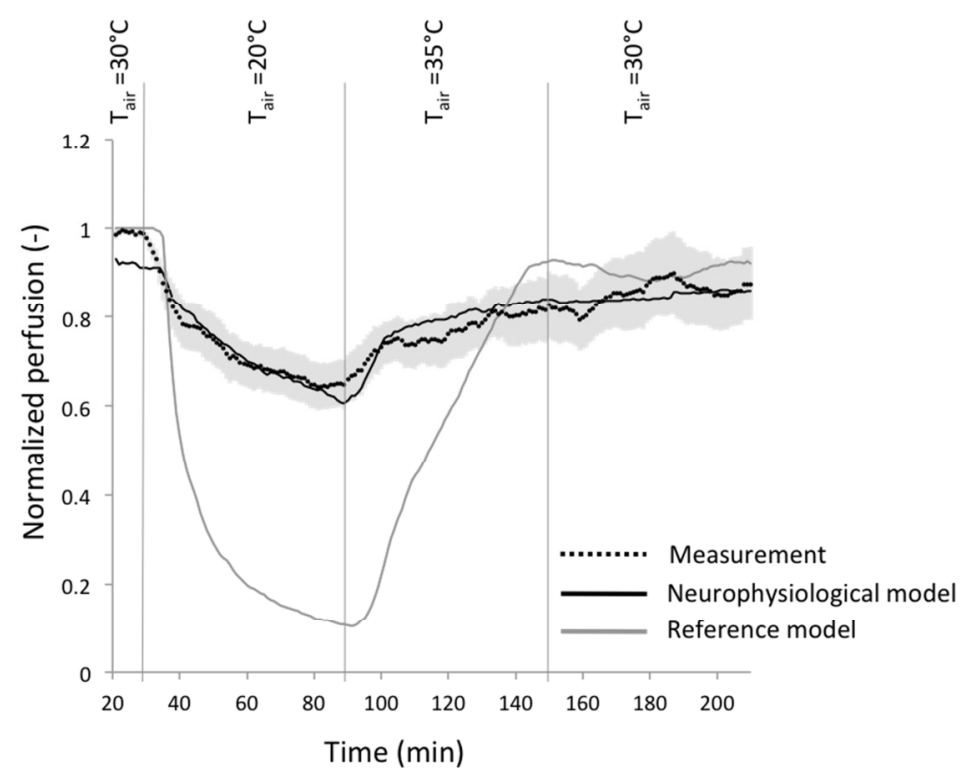

Figure 5: Averaged skin blood flow measurement at ventral forearm (black dots) and skin blood flow prediction of the neurophysiological model (black line) and reference model (gray line). Error bars (light gray area) represent the standard error of the mean $(n=12)$. 


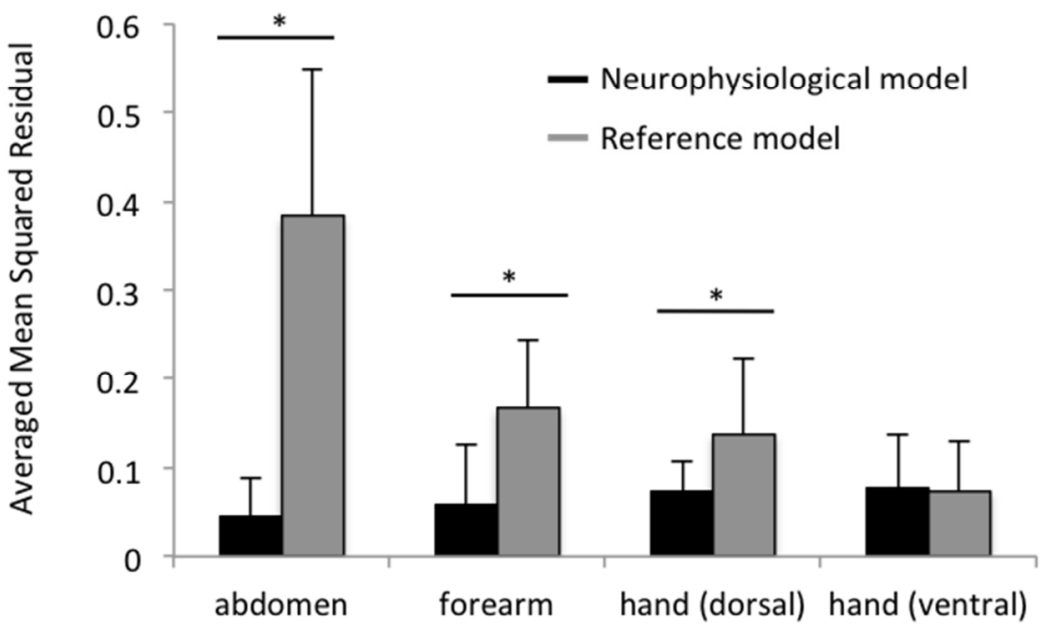

Figure 6: Averaged mean squared residual (MSR) between skin blood flow predictions and measurement data. Bars represent standard deviation of the MSR. *: $p<0.05, n=12$.

\section{Validation of mean skin temperature simulation}

Body temperatures were simulated with ThermoSEM, using either the reference SBF-model for skin blood flow or the neurophysiological SBF-model. The final, averaged $\gamma$-sets as obtained from the development phase are presented in Table 2.

Table 2: Mean $\gamma \pm S E(n=12)$ as estimated by $k$-fold cross validation. The mean value was used in the model simulation.

\begin{tabular}{|c|c|c|c|}
\hline Site & $\gamma_{1}$ & $\gamma_{2}$ & $\gamma_{3}$ \\
\hline Abdomen & $2.4250 \pm 0.0558$ & $-0.1246 \pm 0.0029$ & $0.1658 \pm 0.0076$ \\
\hline Forearm & $-0.2321 \pm 0.1633$ & $-0.0231 \pm 0.0115$ & $-0.2126 \pm 0.0224$ \\
\hline Hand dorsal & $0.7906 \pm 0.1039$ & $-0.1853 \pm 0.0047$ & $-0.0816 \pm 0.0149$ \\
\hline Hand ventral & $0.7368 \pm 0.2595$ & $-0.2190 \pm 0.0113$ & $-0.0704 \pm 0.0363$ \\
\hline
\end{tabular}

Mean skin temperature predictions and measured mean skin temperature are given in Figure 7. The neurophysiological model yields a lower MSR than the reference model on mean skin temperature (MSR neurophysiological=0.135 vs. MSR reference $=0.329$ ). Furthermore, mean skin temperature simulation with the neurophysiological model remains within the $95 \%$ confidence interval bounds of the measurements throughout the simulation, whereas with the reference model there is a significant underestimation of mean skin temperature during mild cold exposure (Figure 7). 


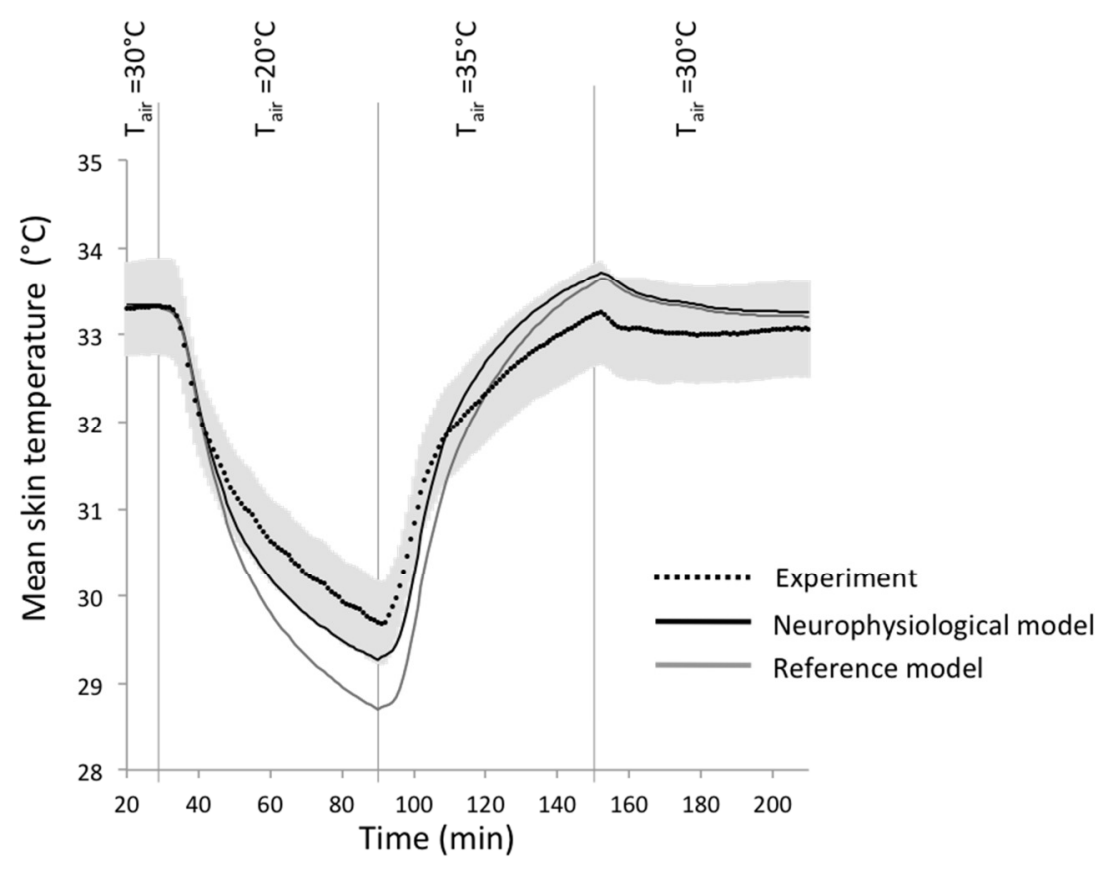

Figure 7: Averaged mean skin temperature from measurements (black dots) with 95\% confidence interval (light gray area, $n=12$ ) and model simulation using the neurophysiological model (black line) and the reference model (gray line).

\section{Discussion}

This study shows that 1 ) thermal reception and neurophysiological pathways involved in thermoregulatory SBF control can be captured in a mathematical model and 2) human thermoregulation models can be equipped with skin blood flow control functions that are based on neurophysiology without loss of performance.

With respect to modeling human thermoregulation several approaches exist. The most frequently used approach is based on setpoints. A setpoint defines a reference temperature to which the actual body temperature is compared. The difference between the actual temperature and the setpoint temperature defines the error signal. Thermoregulatory mechanisms are assumed to scale proportional to the error signal (6). The reference skin blood flow model in this study was based on setpoints for skin temperatures (6). The concept of a setpoint has been debated for decades. Even in recent literature elaborate pleas can be found to either abandon or maintain the "setpoint" (31-33). Irrespective of the validity of the setpoint concept, it remains useful to explain various regulatory mechanisms in homeostasis.

With the neurophysiological approach, skin blood flow scales proportional to the activity of the ventromedial medulla (Figure 2). In turn, the ventromedial medulla scales (inversely) proportional to the actual state of the hypothalamic warm and 
cold pathways (34). This is essentially different than a setpoint. In that case the ventromedial medulla activity would scale proportional to the difference between the neutral and actual state (33).

ThermoSEM simulated mean skin temperature within an acceptable margin of error for most applications with both skin blood flow models (root MSR: neurophysiologi$\mathrm{cal}=0.37^{\circ} \mathrm{C}$ vs. reference $=0.57^{\circ} \mathrm{C}$ ). Part of the discrepancy between simulation and measurements can be explained by imperfect knowledge of the boundary conditions. For instance, wind speed and humidity were measured at a single point near the subjects, yet no data was available close to the local skin sites. Moreover, assumptions on body composition, morphology, acclimatization, etc. might also have influenced the simulation results (27). Nevertheless, the relatively small error obtained by the neurophysiological SBF model is promising. Especially considering the model simplifications relative to reality (e.g. number of neurons involved, exact neural pathway, etc.).

Further research should focus on the relation between neuron fire rate and skin blood flow in more extreme temperature ranges. More specifically, according to Figure 1, the neuron fire rate of cold sensitive neurons increases with falling skin temperature in the range between $25^{\circ} \mathrm{C}$ to $35^{\circ} \mathrm{C}$ suggesting vasoconstriction, as expected, would rise with falling skin temperature. However, for skin temperatures below $25^{\circ} \mathrm{C}$ the neuron fire rate decreases again, which means that the neural drive for vasoconstriction would also decrease, while at that temperature range no increase in skin blood flow is expected. Part of this may be explained by the interaction between central (e.g. neural) and local regulatory mechanisms (e.g. $\mathrm{Q}_{10}$-effect). At skin temperatures of about $25^{\circ} \mathrm{C}$ local effects cap maximal skin blood flow to about $50 \%$ of baseline level (35). When skin temperature decreases further, local effects may cause the cap to decrease as well. Also, very low tissue temperatures are associated with paralysis to neural in or output (36). Thus, it may be that at more extreme skin temperatures local effects play a dominant role relative to neural effects.

This study focused on the simulation of skin blood flow and skin temperature in thermoregulatory models. Nevertheless, data in Figure 8 show that the neurophysiological model overestimated the change in core temperature during cold exposure beyond the $95 \%$ confidence interval of the measurements.

The greater error in core temperature simulation is not necessarily a falsification of the neurophysiological model hypothesis. Instead, it may indicate flaws in other parts of the model that were corrected for by overestimation of vasoconstriction in the reference model (see Figure 5). Overestimation of vasoconstriction indicates that more body heat needs to be conserved, or produced, when more realistic skin blood flow is used.

Options to achieve greater heat conservation are: 1) reducing the basal skin blood flow level or 2 ) increasing the counter current heat exchange. An option to achieve 
a greater heat production is to consider non-shivering thermogenesis. A post hoc analysis showed that decreasing basal skin blood flow by $10 \%$ improved the change in core temperature by $0.05^{\circ} \mathrm{C}$. Furthermore, increasing the counter current heat exchange coefficients by $10 \%$ did not significantly affect the change in core temperature, although the absolute value of the core temperature was increased by $0.2^{\circ} \mathrm{C}$. However, it might be that a different distribution of the counter current heat exchange over body parts has a larger effect. The third option, a $10 \%$ increase in heat production (i.e. non-shivering thermogenesis) during cold exposure improved the change in core temperature by $0.1^{\circ} \mathrm{C}$. Because of the complex interaction between all mechanisms during simulations it is difficult to pinpoint a single issue. Overall, these data suggest that further study is warranted on the interaction between basal skin blood flow, counter current heat exchange in human vessel-pairs and nonshivering thermogenesis.

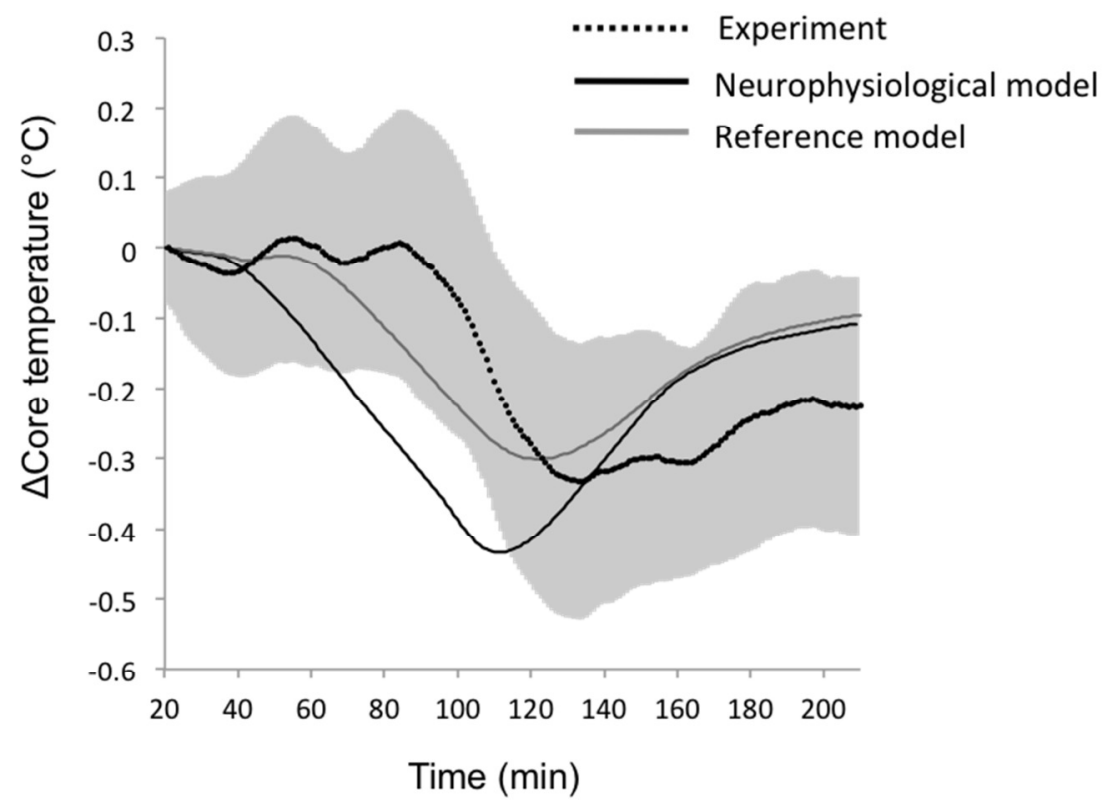

Figure 8: Averaged change in core temperature from measurements (black dots) with 95\% confidence interval (light gray area, $n=12$ ) and model simulation using the neurophysiological model (black line) and the reference model (gray line).

Furthermore, the subjects used for analysis in this study were all healthy young adult males with a lean body composition. Future studies should include other groups as well. Furthermore, the reference model was developed on averaged measurement data on heterogeneous subject groups (i.e. males, females, young, elderly etc.) (6), which may partly explain the greater prediction error relative to measurement data from this specific subject group (i.e. young adult males). 
An advantage of the neurophysiological model approach is its extendibility to incorporate other physiological factors that influence skin blood flow (e.g. anesthetic drugs, blood pressure or hormones). For instance, in hemodialysis a large blood volume is transported out the body, which is accompanied with a fall in blood pressure (37). Reduction of skin blood flow by vasoconstriction helps to maintain internal blood pressure normal. An accurate model of skin blood flow that combines both barometric and thermal influences is therefore useful in a clinical setting. To incorporate the influence of blood pressure on skin blood flow the model could be formulated as: $\mathrm{N}=\gamma_{1}^{*}-\gamma_{2} \cdot\left(H_{\text {warm }}-P_{\text {cold }}\right)-\gamma_{3} \cdot\left(H_{\text {warm }}+P_{\text {warm }}\right)-\gamma_{4} \cdot\left(P_{\text {baroreceptor }}\right)$, where $P_{\text {baroreceptor }}$ represents the neural fire rate of baroreceptors and $\gamma_{1}^{*}$ represents the non-thermal and non-barometric effects on the thermoregulation. For a review of other factors that influence thermoregulation see ref. (24).

\section{Conclusion}

A neurophysiological basis for control functions in numerical thermoregulation models creates synergy between physiology and mathematical modelling. This study shows that 1) thermal reception and neurophysiological pathways involved in thermoregulatory SBF control can be captured in a mathematical model and 2) human thermoregulation models can be equipped with skin blood flow control functions that are based on neurophysiology without loss of performance. Incorporation of the neurophysiological approach to mathematical thermoregulation models may be beneficial for research fields that apply those models such as: the built environment and health clinics.

\section{References}

1. Kellogg, D.L., Jr., In vivo mechanisms of cutaneous vasodilation and vasoconstriction in humans during thermoregulatory challenges. J Appl Physiol, 2006. 100(5): p. 1709-18.

2. Brengelmann, G.L. and M.V. Savage, Temperature regulation in the neutral zone. Ann N Y Acad Sci, 1997. 813: p. 39-50.

3. Fiala, D., et al., Physiological modeling for technical, clinical and research applications. Frontiers in bioscience, 2010. 2: p. 939-68.

4. Tanabe, S., et al., Evaluation of thermal comfort using combined multi-node thermoregulation $(65 \mathrm{MN})$ and radiation models and computational fluid dynamic (CFD). Energ. Buildings, 2002. 34: p. 637-646.

5. Stolwijk, J.A., A mathematical simulation model of the skin for evaluation of surface temperature gradients resulting from local variations in metabolism and blood flow. Bibl Radiol, 1975(6): p. 151-6.

6. Fiala, D., K.J. Lomas, and M. Stohrer, Computer prediction of human thermoregulatory and temperature responses to a wide range of environmental conditions. Int J Biometeorol, 2001. 45(3): p. 143-59. 
7. Wissler, E.H., A quantitative assessment of skin blood flow in humans. Eur J Appl Physiol, 2008. 104(2): p. 145-57.

8. Severens, N.M., et al., Measurement of model coefficients of skin sympathetic vasoconstriction. Physiol Meas, 2010. 31(1): p. 77-93.

9. Johnson, J.M. and D.L. Kellogg, Jr., Thermoregulatory and thermal control in the human cutaneous circulation. Frontiers in bioscience, 2010. 2: p. 825-53.

10. Hammel, H.T., et al., Temperature Regulation by Hypothalamic Proportional Control with an Adjustable Set Point. J Appl Physiol, 1963. 18: p. 1146-54.

11. Benzinger, T.H., Heat regulation: homeostasis of central temperature in man. Physiol Rev, 1969. 49(4): p. 671-759.

12. Boulant, J.A., Neuronal basis of Hammel's model for set-point thermoregulation. J Appl Physiol, 2006. 100(4): p. 1347-54.

13. Bligh, J., A theoretical consideration of the means whereby the mammalian core temperature is defended at a null zone. J Appl Physiol, 2006. 100(4): p. 1332-7.

14. Furber, S. and S. Temple, Neural systems engineering. Journal of the Royal Society, Interface / the Royal Society, 2007. 4(13): p. 193-206.

15. Mekjavic, I.B. and J.B. Morrison, A model of shivering thermogenesis based on the neurophysiology of thermoreception. IEEE Trans Biomed Eng, 1985. 32(6): p. 407-17.

16. Kingma, B.R.M., et al., Modeling Skin Blood Flow: A Neuro-physiological Approach, in Proceedings of the International Conference on Fuzzy Computation and 2nd International Conference on Neural Computation2010, SciTePress: Valencia (Spain). p. 156-162.

17. Fiala, D., K.J. Lomas, and M. Stohrer, A computer model of human thermoregulation for a wide range of environmental conditions: the passive system. J Appl Physiol, 1999. 87(5): p. 1957-72.

18. Parsons, K., Human Thermal Environments. 2 ed, ed. K.C.Parsons2003: Taylor \& Francis (London).

19. van Marken Lichtenbelt, W.D., et al., Evaluation of wireless determination of skin temperature using iButtons. Physiol Behav, 2006. 88(4-5): p. 489-97.

20. Kingma, B., et al., Increased systolic blood pressure after mild cold and rewarming: relation to cold-induced thermogenesis and age. Acta physiologica, 2011.

21. Zotterman, Y., Special senses: thermal receptors. Annu Rev Physiol, 1953. 15: p. 357-72.

22. Nakamura, K. and S.F. Morrison, A thermosensory pathway that controls body temperature. Nat Neurosci, 2008. 11(1): p. 62-71.

23. Nakamura, K. and S.F. Morrison, Preoptic mechanism for cold-defensive responses to skin cooling. J Physiol, 2008. 586(10): p. 2611-20. 
24. Mekjavic, I.B. and O. Eiken, Contribution of thermal and nonthermal factors to the regulation of body temperature in humans. J Appl Physiol, 2006. 100(6): p. 2065-72.

25. Rodriguez, J.D., A. Perez, and J.A. Lozano, Sensitivity Analysis of k-Fold Cross Validation in Prediction Error Estimation. IEEE trans Pattern Analysis and Machine Intelligence, 2010. 32(3): p. 567-575.

26. Field, A., Discovering Statistics Using SPSS. 3 ed2009, London: SAGE Publications Ltd.

27. van Marken Lichtenbelt, W.D., et al., Validation of an individualised model of human thermoregulation for predicting responses to cold air. Int J Biometeorol, 2007. 51(3): p. 169-79.

28. Severens, N.M., et al., A model to predict patient temperature during cardiac surgery. Phys Med Biol, 2007. 52(17): p. 5131-45.

29. Bergersen, T.K., A search for arteriovenous anastomoses in human skin using ultrasound Doppler. Acta Physiol Scand, 1993. 147(2): p. 195-201.

30. Roddie, I., Circulation to skin and adipose Tissue, in Handbook of Physiology, A critical, comprehensive presentation of physiological knowledge and concepts, J.T. Shepherd, F.M. Abboud, and S.R. Geiger, Editors. 1983, American Physiological Society: Bethesda, Maryland.

31. Cabanac, M., Adjustable set point: to honor Harold T. Hammel. Journal of Applied Physiology, 2006. 100(4): p. 1338-46.

32. Romanovsky, A.A., Thermoregulation: some concepts have changed. Functional architecture of the thermoregulatory system. Am J Physiol Regul Integr Comp Physiol, 2007. 292(1): p. R37-46.

33. Werner, J., System properties, feedback control and effector coordination of human temperature regulation. European journal of applied physiology, 2010. 109(1): p. 13-25.

34. Morrison, S.F., 2010 Carl Ludwig Distinguished Lectureship of the APS Neural Control \& Autonomic Regulation Section: Central Neural Pathways for Thermoregulatory Cold Defense. Journal of Applied Physiology, 2011.

35. Kingma, B.R., et al., Cold-induced vasoconstriction at forearm and hand skin sites: the effect of age. Eur J Appl Physiol, 2010. 109(5): p. 915-21.

36. Johnson, J.M., et al., Regulation of the cutaneous circulation. Fed Proc, 1986. 45(13): p. 2841-50.

37. Gotch, F.A., M.L. Keen, and S.R. Yarian, An analysis of thermal regulation in hemodialysis with one and three compartment models. ASAIO transactions / American Society for Artificial Internal Organs, 1989. 35(3): p. 622-4. 



\section{CHAPTER 6}

\section{MATHEMATICAL MODEL OF THERMAL SENSATION BASED ON THE NEUROPHYSIOLOGY OF THERMAL RECEPTION}




\begin{abstract}
Background

Thermal sensation has a large influence on thermal comfort, which is an important parameter for building performance. Understanding of thermal sensation may benefit from incorporating the physiology of thermal reception. The main issue is that humans do not sense temperature directly; the information is coded into neural discharge rates. This manuscript describes the development of a mathematical model of thermal sensation based on the neurophysiology of thermal reception..
\end{abstract}

\title{
Methods
}

Experimental data from two independent studies were used to develop and validate the model. In both studies skin and core temperature were measured. Thermal sensation votes were asked on the 7-point ASHRAE thermal sensation scale. For the development dataset young adult males $(n=12,0.04 \mathrm{Clo}$ ) were exposed to transient conditions; $T_{\text {air }} 30-20-35-30^{\circ} \mathrm{C}$. For validation, young adult males ( $n=8,1.0 \mathrm{Clo}$ ) were exposed to transient conditions; $\mathrm{T}_{\text {air }}: 17-25-17^{\circ} \mathrm{C}$.

\section{Results}

The neurophysiological model significantly predicted thermal sensation for the development dataset $\left(r^{2}=0.89, p<0.001\right)$. Only information from warm sensitive skin and core thermoreceptors was required. Validation revealed that the model predicted thermal sensation within acceptable range (root mean squared residu$\mathrm{al}=0.38)$.

\section{Conclusion}

The neurophysiological model captured the dynamics of thermal sensation. Therefore, the neurophysiological model of thermal sensation can be of great value in the design of high performance buildings. 


\section{Introduction}

Thermal comfort, determined by the influence of the indoor environmental parameters on thermal sensation, is regarded as an important indicator of building performance. Therefore, accurate mathematical models of thermal sensation are extremely useful in design of new high performance buildings. Recently, de Dear (2011) reintroduced the concept of 'thermal alliesthesia', which deals with the neurophysiological mechanisms responsible for thermal sensation. According to de Dear, with the concept of alliesthesia it should be possible to explain in the future: 'why occupants of today's so called sustainable buildings can enjoy positive indoor environmental quality in indoor climates that would have failed the criteria established under yesterday's standards of thermal comfort'.

In this study we aim to expand the synthesis between neurophysiology and mathematical modeling to make a better prediction of the thermal sensation. One of the key principles in the neurophysiology of thermal reception is that humans do not sense temperature directly. Temperature information is coded into the firing rate of temperature sensitive neurons (thermoreceptors). These neurons are found all over the body. Two types of thermoreceptors can be distinguished: "cold" or "warm" sensitive (see Chapter 5, Figure 1). Skin contains both types of thermoreceptors, whereas deeper laying tissues (e.g. intestines, spinal cord and hypothalamus) contain mostly warm sensitive thermoreceptors (1).

The main hypothesis is that through simulation of the neurophysiological pathways the dynamics of thermal sensation can be captured. Therefore, we developed a new model for thermal sensation based on the neurophysiology of thermal reception and integration through neural pathways.

\section{Context}

Both thermal comfort and energy-use play an important role in the performance of a building. About one-third of the primary energy used in developed countries is consumed by heating, ventilating and air conditioning in residential, commercial and public buildings (2). This reveals the high importance of reducing the energy use in buildings. However, satisfaction of the occupants with their thermal environment mainly determines the success of the application of low-energy HVAC (Heating Ventilation and Air Conditioning) systems. A lot of effort has been taken to design optimal energy HVAC systems; this resulted in among others, low temperature heating systems, high temperature cooling systems, different ventilation principles etc. However, the Annex 37 (Juusela, 2003) study revealed that an optimal energy use does not always results in an increased comfort level. Non-uniform thermal conditions, which may occur due to application of low-energy systems, can be responsible for discomfort (e.g. a low temperature floor heating system in combination with natural ventilation (3)). Contrary, Arens et al. (2006) concluded that through asym- 
metrical and transient thermal environments higher levels of thermal comfort could be achieved in comparison to steady-state uniform environments. Regarding transient environments de Dear and Brager (2001) concluded that satisfaction with the thermal environment does not mean that this environment has to be controlled at a constant indoor air temperature (4). A study by Schellen et al. (2010) confirmed this statement. Furthermore, compared to a constant temperature, allowing the temperature to drift could be a means to reduce energy-use.

To adequately design optimal environmental conditions in the future, both in an energy-friendly and comfortable way, more knowledge on the interaction between the systems, indoor climate and the human body is indispensable.

\section{Thermal sensation}

Thermal sensation and satisfaction with the thermal environment is a complex phenomenon, and therefore complicated to predict in the design phase. Due to the large differences between persons, both psychological and physiological, it is difficult to satisfy everyone in the same room. Many researchers have studied the parameters that affect thermal sensation with the objective of developing a model to predict thermal sensation. The most used and referred model is the PMV (Predicted Mean Vote) model of Fanger (5). This model is included in current building standards to predict thermal sensation, and therefore often used to assess the thermal comfort in the design phase. This model intended to be a method that could be used by HVAC engineers to determine the optimum environmental conditions (combination of air temperature, mean radiant temperature, relative humidity, mean air velocity, activity level and clothing) to satisfy the largest possible percentage of a given group of occupants. It was assumed that a person is most comfortable in a thermal neutral condition, which is defined as the condition wherein a person does not prefer either a colder or warmer environment.

Although, this method is frequently used and implemented in building regulations, many researchers showed the limitations of the model e.g., for differences between subpopulations (males/females, young/older people etc), thermal neutrality, expected discomfort, and driving mechanisms (dependent parameters) for thermal comfort (4, 6-10).

According to de Dear (2011) the PMV theory from Fanger led to the thermal comfort mantra 'cool, dry, still indoor air'. Which was achieved by static isothermal indoor climates. As described above a growing interest is on dynamic non-uniform environments since they can provide an energy-saving potential, more comfortable environment and probably healthier environment $(11,12)$. The above-mentioned studies indicate there is a need for new sensation models that cope with dynamic, transient environments and individual effects and requirements.

de Dear et al. (1993) showed with a mathematical simulation that the discharge rate of skin thermoreceptors correlated to the change in thermal sensation during sud- 
den temperature transitions (13). Hence simulating the actual physiology of humans (i.e. neuron discharge rate instead of using skin temperatures) can be highly beneficial when designing buildings whilst optimizing energy costs and thermal comfort.

\section{Neurophysiology of thermal reception and thermal sensation}

Most knowledge of thermoreceptor responses comes from experiments on isolated nerves of anesthetized animals (e.g. cats, rabbits and primates), nevertheless, the fundamental properties of thermoreception also have been confirmed in man (14). Still, the exact neuron discharge rate vs. temperature may differ substantially between species or between tissues. However, the general characteristics of thermoreception are assumed to be sufficient to serve the purpose of this study.

Zotterman et al. (1952) reported the averaged non-linear characteristic of thermoreceptor firing rates from steady state temperature experiments on cat tongue. The maximum steady state discharge rate for cold sensitive receptors lies around $25^{\circ} \mathrm{C}$ (11 impulses/sec) and for warm sensitive receptors the maximum firing rate lies around $38^{\circ} \mathrm{C}(4$ impulses/sec) $(15,16)$. Contrary, other researchers showed that in cat nose the maximum steady state discharge rate for cold sensitive receptors was at $27^{\circ} \mathrm{C}$ ( $9 \mathrm{impulses} / \mathrm{sec}$ ) and for warm sensitive neurons the maximum was at $46^{\circ} \mathrm{C}$ (36 impulses/sec) (17). Therefore it can be concluded that thermoreceptor data reported in literature differs considerably.

In addition to the steady state discharge rate, time dependent changes in skin temperature (i.e. direction and rate of temperature change) also influence the discharge rate. For instance, warm sensitive neurons increase their discharge rate when heated, and even more when strongly heated, whereas during cooling the discharge rate of warm sensitive neurons is decreased (Figure 1).

The neural pathway from local thermal reception to thermal sensation is described in literature as follows $(18,19)$. 1) The thermoreceptors bring the information to the spinal cord (i.e. from peripheral skin and deep body tissues) and to the trigeminal nucleus (i.e. from face skin). 2) From the dorsal horn (top of spinal cord) and trigeminal nucleus, second-order neurons project to the thalamus. This is a different pathway than for thermoregulation, because for thermoregulation the secondary neurons connect to the hypothalamus instead of the thalamus $(19,20)$. 3) The thalamus projects to the insular cortex, which is presumed to be the brain area for perception and localization of thermal stimulus intensity (18).).

\section{Methods}

\section{Experiments}

The mathematical model developed in this study uses experimentally measured skin and core temperature as input variables. Temperature recordings were then trans- 
duced to their equivalent neuron discharge rate. Finally, the neuron discharge rates were correlated to the experimentally measured sensation votes.

In this study two data sets of independent experiments were used. The first data set was used for development of the model; the second data set was used for validation. In both studies core temperature was measured with an ingested telemetric pill (CorTemp, USA). The skin temperatures were measured according to ISO 9886 (2004) by wireless iButtons (Thermochron iButton DS1291H, Dallas Maxim) at the 14-points as proposed by ISO $9886(2004)(21,22)$. Thermal sensation votes were asked on a continuous 7-point thermal sensation interval scale, where each point on the line could be marked (ASHRAE, 2005). As a result, the thermal sensation could be assessed within \pm 0.05 scale unit of accuracy.

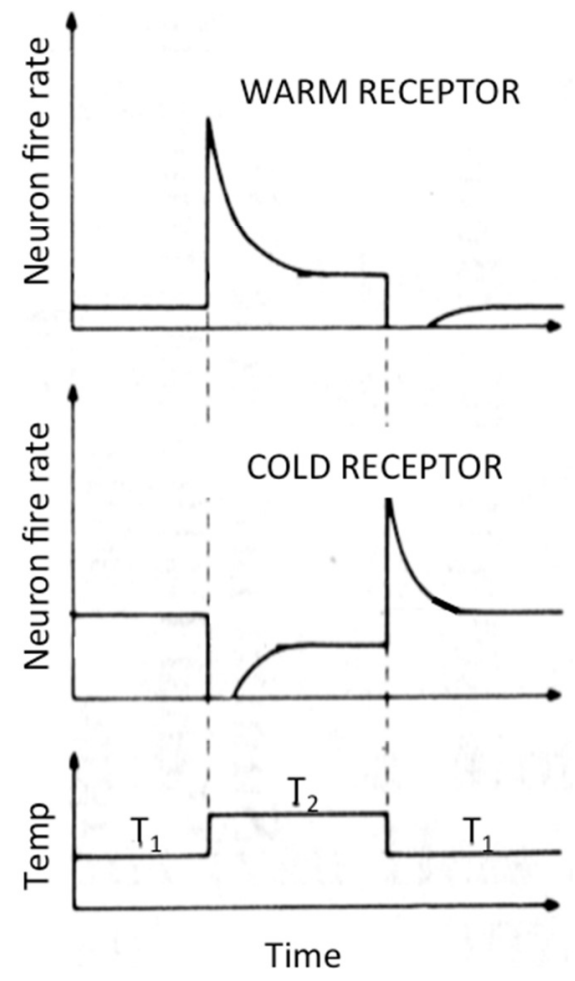

Figure 1: Dynamic neuron firing rate of temperature sensitive neurons. With increasing temperature warm thermoreceptors show an initial overshoot in firing rate and cold thermoreceptors show an initial undershoot. Vice versa for decreasing temperature. Modified from (16).

For the development dataset, male subjects were in supine position and wearing shorts only $(0.04 \mathrm{Clo})$. Firstly, subjects were exposed to baseline air-temperature $\left(30^{\circ} \mathrm{C}, 0.5 \mathrm{~h}\right)$. Next subjects were exposed to mild cold followed by warm conditions $\left(20^{\circ} \mathrm{C}, 1 \mathrm{~h} ; 35^{\circ} \mathrm{C}, 1 \mathrm{~h}\right)$, Finally, subjects were exposed to baseline conditions again for $1 \mathrm{~h}$ (details in Chapter 4). For the validation data set, male subjects were sedentary 
and dressed (1.0 clo, including desk chair). The subjects were exposed to a transient condition; temperature range: $17-25^{\circ} \mathrm{C}$, duration: $8 \mathrm{~h}$, temperature drift: first $4 \mathrm{~h}$ : $+2{ }^{\circ} \mathrm{C} / \mathrm{h}$, last $4 \mathrm{~h}:-2{ }^{\circ} \mathrm{C} / \mathrm{h}(9)$. Thus subjects were exposed to considerably different conditions in both datasets.

Subject characteristics of both data sets are shown in Table 1.

Table 1: Subject characteristics of young adult males used for model development and for validation.

\begin{tabular}{llll}
\hline & Model development $(n=12)$ & & $\begin{array}{l}\text { Validation } \\
(n=8)\end{array}$ \\
\cline { 2 - 2 } Age $(\mathrm{yr})$ & $24.9 \pm 1.0$ & & $23.6 \pm 1.2$ \\
Mass $(\mathrm{kg})$ & $76.1 \pm 3.3$ & & $82.7 \pm 8.6$ \\
Height $(\mathrm{m})$ & $1.80 \pm 0.02$ & $1.83 \pm 0.11$ \\
Body fat $(\%)$ & $16.7 \pm 1.4$ & $14.5 \pm 3.3$ \\
BMI $\left(\mathrm{kg} / \mathrm{m}^{2}\right)$ & $23.4 \pm 0.9$ & $24.8 \pm 3.1$ \\
\hline
\end{tabular}

\section{Modelling of thermal reception and neural pathways}

For the development phase of the thermo-sensation model, skin temperature and core temperature recordings were used. First, the firing rates of skin cold (C) and warm (W) thermal receptors and core warm $\left(\mathrm{H}_{\text {warm }}\right)$ receptors were calculated as described in Chapter 5. Local skin temperatures were used instead of mean skin temperature: using mean skin temperature would lead to significant errors in calculation of the average firing rate of temperature sensitive neurons, due to the nonlinear characteristic of neuron firing rate vs. temperature. For instance, the average firing rate of two cold sensitive neurons with temperature $\left(T_{1}=20^{\circ} \mathrm{C}\right.$ and $\left.T_{2}=30^{\circ} \mathrm{C}\right)$ is not equal to the firing rate of a neuron with temperature $T_{\text {mean }}=25^{\circ} \mathrm{C}$ (see Figure 1 in Chapter 5). Local neuron firing rates are integrated at the spinal cord and trigeminal nucleus. This is calculated by averaging neuron-firing rate over skin positions $\left(P_{\text {warm }}\right.$ $=\Sigma \mathrm{W} / \mathrm{n}$ and $\mathrm{P}_{\text {cold }}=\Sigma \mathrm{C} / \mathrm{n}$ ). Here, $P_{\text {warm }}$ and $P_{\text {cold }}(\mathrm{P}$ stands for peripheral) are the averaged (i.e. integrated) peripheral warm and peripheral cold firing rates and $n$ is the number of positions where temperature is measured. From the dorsal horn (top of spinal cord) and trigeminal nucleus, the secondary order neurons project to the thalamus. In turn, the thalamus projects to the insular cortex (18). There the thermal information from the body core (Hwarm) and skin (Pcold and Pwarm) is integrated. Some hypotheses on the neural pathways involved in thermal sensation exist $(11,22)$. Therefore we fitted several models where the subject averaged thermal sensation vote was used as dependent variable (see Table 2).

Each model represents a different hypothesis, or assumption, of the neural pathway involved in thermal sensation. All variables are expressed in the firing rate unit "pulses/sec". Therefore the model coefficient signs define excitation and inhibition within the neural pathway, a positive sign denotes excitation and a negative sign 
denotes inhibition. The first model is based on the assumption that only skin thermoreception contributes to thermal sensation (11). The second model assumes that all three thermoreception pathways project individually to the thermal sensation (22). The third model assumes that core body thermoreception and skin warm thermo-reception contribute to thermal sensation. Finally, the fourth model assumes that core body thermo-reception and skin cold thermoreception contribute to thermal sensation. Only one model was selected for validation against the independent data set. Model selection for validation was based on the following criteria: 1) all $\kappa$-coefficients significantly differed from zero 2 ) highest explained variance (i.e. highest $r^{2}$-value).

Table 2: Thermo-sensation models that were fitted to experimental data. $S$ is the thermal sensation vote as defined on an ASHRAE scale. Hwarm (pulse/sec) is the neuron-firing rate corresponding to measured core temperature. Pcold (pulse/sec) is the averaged neuron-firing rate of skin cold sensitive thermo receptors. Pwarm (pulse/sec) is the averaged neuron-firing rate of skin warm sensitive thermo receptors.

\begin{tabular}{l} 
Model \\
\hline$S=\kappa_{0}+\kappa_{1} P_{\text {cold }}+\kappa_{2} P_{\text {warm }}$ \\
$S=\kappa_{0}+\kappa_{1} H_{\text {warm }}+\kappa_{2} P_{\text {cold }}+\kappa_{3} P_{\text {warm }}$ \\
$S=\kappa_{0}+\kappa_{1} H_{\text {warm }}+\kappa_{2} P_{\text {warm }}$ \\
$S=\kappa_{0}+\kappa_{1} H_{\text {warm }}+\kappa_{2} P_{\text {cold }}$
\end{tabular}

\section{Validation}

The thermosensation model was validated by calculation of the root mean squared residual (RMSR) between model prediction and measured sensation votes of the validation data set. The model prediction quality was considered acceptable when $\mathrm{RMSR}<1$, thus the model prediction should be within 1-scale points of the measured sensation vote. This value was based on a power calculation to have $95 \%$ chance to detect a significant error in model prediction using $n=8$ subjects for validation. Given the variation in sensation votes as estimated from the development dataset.

Model prediction was carried out by repetition of the thermoreceptor firing rate calculation procedure as described in the model development phase. However, this time skin and core temperature data from the validation data set were used. All calculations were performed with Matlab R2010a.

\section{Results}

\section{Model development phase}

Regression analysis revealed that all models, each with different assumptions on the neural pathways, significantly explained the thermal sensation vote (see Table 3 ). 
However, only in model 3 and model 4 did all $\beta$-coefficients differ significantly from zero. In models 2 through 4 the core warm thermoreception pathway had a significant negative contribution to the thermal sensation. Hence, during the mild thermal challenge a decrease in core temperature related to a warm thermal sensation. In model 3, the skin warm thermoreception pathway had a significant positive contribution to the thermal sensation. Thus, warm or heated skin related to a warm thermal sensation. Vice versa, in model 4, the skin cold thermoreception pathway had a significant negative contribution to the thermal sensation, such that cold or cooled skin related to a cold thermal sensation. The measured sensation votes and the prediction of model 3 on the development data set are shown in Figure 2.

Table 3: Regression coefficients $\pm 95 \%$ confidence intervals $(\kappa$ 's) with the corresponding variable, explained variance ( $r 2$ ) and p-value of sensation models during development phase. Coefficients in bold differ significantly from zero.

\begin{tabular}{lllllll}
\hline Model & $\kappa_{0}$ & $\kappa_{1}$ & $\kappa_{2}$ & $\kappa_{3}$ & $r^{2}$ & $p$-value \\
\hline 1 & $-0.12 \pm 55.1$ & $\begin{array}{l}-0.6 \pm 4.3 \\
\left(P_{\text {cold }}\right)\end{array}$ & $\begin{array}{l}1.9 \pm 9.6 \\
\left(P_{\text {warm }}\right)\end{array}$ & 0.81 & $<1.8 \times 10^{-6}$ \\
2 & $36.4 \pm 49.6$ & $\begin{array}{l}-14.8 \pm 9.6 \\
\left(H_{\text {warm }}\right)\end{array}$ & $\begin{array}{l}0.7 \pm 3.5 \\
\left(P_{\text {cold }}\right)\end{array}$ & $\begin{array}{l}3.9 \pm 7.7 \\
\left(P_{\text {warm }}\right)\end{array}$ & 0.89 & $<2.1 \times 10^{-7}$ \\
3 & $\mathbf{4 4 . 0 \pm 3 2 . 8}$ & $\begin{array}{l}-14.3 \pm 9.0 \\
\left(H_{\text {warm }}\right)\end{array}$ & $\begin{array}{l}\mathbf{2 . 3 \pm 0 . 9} \\
\left(P_{\text {warm }}\right)\end{array}$ & & 0.89 & $<2.5 \times 10^{-8}$ \\
4 & $\mathbf{5 6 . 1 \pm 3 0 . 7}$ & $\begin{array}{l}-13.9 \pm 9.4 \\
\left(H_{\text {warm }}\right)\end{array}$ & $\begin{array}{l}-1.0 \pm 0.4 \\
\left(P_{\text {cold }}\right)\end{array}$ & & 0.87 & $<8.2 \times 10^{-8}$ \\
\hline
\end{tabular}

\section{Model validation phase}

Model 3 was selected for the validation phase since it best explained the variation $\left(r^{2}=0.89\right)$. The sensation votes of the validation set and the model prediction are shown in Figure 3. The root mean square error (RMSR) of the thermal sensation prediction on the validation set was 0.38 , which means that on average there was a 0.38 prediction error in thermal sensation. The maximum error observed was 1.16 scale points at the beginning of the experiment. The minimum error observed was 0.02 scale points at $t=100 \mathrm{~min}$. In general, the model predictions were within the standard deviation of the measurements. 


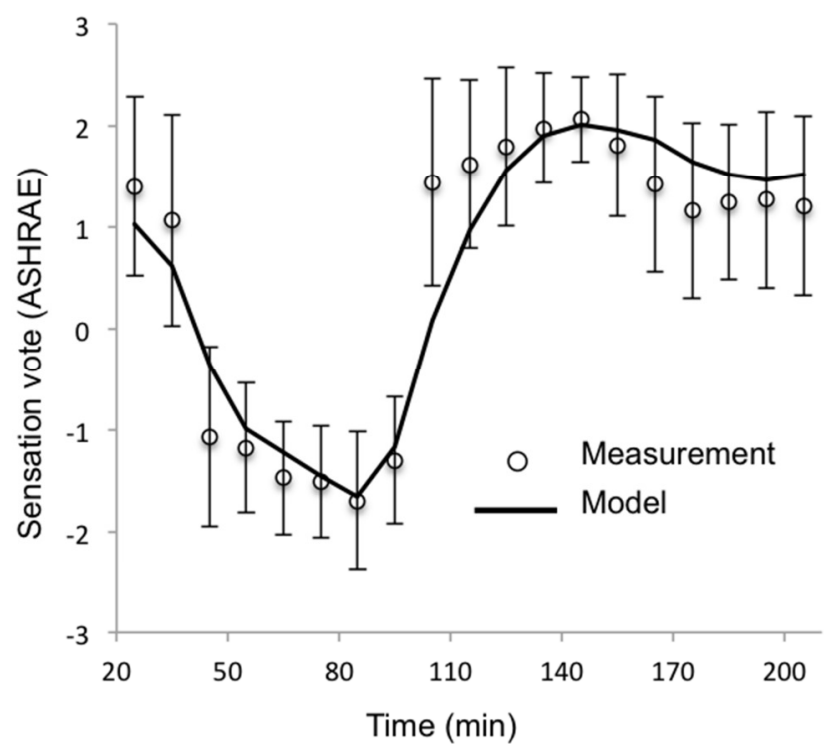

Figure 2: Averaged sensation votes and model fit (i.e. Model 3) of the development data set. Error bars represent the standard deviation.

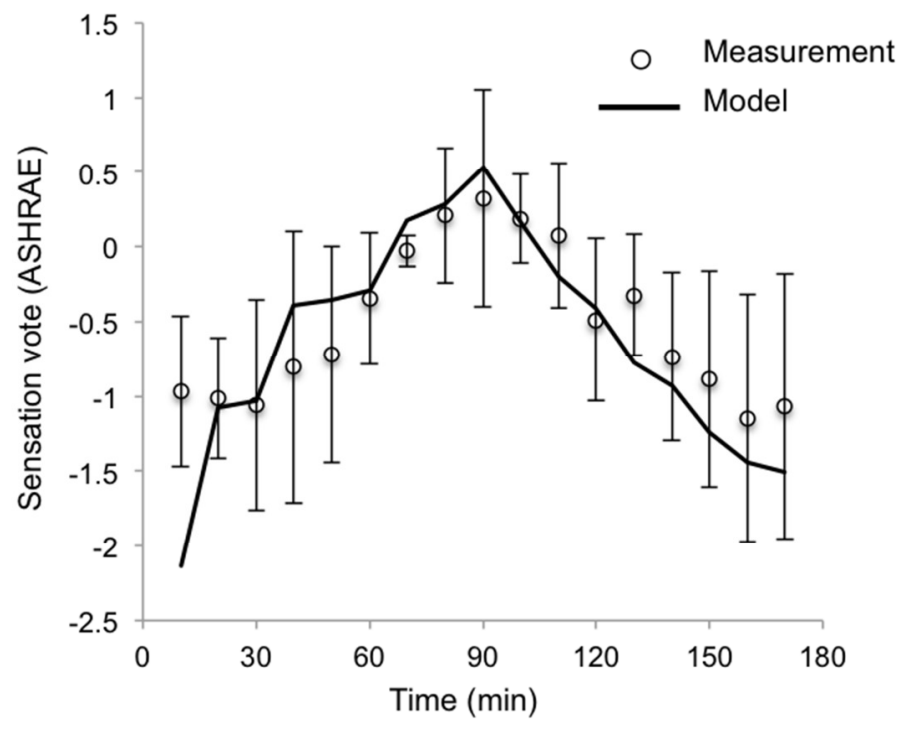

Figure 3: Averaged sensation votes and model prediction of the validation data set. Error bars represent the standard deviation.

\section{Discussion}

In this study a mathematical model of thermal sensation based on neurophysiology was validated on an independent dataset. The results indicate that the simulation of 
the neural pathways was able to capture characteristics of thermal sensation. Such a model of human thermal sensation can be of great value in designing of high performance buildings.

A comfortable environment could be described as an environment where the average rating of a group of persons is between -1 and +1 on the ASHRAE thermal sensation scale $(5,8)$. The model developed in this study was able to predict thermal sensation within 0.5-scale unit accuracy for both datasets (development and validation). Foda et al. (2010) found for four different thermal sensation models a discrepancy between predicted and measured overall thermal sensation within \pm 1.0 scale unit. Thus, the model presented in this paper provides a greater accuracy and therefore more detailed information can be obtained regarding the overall thermal sensation. In practice this could be beneficial because small deviations from a neutral thermal sensation (i.e. a overshoot or undershoot in thermal sensation) could provide a more comfortable thermal environment $(6,9)$.

In current building practice the PMV (predicted mean vote) model of (5) is used to predict the future thermal sensation of occupants. However as mentioned in the introduction this model has limitations regarding the prediction of thermal sensation (e.g. for different sub-populations). Van Hoof et al. (2010) concluded in an extensive literature review that multi-segmental models of human physiology have a large potential to predict high resolution thermal sensation of occupants in both the design phase of a building and laboratory conditions (26). Especially, a large potential exists for complex environments regarding non-uniform and transient conditions which, in the end, could turn out to be the most comfortable environments (12). However, van Hoof et al. also concluded that it is a great challenge to link the outcomes of a thermophysiological model to thermal sensation.

Until now, few studies have been available where physiological responses are related to thermal sensation. All current models require a body temperature setpoint to simulate thermal sensation. Fiala (1998) developed the DTS model to predict the dynamic thermal sensation based on core temperature, mean skin temperature and rate of change in mean skin temperature (27). Another study conducted by Zhang et al. $(2010 a, b, c)$ related physiological responses to local thermal sensation based on differences between local skin temperature and the setpoint of skin temperature for a specific body part, rate of change in local skin temperature and rate of change in core temperature (28-30). Although these models show promising results, one could argue whether setpoints are a good representation of the physiology behind thermoregulation or thermal sensation $(31,32)$. Interestingly, the model developed in this study only required thermal information from warm sensitive receptors of skin and core. The reason for this becomes clear after analysis of simulated core and skin thermoreception over time. Figure 4 shows the simulated neuron discharge 
rate for core warm receptors $\left(\mathrm{H}_{\text {warm }}\right)$ and integrated skin cold $\left(\mathrm{P}_{\text {cold }}\right)$ and warm $\left(P_{\text {warm }}\right)$ receptors. The signals of $P_{\text {cold }}$ and $P_{\text {warm }}$ are almost mirrored images of each other; therefore both signals contain the same information. It is possible that in more extreme situations (colder, hotter or larger temperature changes) information of both cold and warm skin receptors is necessary to correctly predict thermal sensation. For instance, when skin temperature decreases below $26^{\circ} \mathrm{C}$, temperature information is dominated by the discharge rate of skin cold sensitive thermoreceptors (Figure 1): the discharge rate of warm sensitive thermoreceptors decreases to zero. Likewise, above $35^{\circ} \mathrm{C}$, virtually no skin cold thermoreceptor input is generated, and all information is coded by skin warm thermoreceptors (Figure 1). In more neutral environments, however, skin warm and cold thermoreceptors seem to reveal the same.
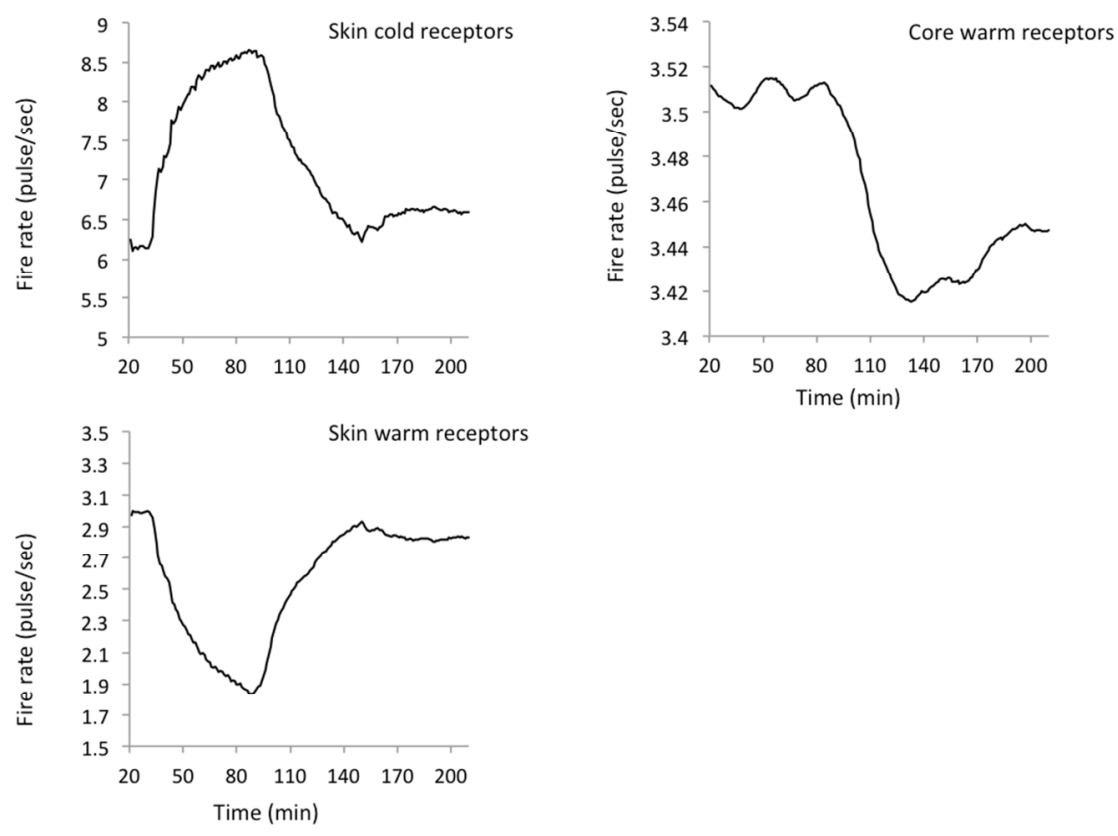

Figure 4: Simulated thermoreceptor-firing rates of (top right) core warm thermoreceptors (Hwarm), (top left) integrated skin cold thermoreceptors (Pcold) and (bottom left) integrated skin warm thermoreceptors (Pwarm).

To the best of our knowledge, only one other study correlated thermal reception to thermal sensation (13). de Dear et al. showed that the change in thermal sensation correlated to the discharge rate of both cold and warm skin thermoreceptors during a sudden ambient temperature transition. The authors did not report correlations to absolute sensation votes. The results presented in this paper suggest that apart from skin thermal reception, absolute thermal sensation is also dependent on warm core thermoreceptors. It could be that skin thermoreceptors correlate well to changes in thermal sensation, yet the core thermoreceptors are important for an 
absolute "basal" level of thermal sensation. We will again illustrate this with Figure 5. This figure shows that there is a delayed response of the core thermoreceptors relative to the skin thermoreceptors ( $t=30$ to $t=90 \mathrm{~min}$ ). The warm core thermoreceptors decrease their discharge rate (Figure 4, Top Right), while skin thermoreception already returned to near baseline values (Figure 4 Left). Note that the delay of core thermoreception might differ depending of the exact site and method of core temperature measurement $(20,33)$. Due to the slow response, abdominal core thermoreception cannot be associated with thermal sensation during sudden ambient temperature transitions. However, during rewarming, the afterdrop in core temperature is clearly visible in the core warm thermoreception. An afterdrop in core temperature is caused by the return of cooled blood from the peripheral tissues (34). Although the range of the discharge rate change for core warm thermoreceptors is not as large as for skin warm thermoreceptors ( $\mathrm{H}_{\text {warm }}: 3.4$ pulse/sec to 3.5 pulse/sec and $P_{\text {warm: }} 1.9$ pulse/sec to 3.1 pulse/sec), the associated weight ( $\left.\kappa\right)$, is considerably larger for core thermoreception than for skin thermoreception $\left(\kappa_{\text {Hwarm }}=-14.3\right.$ and $\left.\kappa_{\text {Pwarm }}=2.3\right)$, which evens out the difference in discharge rate. Hence, core thermoreception has a large long lasting influence on thermal sensation and skin thermoreception has a fast changing influence on thermal sensation. The negative sign of the core warm thermoreception pathway model coefficient may seem counter-intuitive at first, because it suggests that a decrease in core temperature relates to a warm thermal sensation. However, during the mild thermal challenge, core temperature remained stable during mild cold, yet during rewarming, core temperature dropped on average by $0.3^{\circ} \mathrm{C}(23)$. A paradoxical decrease in core temperature during rewarming or an increase in core temperature during mild cold has been described in physiological literature $(20,35)$. The inverse relation between core temperature change and thermal sensation during a mild thermal challenge might be part of thermal alliesthesia, since during stable conditions a high core temperature is associated with to a warm thermal sensation and thermal discomfort (36). Another issue for thermal alliesthesia relates to the dominance of thermoreception to thermal sensation. When the thermal environment continuously changes, there is a large contribution of thermoreception to the overall thermal sensation. This can be explained by the importance of detecting changes in the thermal environment to maintain thermal homeostasis. However, when the ambient environment is more stable, the relative influence of non-thermal factors may increase. Therefore, thermoreception and thermal sensation may have a stronger coupling during thermal transients relative to stable thermal conditions. Overall, this suggests that the currently developed model may be suitable for predicting thermal sensation during transient thermal conditions, yet less so during stable thermal conditions.

The model presented in this study relies on simulated neuron discharge rate. In literature different experimentally measured thermoreceptor data exist. For in- 
stance, a study by Hensel and Kensalo (1969) showed a near 10-fold increase in the maximum steady state discharge rate of warm sensitive neurons in comparison to the data presented by Zotterman (1953) (36 impulses/sec vs. 4 impulses/sec respectively). Especially during transient conditions such differences could have a large impact on model performance. Which is mainly because the magnitude of the dynamic response scales with the difference between two steady state discharge rates. For instance, when a warm sensitive neuron is heated using the data presented by Hensel and Kensalo (1969), a higher steady state discharge rate would also result in a larger dynamic response. Vice versa, when a warm sensitive neuron is cooled, its discharge rate is also suppressed more. Theoretically, cooling could even nullify the discharge rate of warm sensitive neurons, leaving only cold sensitive neurons to obtain information on the thermal status of the body. Therefore, future studies should elucidate how using different thermoreceptor data might alter the results of this study.

In summary, the neurophysiological approach for developing a mathematical thermal sensation model as presented in this paper offers a method to predict the thermal sensation under complex non-uniform and transient mild thermal environments. Furthermore, this approach can be extended to a thermal sensation prediction on a local body part level; however, more research is needed for this. Therefore, future work should focus on:

1. relative importance of specific skin areas to whole body thermal perception,

2. relative importance of core temperature measurement site to thermal perception,

3. thermoreception in more extreme environments (e.g. colder, warmer and larger temperature changes),

4. steady state thermoreception characteristics

5. inclusion of other subpopulations such as, females, older people or people with obesity,

6. application of local thermoreception to local comfort.

\section{Conclusion}

In this study a new model for predicting thermal sensation is developed. This model is based on the neurophysiology of thermal reception. The model is validated on an independent dataset. The only dependent parameters for thermal sensation in the model are core body warm thermoreception and skin warm thermoreception. The model was capable to significantly predict thermal sensation within 0.5 -scale unit accuracy for both the development dataset and the validation dataset. In current building practice an accuracy of \pm 1.0 is considered as acceptable. Though, rather small deviations from optimum (neutral), less than 1.0 scale unit, could provide a more comfortable thermal environment and occupants would therefore be more satisfied with their environment. The presented method can be highly beneficial for 
predicting thermal sensation under complex environments with respect to nonuniform and transient environments, especially in combination with thermophysiological models to link physiological responses to thermal sensation. Therefore, the neurophysiological model of thermal sensation can be of great value in the design of high performance buildings.

\section{References}

1. Boulant, J.A., Neuronal basis of Hammel's model for set-point thermoregulation. J Appl Physiol, 2006. 100(4): p. 1347-54.

2. IEA. ECBCS. 2007; Available from: http://www.ecbcs.org.

3. Boerstra, A., P. Op 't Veld, and H. Eijdems, The Health, Safety and Comfort Advantages of Low Temperature Heating Systems - A Literature Review, in Healthy Buildings Conference2000.

4. de Dear, R. and G.S. Brager, The adaptive model of thermal comfort and energy conservation in the built environment. International journal of biometeorology, 2001. 45(2): p. 100-8.

5. Fanger, P.O., Thermal Comfort, 1970: Copenhagen: Danish Technical Press.

6. Humphreys, M.A. and M. Hancock, Do people like to feel 'neutral'? Exploring the variation of the desired sensation on the ASHRAE scale. Energy and Buildings, 2007. 39(7): p. 867-874.

7. Nakano, J., S. Tanabe, and K. Kimura, Differences in perception of indoor environment between Japanese and non-Japanese workers. Energy and Buildings, 2002. 34(6): p. 615-621.

8. Parsons, K., The effects of gender, acclimation state, the opportunity to adjust clothing and physical disability on requirements for thermal comfort. Energy and Buildings, 2002. 34(6): p. 593-599.

9. van Hoof, J., Forty years of Fanger's model of thermal comfort: comfort for all? Indoor Air, 2008. 18(3): p. 182-201.

10. Schellen, L., et al., Differences between young adults and elderly in thermal comfort, productivity, and thermal physiology in response to a moderate temperature drift and a steady-state condition. Indoor Air, 2010. 20(4): p. 273-83.

11. Johnson, F., et al., Could increased time spent in a thermal comfort zone contribute to population increases in obesity? Obes Rev, 2011.

12. de Dear, R., Revisiting an old hypothesis of human thermal perception: alliesthesia. Building Research \& Information, 2011. 39(2): p. 108-117.

13. de Dear, R., J.W. Ring, and P.O. Fanger, Thermal Sensations Resulting from Sudden Ambient Temperature Changes. Indoor Air, 1993. 3: p. 181-192.

14. Hensel, H., Thermoreception and Temperature Regulation. Monographs of the Physiological Society1981, London: Academic Press Inc. LTD.

15. Dodt, E. and Y. Zotterman, Mode of action of warm receptors. Acta Physiol Scand, 1952. 26(4): p. 345-57. 
16. Zotterman, Y., Special senses: thermal receptors. Annu Rev Physiol, 1953. 15: p. 357-72.

17. Hensel, H. and D.R. Kenshalo, Warm receptors in the nasal region of cats. The Journal of physiology, 1969. 204(1): p. 99-112.

18. Craig, A.D., et al., Thermosensory activation of insular cortex. Nature neuroscience, 2000. 3(2): p. 184-90.

19. Morrison, S.F., 2010 Carl Ludwig Distinguished Lectureship of the APS Neural Control \& Autonomic Regulation Section: Central Neural Pathways for Thermoregulatory Cold Defense. Journal of Applied Physiology, 2011.

20. Benzinger, T.H., Heat regulation: homeostasis of central temperature in man. Physiol Rev, 1969. 49(4): p. 671-759.

21. Parsons, K., Human Thermal Environments. 2 ed, ed. K.C.Parsons2003: Taylor \& Francis (London).

22. van Marken Lichtenbelt, W.D., et al., Evaluation of wireless determination of skin temperature using iButtons. Physiol Behav, 2006. 88(4-5): p. 489-97.

23. Kingma, B.R., et al., Increased systolic blood pressure after mild cold and rewarming: relation to cold-induced thermogenesis and age. Acta physiologica, 2011.

24. Mekjavic, I.B. and J.B. Morrison, A model of shivering thermogenesis based on the neurophysiology of thermoreception. IEEE Trans Biomed Eng, 1985. 32(6): p. 407-17.

25. Chatonnet, J., et al., [On the origin of conscious impression of thermal comfort]. Lyon medical, 1966. 216(50): p. 1387-92.

26. van Hoof, J., M. Mazej, and J.L. Hensen, Thermal comfort: research and practice. Frontiers in bioscience : a journal and virtual library, 2010. 15: p. 765-88.

27. Fiala, D., Dynamic simulation of human heat transfer and thermal comfort., in Institute of Energy and Sustainable Development1998, De Montfort University: Leicester.

28. Zhang, H., et al., Thermal sensation and comfort models for non-uniform and transient environments: Part I: Local sensation of individual body parts. Building and Environment, 2010. 45(2): p. 380-388.

29. Zhang, H., et al., Thermal sensation and comfort models for non-uniform and transient environments, part II: Local comfort of individual body parts. Building and Environment, 2010. 45(2): p. 389-398.

30. Zhang, H., et al., Thermal sensation and comfort models for non-uniform and transient environments, part III: Whole-body sensation and comfort. Building and Environment, 2010. 45(2): p. 399-410.

31. Cabanac, M., Adjustable set point: to honor Harold T. Hammel. Journal of Applied Physiology, 2006. 100(4): p. 1338-46. 
32. Romanovsky, A.A., Thermoregulation: some concepts have changed. Functional architecture of the thermoregulatory system. Am J Physiol Regul Integr Comp Physiol, 2007. 292(1): p. R37-46.

33. Teunissen, L.P., et al., Non-invasive continuous core temperature measurement by zero heat flux. Physiological measurement, 2011. 32(5): p. 559-70.

34. Severens, N.M., et al., Effect of forced-air heaters on perfusion and temperature distribution during and after open-heart surgery. Eur J Cardiothorac Surg, 2007. 32(6): p. 888-95.

35. Sessler, D.I., Perioperative heat balance. Anesthesiology, 2000. 92(2): p. 578-96.

36. Mayer, E., Objective Criteria for Thermal Comfort. Building and Environment, 1993. 28(4): p. 399-403. 

CHAPTER 7

GENERAL DISCUSSION 


\section{Introduction}

Skin blood flow and non-shivering thermogenesis are the key players in human thermoregulation during the thermal challenges that we experience in our daily life $(1,2)$. There is a large interindividual variation in these thermoregulatory responses $(3,4)$. Moreover, apart from variability on the individual level, thermoregulatory responses also vary considerably between subpopulations (e.g. lean vs. obese or young adults vs. elderly) $(5,6)$. As a consequence, mild thermal challenges may have different effects for different subpopulations. Because of age-related impairment of thermoregulation, the elderly form a subpopulation that may require extra attention with respect to their ambient environment. Understanding of the impact of mild thermal challenges on young adults and elderly is important for the design of new energy efficient buildings that may allow temperature drifts according to time of day or season (7).

Building design relies heavily on mathematical simulations to predict structural integrity and energy cost. On top of that, there is an increased demand to ensure that ambient conditions are within the constraints of comfort, health and productivity of occupants $(8,9)$. Currently, the Fanger thermal comfort model is widely used for this purpose in building design (10). However, the Fanger model is only suitable for constant ambient conditions and does not incorporate individual characteristics. To model thermoregulatory responses during temperature drifts, a dynamic thermoregulation model is indispensible. In the past, our laboratory validated and improved an advanced dynamic thermoregulation model (ThermoSEM) that was originally developed by Fiala et al. (11-13). This thesis aims to improve the dynamic thermoregulation model such that it is better applicable for simulating daily living thermal conditions. The main hypothesis is that increasing the level of physiological concepts of thermoregulatory control to the mathematical model will improve the models performance. Therefore this thesis focused on: 1) the physiological regulation of skin blood flow and non-shivering thermogenesis in young adults and elderly; 2) enhancement of ThermoSEM by translating physiological control mechanisms to mathematical equivalents.

\section{Summary of results}

The review in Chapter 2 showed that the thermoneutral zone varies among subpopulations (e.g. young adults vs. elderly). Therefore, exposure to a mild thermal challenge may dispose one individual further from its thermoneutral zone than another individual. Furthermore, Chapter 2 indicated that the range of the thermoneutral zone changes mainly due to differences in insulation (e.g. regulation of skin blood flow, body composition or clothing). In Chapter 3, we showed that the regulation of skin blood flow during local cooling is not significantly affected by age at hand skin. This is important because normally the hands and the face are the only 
skin areas that are directly exposed to the environment, the other areas are covered by clothing. Therefore, these results indicate that elderly maintain the ability to regulate heat loss at these primary positions for heat exchange. Nevertheless, in contrast to young adults, elderly failed to defend their core temperature during whole body mild cold exposure, as we showed in Chapter 4. Remarkably, young adults increased heat production (i.e. non-shivering thermogenesis) upon cold exposure, whereas elderly even decreased heat production. Clearly, the thermoregulatory response is negatively affected by age. With respect to health, mild cold exposure caused increased systolic blood pressure in both age groups. The mean increase was up to three times greater in elderly, reaching even over $190 \mathrm{mmHg}$ in some elderly individuals. In medical practice a systolic blood pressure over $180 \mathrm{mmHg}$ is considered hazardous (14). Systolic blood pressure remained at increased levels even after a $2 \mathrm{~h}$-rewarming period, which indicates a long lasting effect of mild cold. The elevated systolic blood pressure after rewarming was inversely related to non-shivering thermogenesis upon mild cold exposure. It is interesting to note that elderly with a greater percent body fat showed significantly smaller increases in systolic blood pressure. Therefore, especially lean elderly should pay attention to their ambient environment.

From Chapter 5 onwards the topic of this thesis shifts from physiological experiments to mathematical modelling of human thermoregulation. The classic "engineering" perspective to model thermoregulation includes the explicit definition of temperature setpoints, which when exceeded trigger thermoregulatory control mechanisms. Although these models may simulate the thermoregulatory response with great accuracy, they may lack coherence with physiological reality. In Chapter $\mathbf{5}$ we showed a neurophysiological approach to model thermoregulatory changes in skin blood flow. The neurophysiological approach is based on the principle that the human body does not sense temperature directly; instead the information is coded into neuron fire rates. Through the neurophysiology of thermal reception and neural integration skin blood flow is regulated. A comparison between both approaches (i.e. engineering vs. neurophysiology) shows that the neurophysiological approach was more robust to predict changes in skin blood flow under various dynamic conditions. In Chapter 6 the neurophysiological modelling approach was expanded to model thermal sensation in young adult males. Thermal sensation dictates the satisfaction of persons with their environment. Using datasets of two independent physiological experiments the thermal sensation model was both developed and validated. In contrast to the widely used Fanger model that is only suitable for simulating thermal comfort for whole groups under constant thermal environments, the neurophysiological approach can be highly beneficial for predicting thermal sensation of individuals under transient thermal environments. 


\section{Implications for health}

One of the major implications of this thesis is that already mild thermal challenges can induce strong physiological responses. The results in Chapter 4 confirmed that mild cold exposure causes systolic blood pressure to increase more in elderly than in young adults (15). Furthermore the results showed that even after a rewarming period systolic blood pressure remained significantly elevated. This is very relevant for daily living situations. Long-term-elevated levels of systolic blood pressure are associated with increased risk for coronary disease and stroke and also increased mortality $(16,17)$. Therefore, mild cold exposure may be hazardous for elderly. The reduced ability to cope with mild thermal challenges in elderly results in a greater disturbance of their heat balance. This can be caused either by a blunted nonshivering thermogenesis (Chapter 4) or impaired regulation of skin blood flow (18, 19). As a result, the elderly were displaced further from their thermoneutral zone than young adults, despite that all were exposed to the same ambient temperatures (Chapter 2).

With respect to the built environment it is clear that we should protect our elderly from even mild thermal disturbances. Ambient temperature drifts are therefore not advisable as an energy-saving strategy for buildings inhabited by elderly. For our young adults, however, the ambient temperature drift strategy may be beneficial for health. For instance, a logical consequence of increased energy expenditure through non-shivering thermogenesis is that it lowers the risk of becoming obese, whilst maintaining the same food intake. On top of that, for those that are already overweight or obese, mild thermal challenges may be part of a life style intervention to restore normal weight (20).

\section{Synergy between physiology and mathematical modelling}

Since the 1970's mathematical models of human thermoregulation have continuously been extended and improved (13). While attempting to capture the dynamics of thermoregulation, the dominant approach has been to map body temperature data directly to thermoregulatory responses (21-24). However, humans do not sense temperature directly; instead, the information is coded into neural fire rates. In this thesis, we explored an alternate approach to model thermoregulation by simulating the neurophysiology of temperature reception and neural integration. Thus increasing the level of physiological knowledge incorporated in the mathematical models. The developed models for skin blood flow (Chapter 5) and thermal sensation (Chapter 6) yielded promising results both in accuracy and in robustness during simulations with dynamically changing thermal environments. Future studies could extend the physiological approach by including other thermoregulatory mechanisms (e.g. non-shivering thermogenesis and sweating) and also non-thermal 
mechanisms that indirectly influence heat balance (e.g. blood pressure, drugs, and pathogens) (25).

Mathematical modelling of thermoregulation benefitted from increasing the coherence with the human physiology involved. The other way around, mathematical modelling may assist in our understanding of physiology. This is illustrated by comparing measurements and simulations of energy expenditure during mild cold exposure (see Figure 1). Once distal parts of the body started cooling down, energy expenditure declined in the simulation ( $t=30 \mathrm{~min}$ to $t=90 \mathrm{~min}$ in Figure 1 ). This is caused by Arrhenius law, also known as the $Q_{10}$-effect, which states that the metabolic rate changes with a constant ratio for a given temperature change $\left(\Delta_{\text {metabolic rate }}=\mathrm{Q}_{10}{ }^{(\Delta \mathrm{T}) / 10}\right)$ $(23,26,27)$.

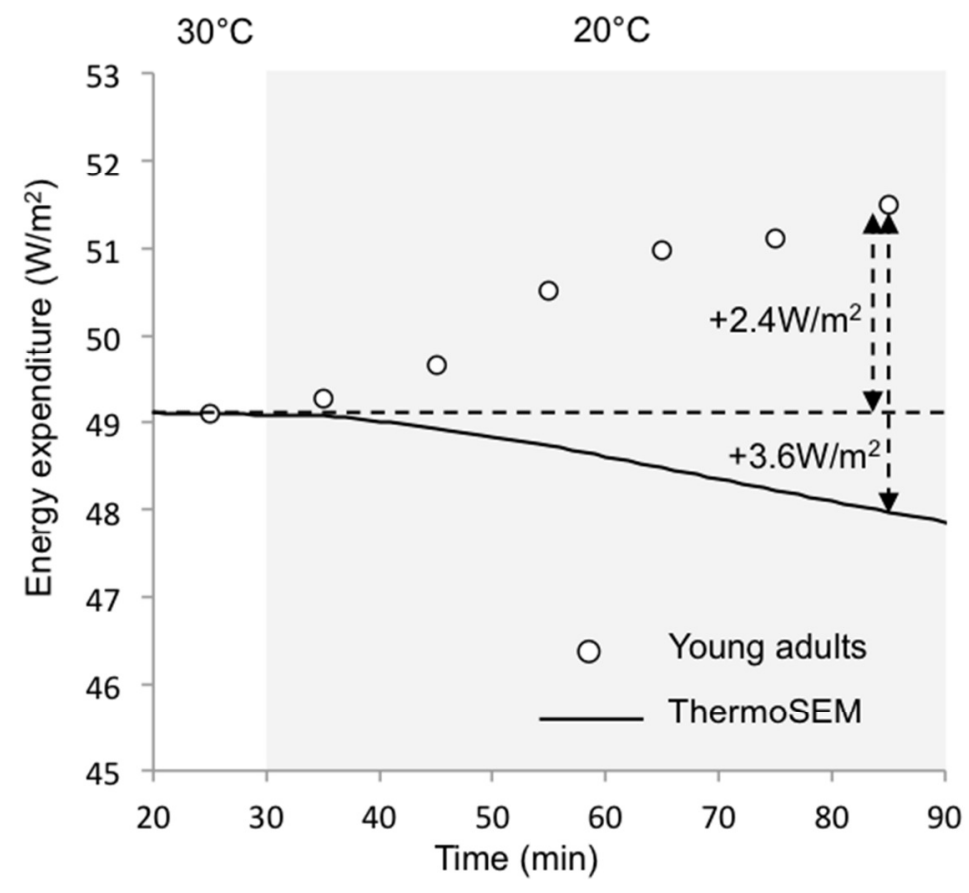

Figure 1: Energy expenditure during a mild cold exposure measured in young adults (open circle) and simulated by ThermoSEM (solid line). The horizontal dashed line indicates the baseline level and the vertical dashed lines indicate cold induced thermogenesis relative to baseline $(+2.4 \mathrm{~W} / \mathrm{m} 2)$ and with consideration of the Q10-effect $(+3.6 \mathrm{~W} / \mathrm{m} 2)$.

When non-shivering thermogenesis is neglected in ThermoSEM, decreased energy expenditure contradicts physiological experimental results that show increased whole body energy expenditure (i.e. non-shivering thermogenesis). However, it provided the insight that part of the non-shivering thermogenesis in the physiological experiments could be obscured by the $\mathrm{Q}_{10}$-effect in cooled tissues. In this example, the non-shivering thermogenesis would not be $+2.4 \mathrm{~W} / \mathrm{m}^{2}$, but $+3.6 \mathrm{~W} / \mathrm{m}^{2}$. Not considering the $\mathrm{Q}_{10}$-effect, by only subtracting baseline energy expenditure from 
total energy expenditure during cold, would in this case have caused a $50 \%$ underestimation of the actual non-shivering thermogenesis! Furthermore, the $\mathrm{Q}_{10}$-effect may also explain why some individuals decreased whole body energy expenditure upon cold exposure $(28,29)$. In practice, it is possible to measure reduced whole body energy expenditure, while tissues involved in non-shivering thermogenesis are fully active, yet unable to compensate for decreased energy expenditure elsewhere in the body. Tissues likely to mediate non-shivering thermogenesis are skeletal muscle and brown adipose tissue (29-31). These tissues metabolize glucose and free fatty acids substrates to form ATP, a substance with a high chemical energy potential (14). Skeletal muscle and brown adipose tissue can adjust the efficiency of ATP production such that the chemical energy in the substrates is not stored in ATP, but directly degraded to heat. In active brown adipose tissue free fatty acids contribute around $90 \%$ of brown adipose tissue metabolism (32). In combination with the $50 \%$ underestimation of non-shivering thermogenesis in the example above, this suggests that mild cold causes even more Joules to be burned than is calculated in most studies. Since fatty acids are the main metabolized substrate in non-shivering thermogenesis, this is good news for the battle against obesity.

Another example of how mathematical modelling may assist understanding of physiology is by helping to explain why hand skin temperature remained significantly higher in elderly compared to young adults during mild cold exposure (Figure 2).

The greater the temperature difference between skin and surroundings, the greater heat loss will be. Therefore, Figure 2 indicates that elderly lost more heat from their distal body parts than young adults.

In literature, higher skin temperatures in elderly during cooling are explained by impaired vasoconstriction (33). However, in our study we did not observe an age effect in vasoconstriction at hand skin (Chapter 3 and Chapter 4). A mathematical analysis of the factors involved in the heat exchange lead to the hypothesis that counter current heat exchange between arteries and veins might be involved. Counter current heat exchange causes arterial blood to cool before it reaches the periphery and venous blood to warm before it is returned to the body core (34). The effectiveness of blood rewarming has already been stressed by Jiji et al. (1984), who stated that the temperature difference between arterioles and venules in the skin is only between $0.1^{\circ} \mathrm{C}$ to $0.2^{\circ} \mathrm{C}$, whereas the temperature difference between major vessels and skin temperature is between $5^{\circ} \mathrm{C}$ to $10^{\circ} \mathrm{C}(35,36)$. Counter current heat exchange is affected by 1 ) the amount of blood flowing through arteries and veins, 2 ) the distance between the centroids of arteries and veins, 3) the length that arteries and veins are close to each other and 4) the thickness of the vessel walls. Aging is associated with increased thickness of arterial walls (intima and media) (37). Therefore, elderly may be prone to impaired counter current heat exchange, which, during cold exposure, may lead to greater heat loss compared to young adults, despite the absence of an age effect in vasoconstriction. 


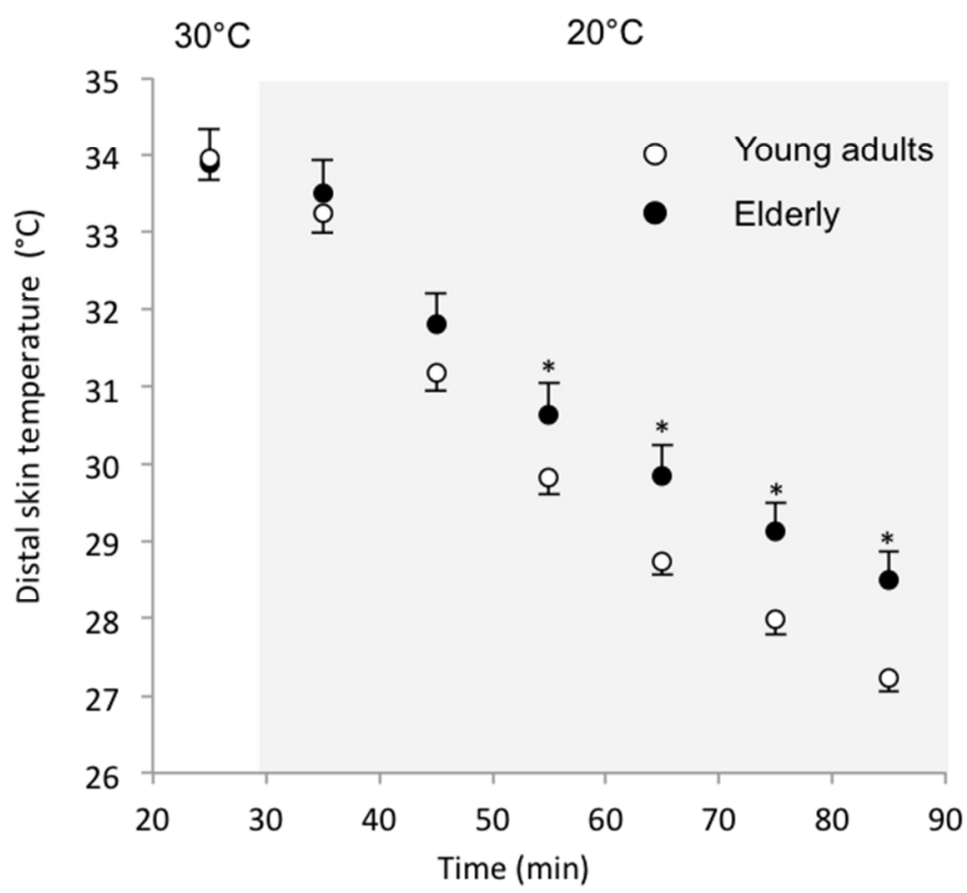

Figure 2: Mean distal skin temperature (hands and feet) in young adults and elderly during thermoneutral $\left(30^{\circ} \mathrm{C}\right)$ and mild cold conditions $\left(20^{\circ} \mathrm{C}\right)$. Error bars denote SEM. ${ }^{*}: p<0.05$.

\section{Concluding remarks and future directions}

Body composition, skin blood flow, clothing, thermogenesis, age and gender all contribute to the thermoneutral zone of individuals. The results of this thesis suggest that a mild cold exposure displaces elderly further from their thermoneutral zone than young adults. The impaired non-shivering thermogenesis in elderly lead to a greater decrease in core temperature and a long-lasting elevated systolic blood pressure in elderly compared to their younger counterparts. In some elderly systolic blood pressure reached hazardous levels $(190 \mathrm{mmHg})$. It is concluded that especially in elderly, mild thermal challenges may induce strong physiological responses.

With respect to mathematical modelling, knowledge of the neurophysiology of thermoregulation helped to capture the dynamics of the regulation of skin blood flow as well as thermal sensation during mild thermal transients. The other way around, mathematical modelling offered insight in the possible obscuring effect of Arrhenius law on non-shivering thermogenesis and the possible role of counter current heat exchange in skin temperature dynamics. Therefore, this thesis is truly a product of synergy between physiology and mathematical modelling.

Future studies could elucidate the masking effect of Arrhenius law on non-shivering thermogenesis. These measurements could include recordings of local tissue temperature (e.g. calf muscle temperature), and oxygen uptake in the same tissue re- 
gion during cold exposure. With respect to mathematical modelling of thermoregulation, future studies could further expand the incorporation of physiological concepts of thermoregulatory control by developing a more detailed mapping of thermal reception and the coupling of neurophysiology to other thermoregulatory mechanisms such as non-shivering thermogenesis, shivering or sweating. On top of that, hormonal and non-thermal (e.g. blood pressure) factors that indirectly influence heat balance could be incorporated to further increase the applicability of the model.

\section{References}

1. Johnson, J.M. and D.L. Kellogg, Jr., Thermoregulatory and thermal control in the human cutaneous circulation. Frontiers in bioscience, 2010. 2: p. 825-53.

2. van Marken Lichtenbelt, W.D. and P. Schrauwen, Implications of non-shivering thermogenesis for energy balance regulation in humans. American journal of physiology. Regulatory, integrative and comparative physiology, 2011.

3. van Ooijen, A.M., et al., Cold-induced heat production preceding shivering. $\mathrm{Br} \mathrm{J}$ Nutr, 2005. 93(3): p. 387-91.

4. Rowell, L.B., Cardiovascular aspects of human thermoregulation. Circ Res, 1983. 52(4): p. 367-79.

5. Van Someren, E.J., et al., Circadian and age-related modulation of thermoreception and temperature regulation: mechanisms and functional implications. Ageing Res Rev, 2002. 1(4): p. 721-78.

6. Wijers, S.L., W.H. Saris, and W.D. van Marken Lichtenbelt, Cold-Induced Adaptive Thermogenesis in Lean and Obese. Obesity (Silver Spring), 2010.

7. de Dear, R. and G.S. Brager, The adaptive model of thermal comfort and energy conservation in the built environment. International journal of biometeorology, 2001. 45(2): p. 100-8.

8. van Hoof, J., M. Mazej, and J.L. Hensen, Thermal comfort: research and practice. Frontiers in bioscience : a journal and virtual library, 2010. 15: p. 765-88.

9. Johnson, F., et al., Could increased time spent in a thermal comfort zone contribute to population increases in obesity? Obes Rev, 2011.

10. Fanger, P.O., Thermal Comfort, 1970: Copenhagen: Danish Technical Press.

11. Severens, N.M., Modelling Hypothermia in Patients Undergoing Surgery, in Energy Technology, Mechanical engineering2008, Eindhoven University of Technology: Eindhoven.

12. Janssen, F., Modelling physiological and biochemical aspects of scalp cooling, in Energy Technology, Mechanical Engineering2007, Eindhoven University of Technology: Eindhoven.

13. Fiala, D., et al., Physiological modelling for technical, clinical and research applications. Frontiers in bioscience, 2010. 2: p. 939-68. 
14. Guyton, A.C. and J.E. Hall, Textbook of Medical Physiology. 10 ed2000, Philadelphia: W.B.Saunders Company.

15. Hess, K.L., et al., Aging affects the cardiovascular responses to cold stress in humans. J Appl Physiol, 2009. 107(4): p. 1076-82.

16. He, J. and P.K. Whelton, Elevated systolic blood pressure and risk of cardiovascular and renal disease: overview of evidence from observational epidemiologic studies and randomized controlled trials. American heart journal, 1999. 138(3 Pt 2): p. 211-9.

17. Clarke, R., et al., Underestimation of the importance of blood pressure and cholesterol for coronary heart disease mortality in old age. Eur Heart J, 2002. 23(4): p. 286-93.

18. deGroot, D.W. and W.L. Kenney, Impaired defense of core temperature in aged humans during mild cold stress. Am J Physiol Regul Integr Comp Physiol, 2007. 292(1): p. R103-8.

19. Brengelmann, G.L. and M.V. Savage, Temperature regulation in the neutral zone. Ann N Y Acad Sci, 1997. 813: p. 39-50.

20. Vijgen, G.H., et al., Brown adipose tissue in morbidly obese subjects. PLoS ONE, 2011. 6(2): p. e17247.

21. Fiala, D., K.J. Lomas, and M. Stohrer, Computer prediction of human thermoregulatory and temperature responses to a wide range of environmental conditions. Int J Biometeorol, 2001. 45(3): p. 143-59.

22. Severens, N.M., et al., Measurement of model coefficients of skin sympathetic vasoconstriction. Physiol Meas, 2010. 31(1): p. 77-93.

23. Stolwijk, J.A., A mathematical simulation model of the skin for evaluation of surface temperature gradients resulting from local variations in metabolism and blood flow. Bibl Radiol, 1975(6): p. 151-6.

24. Wissler, E.H., A quantitative assessment of skin blood flow in humans. Eur J Appl Physiol, 2008. 104(2): p. 145-57.

25. Mekjavic, I.B. and O. Eiken, Contribution of thermal and nonthermal factors to the regulation of body temperature in humans. J Appl Physiol, 2006. 100(6): p. 206572.

26. Burton, A.C. and O.G. Edholm, Man in a cold environment, 1955, London: Edward Arnold (Publishers) LTD.

27. Rubner, M., The laws of energy conservation in nutrition, ed. R.J. Joy1982, London: Academic Press, INC. (London) LTD.

28. van Ooijen, A.M., et al., Seasonal changes in metabolic and temperature responses to cold air in humans. Physiol Behav, 2004. 82(2-3): p. 545-53.

29. Wijers, S.L., et al., Human skeletal muscle mitochondrial uncoupling is associated with cold induced adaptive thermogenesis. PLOS ONE, 2008. 3(3): p. e1777. 
30. Cannon, B. and J. Nedergaard, Brown adipose tissue: function and physiological significance. Physiol Rev, 2004. 84(1): p. 277-359.

31. Wijers, S.L., et al., \{beta\}-Adrenergic Receptor Blockade Does Not Inhibit ColdInduced Thermogenesis in Humans: Possible Involvement of Brown Adipose Tissue. The Journal of clinical endocrinology and metabolism, 2011. 96(4): p. E598-605.

32. Ma, S.W. and D.O. Foster, Uptake of glucose and release of fatty acids and glycerol by rat brown adipose tissue in vivo. Canadian journal of physiology and pharmacology, 1986. 64(5): p. 609-14.

33. Budd, G.M., et al., Effects of fitness, fatness, and age on men's responses to whole body cooling in air. J Appl Physiol, 1991. 71(6): p. 2387-93.

34. Mitchell, J.W. and G.E. Myers, An analytical model of the counter-current heat exchange phenomena. Biophys J, 1968. 8(8): p. 897-911.

35. Jiji, L.M., S. Weinbaum, and D.E. Lemons, Theory and experiment for the effect of vascular microstructure on surface tissue heat transfer--Part II: Model formulation and solution. J Biomech Eng, 1984. 106(4): p. 331-41.

36. Daanen, H., Central and Peripheral control of finger blood flow in the cold, in Medicine1997, Free University: Amsterdam. p. 258.

37. Scuteri, A., et al., Metabolic syndrome amplifies the age-associated increases in vascular thickness and stiffness. J Am Coll Cardiol, 2004. 43(8): p. 1388-95. 


\section{APPENDIX}

THERMO-PHYSIOLOGICAL SIMULATION MODEL EINDHOVEN MAASTRICHT 


\section{Introduction}

This section describes the mathematical thermoregulation model (ThermoSEM) used in this thesis. Mathematical models of human thermoregulation vary in level of detail, complexity and applicability (1). Most models that are suitable to simulate transient conditions are split in a controlled passive part and a controlling active part (2-8). The passive part defines: 1) body characteristics, 2) heat transfer within the body and 3) heat transfer between the body and the environment. The active part defines the thermoregulatory system. The level of detail in modeled body characteristics scales from a rough single cylindrical element with a core and a shell $(7$, $9,10)$, to a more detailed series of cylindrical and spherical elements $(2,3,6,11$, 12 ), and eventually to full scale voxel-models of the human body in which complex shapes of organs and body parts are included (8). However, more geometrically correct models do not necessarily result in more accurate simulations. This is mainly caused by incomplete knowledge on the composition and regulation of local tissues. Moreover, there is a tradeoff between the complexity of the model and the time required to perform simulations. The more geometrically fine-tuned models are, the more time is needed for simulations to complete. For this thesis, the multisegmental cylinder model as shown in Figure 1 is considered detailed enough to simulate the experimental conditions while it allows for reasonably fast computations (about 16 seconds for simulating 3 hours on a $2.53 \mathrm{GHz}$ Intel Core 2 Duo, 4GB 1067MHz DDR3 computer).

ThermoSEM is a descendant of Fiala's model (6), which in turn, is an improved version of Stolwijks' multi-segmental thermoregulation model (11). In the passive part, ThermoSEM differs slightly from Fiala's model in that the arms and legs are split in upper and lower parts and that skin perfusion is corrected for tissue volume (14). Nevertheless, the main difference between the Fiala model and ThermoSEM lies in the controlling (active) part. Our laboratory aims to increase the degree of neurophysiological concepts for thermoregulation in the active part. In this thesis, this is realized by developing a model for skin blood flow based on neurophysiological concepts (see Chapter 5). In the future also other thermoregulatory mechanisms (e.g. shivering or sweating) will be included. However, until now the equations that define shivering or sweating are still obtained from Fiala's active model descriptions (15). 


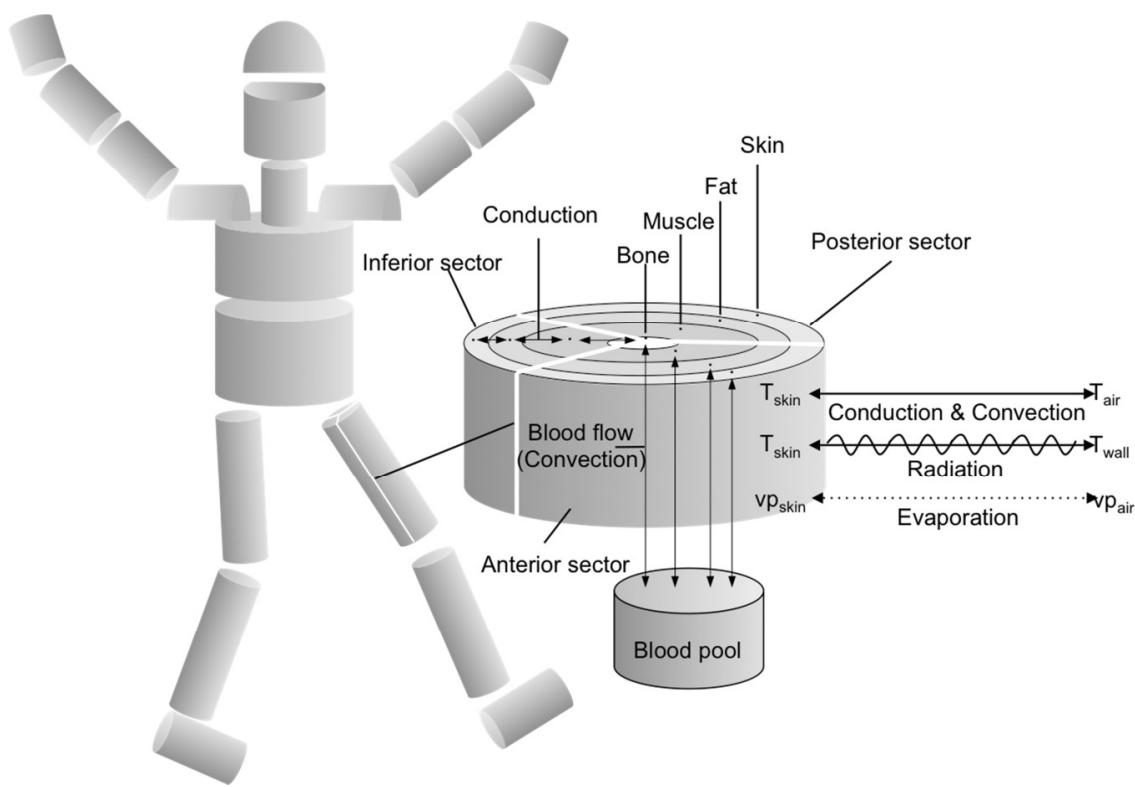

Figure 1: The passive model (based on ref. (6)). The humanoid is composed of elements (concentric cylinders and a concentric sphere). Each element is composed of tissue layers (for the leg: bone, muscle, fat and skin) and split in sectors (for the leg: anterior, posterior and inferior). Within an element heat is transferred through conduction and convection (blood flow) according to the Pennes' bioheat equation (13). Nodes in tissues (depicted as dots) form a volumetric mesh for which the bioheat equation is solved. Between an element and the environment heat is transferred through conduction, convection, radiation and evaporation.

\section{Passive model}

The human body is modeled as a series of concentric cylinders for body parts and a concentric semi-sphere for the head (see Figure 1). These body parts are called elements (element properties in Table 1 through Table 3). Elements are composed of several tissue layers, each with specific density, conductivity, heat capacity, basal blood perfusion and basal metabolic heat production (values in Table 2). Furthermore, elements are split in sectors that define the orientation of the element. For example, in case of the upper leg, the anterior sector is the front side, the posterior sector is the backside and the inferior sector is the side that is directed towards the other leg (sector properties in Table 3).

\section{Heat exchange within the body}

Nodes spaced over tissue layers (depicted as dots in Figure 1) form a volumetric mesh through which heat transfer is calculated. Heat transfer within the body is modeled by the Pennes' bioheat equation (13):

$$
\rho c \frac{\partial T}{\partial t}=k \nabla^{2} T+\rho_{b} c_{b} \omega_{b}\left(T_{a}-T\right)+q_{m}
$$


here, on the left hand side, $\rho$ is the density of the tissue, $c$ is the heat capacity of the tissue and $\frac{\partial T}{\partial t}$ is the change in temperature. On the right hand side, the three terms define conduction $\left(k \nabla^{2} T\right)$, convection $\left(\rho_{b} c_{b} \omega_{b}\left(T_{a}-T\right)\right)$ and heat production $\left(q_{m}\right) ; k$ is tissue heat conductivity, $T$ is tissue temperature, $\rho_{b}$ is density of blood, $c_{b}$ is the specific heat of blood, $\omega_{b}$ is the blood perfusion rate, $T_{a}$ is the arterial blood temperature and $q_{m}$ is the metabolic heat production of the tissue. The tissue specific density, heat capacity, conductivity, basal perfusion rate and basal metabolic heat production are given in Table 2 . The arterial blood temperature $\left(T_{a}\right)$ is calculated from the central blood pool temperature according to Fiala et al. (6). For simplicity, the central blood pool may be interpreted as the heart where returning (venous) blood is mixed and pumped back to the rest of the body. The temperature of the mixed venous blood is the arterial blood temperature of the next simulation iteration. However, for some elements (e.g. arms and legs) the large arteries and veins are close enough to facilitate counter current heat exchange. In those elements the arterial blood temperature is corrected for counter current heat exchange using the coefficients given in Table 1.

\section{Heat exchange between body and the environment}

Heat exchange with the environment occurs at the skin through conduction, convection, radiation and evaporation (Figure 1), and in the respiratory tract through convection and evaporation. The calculations given below are based on Fiala et al. (1999) (6).

\section{Convection}

Area specific convective heat exchange is calculated as (6):

$$
q_{c}=h_{c, \text { mix }}\left(T_{s k}-T_{\text {air }}\right)
$$

here, $q_{c}$ is the convective heat flux, $h_{c, \text { mix }}$ is a mixed convection coefficient combining natural and forced convection, $T_{s k}$ is skin temperature and $T_{\text {air }}$ is the air temperature. The mixed convection coefficient was calculated as (6):

$$
h_{c, \text { mix }}=\sqrt{a_{\text {nat }} \sqrt{T_{s k}-T_{\text {air }}}+a_{\text {frc }} v_{\text {air }, \text { eff }}+a_{\text {mix }}}
$$

here, $a_{n a t}$ is a coefficient for natural convection, $a_{f r c}$ is a coefficient for forced convection and $a_{\text {mix }}$ is a coefficient for the mixed convection effect and $v_{\text {air,eff }}$ is the effective wind speed at the skin surface. The coefficients are given per element in Table 1.

\section{Radiation}

The area specific radiative heat exchange between two diffuse-gray surfaces is given by: 


$$
q_{r}=\frac{\sigma\left(T_{1}^{4}-T_{2}^{4}\right)}{\frac{1-\varepsilon_{1}}{\varepsilon_{1} A_{1}}+\frac{1-\varepsilon_{1}}{F_{12} A_{1}}+\frac{1-\varepsilon_{2}}{\varepsilon_{2} A_{2}}}
$$

here, $q_{r}$ is the radiative heat flux per area unit, $\sigma$ is the Stefan Boltzmann constant $\left(\sigma=5.67 \cdot 10^{-8} \mathrm{Wm}^{-2} \mathrm{~K}^{-4}\right), T$ is surface temperature, $\varepsilon$ is the emissivity and $F_{12}$ is the geometric view factor. In the denominator, $\frac{1-\varepsilon_{1}}{\varepsilon_{1} A_{1}}$ and $\frac{1-\varepsilon_{2}}{\varepsilon_{2} A_{2}}$ account for the surface resistance to radiation and $\frac{1-\varepsilon_{1}}{F_{12} A_{1}}$ accounts for the spatial resistance (14). To account for the different shapes and sectors of the elements, Fiala et al. (1999) introduced sector view factors $\psi_{s r}$. Furthermore the description of radiative heat exchange was split in a radiative heat transfer coefficient and a radiative temperature gradient (6).

$$
q_{r}=h_{r}\left(T_{s k}-T_{w}\right)
$$

The radiative heat transfer coefficient $h_{r}$ is calculated as (6):

$$
h_{r}=\frac{\sigma \psi_{s r}}{\frac{1}{\varepsilon_{s k}}+\frac{1}{\varepsilon_{w}}-1} \frac{\left(T_{s k}^{4}-T_{w}^{4}\right)}{\left(T_{s k}-T_{w}\right)}
$$

here, $T_{s k}$ is skin temperature and $T_{w}$ is the temperature of the surface radiating the skin. Values for $\psi_{\text {sr }}$ and $\varepsilon_{\text {skin }}$ are given in Table 3.

\section{Evaporation}

Area specific evaporative heat exchange is calculated as (6):

$$
q_{e}=h_{e}\left(p_{\text {vap }, \text { sk }}-p_{\text {vap,air }}\right)
$$

Where, $h_{e}$ is the evaporative heat exchange coefficient, $p_{v a p, s k}$ is the vapor pressure at the skin surface and $p_{\text {vap,air }}$ is the vapor pressure in the surrounding air. The evaporative heat exchange coefficient is given by:

$$
h_{e}=\operatorname{Leh}_{c, \text { mix }}
$$

Where, Le is the Lewis constant for air $\left(L e=16.65^{\circ} \mathrm{CkPa}^{-1}\right)$. Vapor pressure at the skin surface is calculated as:

$$
p_{\text {vap }, s k}=\frac{h_{e} p_{\text {vap,air }}+\frac{p_{\text {sweatgland,sat }}}{R_{e, s k}}+\lambda_{\mathrm{H}_{2} O} \frac{d m_{s w}}{A_{s k} d t}}{h_{e}+\frac{1}{R_{e, s k}}}
$$

Where $p_{\text {sweatgland,sat }}$ is the vapor pressure in the sweat glands, $R_{e, s k}$ is the moisture permeability of the skin $\left(R_{e, s k}=0.003 \mathrm{Wm}^{-2} \mathrm{~Pa}^{-1}\right), \lambda_{\mathrm{H}_{2} \mathrm{O}}$ is the heat of vaporization of water, $A_{s k}$ is the skin surface area and $\frac{d m_{S w}}{d t}$ is the sweat rate. The vapor pressure in the sweat glands is assumed to be equal to the saturation value and is calculated according to Antoine's equation:

$$
p_{\text {sweatgland,sat }}=100 e^{18.965-\frac{4030}{T_{\text {sweatgland }}+235}}
$$

Here $T_{\text {sweatgland }}$ is assumed equal to the outer surface temperature. The vapor pressure of the surrounding air is calculated as:

$$
p_{\text {vap,air }}=\phi p_{\text {air,sat }}
$$


Here, $\phi$ is the relative humidity and $p_{\text {air,sat }}$ is the saturated vapor pressure for the surrounding air temperature.

The model accounts for accumulative storage of sweat at the skin surface when sweat rate is higher than the vaporization rate. This is calculated as:

$$
\frac{d m_{a c c}}{d t}=\frac{d m_{s w}}{d t}-\frac{h_{e}\left(p_{v a p, s k, s a t}-p_{v a p, a i r}\right)}{\lambda_{\mathrm{H}_{2} \mathrm{O}}} A_{s k}
$$

The maximum amount of sweat on the skin surface is set at: $m_{a c c, \max }=35 \mathrm{gm}^{-2}$ (16). When $m_{a c c}+\frac{d m_{s w}}{A_{s k}}>m_{a c c, \max }$, the excess sweat is assumed to drop of the body and does not contribute to the heat loss calculation.

\section{Body parts covered by clothing}

For body parts covered by clothing, convective and radiative heat transfer is calculated as:

$$
q_{c+r}=U_{c l}\left(T_{s k}-T_{o p}\right)
$$

Here, $U_{c l}$ is the heat transfer coefficient for a clothing ensemble and $T_{\text {operative }}$ is the operative temperature. The operative temperature is calculated as:

$$
T_{o p}=\frac{h_{r} T_{w}+h_{c, \text { mix }} T_{a i r}}{h_{r}+h_{c, \text { mix }}}
$$

The heat transfer coefficient for clothing is calculated as given by:

$$
U_{c l}=\frac{1}{I_{c l, j}+\frac{1}{f_{c l}\left(h_{c, \text { mix }}+h_{r}\right)}}
$$

Here, $I_{c l, j}$ is the clothing heat resistance covering element $j$ and $f_{c l}$ is the clothing area factor.

For clothed body parts the evaporative heat transfer is calculated as:

$$
q_{e}=U_{e}\left(p_{s k, \text { surf }}-p_{\text {air }}\right)
$$

Where $U_{e}$ is the evaporative heat transfer coefficient for clothing. $U_{e}$ is given by:

$$
U_{e}=\frac{L e}{\frac{I_{c l, j}}{i_{c l, j}}+\frac{1}{f_{c l} h_{c, \text { mix }}}}
$$

here $i_{c l, j}$ is the moisture permeability index. The calculation of the vapor pressure at the skin surface is then rewritten to:

$$
p_{s k, \text { surf }}=\frac{U_{e} p_{\text {vap,air }}+\frac{p_{\text {sweatgland }, \text { sat }}}{R_{e, s k}}+\lambda_{H_{2} O} \frac{d m_{s w}}{A_{s k} d t}}{U_{e}+\frac{1}{R_{e, s k}}}
$$

For a list of commonly used clothing resistances see Table 4. 


\section{Respiration}

Respiratory heat losses consist of a convective and an evaporative part. Total heat loss through respiration is calculated as (6):

$$
q_{\text {res }}=q_{e, r e s}+q_{c, r e s}
$$

here, $q_{e, r e s}$ is the evaporative part and $q_{c, r e s}$ is the convective part. The evaporative part of respiratory heat loss is calculated as (6):

$$
q_{e, r e s}=\dot{V} \lambda_{H_{2} O} \Delta \phi_{s p, e x-i n}
$$

here, $\dot{V}$ is the respiration rate, $\lambda_{\mathrm{H}_{2} \mathrm{O}}$ is the heat of vaporization of water and $\Delta \phi_{\text {sp,ex-in }}$ is the difference of specific humidity between exhaled and inhaled air. $\Delta \phi_{\text {sp,ex-in }}$ is calculated as:

$$
\Delta \phi_{s p, e x-i n}=0.0277+6.5 \cdot 10^{-5} T_{\text {air }}-0.8 \phi_{s p}
$$

The specific humidity $\phi_{s p}$ was calculated as:

$$
\phi_{s p}=0.622 \frac{p_{\text {vap,air }}}{p_{\text {air }}+p_{\text {vap,air }}}
$$

The convective part of respiratory heat loss was calculated as (6):

$$
q_{c, r e s}=\dot{V} c_{\text {air }} \Delta T_{\text {air }, \text { ex }- \text { in }}
$$

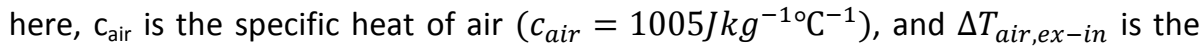
difference between exhaled and inhaled air temperature. $\Delta T_{\text {air,ex-in }}$ is calculated as:

$$
\Delta T_{\text {air }, \text { ex-in }}=32.6-0.934 T_{\text {air }}+32.0 \phi_{s p}
$$

Total respiratory heat loss, $q_{\text {res }}$, is distributed along the respiratory tract according to Fiala et al. (1999) (6) (i.e. face muscles $45 \%$, neck muscles $25 \%$ and lungs $30 \%$ ).

\section{Active model}

The active part of ThermoSEM defines the thermoregulatory system. Again, most calculations are based on the work Fiala et al. (16), with exception of the neurophysiological approach for modeling skin blood flow, which is based on Chapter 5. The active part uses temperature input from the core and skin to calculate the response of thermoregulatory control mechanisms. For core temperature the hypothalamic temperature $T_{h y}$ is used and mean skin temperature is calculated as (16):

$$
T_{s k, \text { mean }}=\sum_{e}^{\text {elements }}\left(a_{s k, e} \sum_{s r}^{\text {sector }} \frac{A_{s k, e, s r}}{A_{s k, e}} T_{s k, e, s r}\right)
$$

here, $a_{s k, e}$ is the skin sensitivity coefficient of element $e$ (see Table 5), $\frac{A_{s k, e, s r}}{A_{s k, e}}$ is the area fraction of sector $s r$ relative to total area of element $e$ and $T_{s k, e, s r}$ is the skin temperature.

The approach presented by Fiala uses the difference between actual temperature and set point temperature $\left(T_{b a s}\right)$ to calculate an error-signal (6):

$$
\Delta T=T-T_{\text {bas }}
$$

The error signal is then used as the measure of heat strain on the body. The thermoregulatory responses are assumed to scale according to $\Delta T$. The set points $\left(T_{\text {bas }}\right)$ 
are defined as the steady state temperature during exposure of a nude body to thermoneutral conditions $\left(T_{\text {air }}=T_{w}=30^{\circ} \mathrm{C} ; \phi=40 \%\right)$.

The thermoregulatory responses can be divided in those that modulate heat production (e.g. shivering), those that modulate heat transport (e.g. blood flow) and those that modulate heat loss (e.g. sweating).

\section{Heat production}

Metabolic heat production in tissue nodes is calculated as:

$$
q_{m, i}=q_{m, i, b a s} \times Q_{10, i}+q_{m, i, s h}
$$

Here $q_{m, i}$ is the metabolic heat production for node $i, q_{m, i, b a s}$ is the basal metabolic rate (values in Table 2 ), the $Q_{10}$-effect on muscle metabolism is given by $Q_{10, i}=$ $2^{\frac{\left(T_{i}-T_{i, b a s}\right)}{10}}$, and $q_{m, i, s h}$ is heat produced by shivering. Heat produced by shivering is distributed over muscle tissue according to (16):

$$
q_{m, i, s h}=a_{s h, j} \frac{S h}{V_{i}}
$$

Here $a_{s h, j}$, is the element specific shivering distribution coefficient given in Table 5, $S h$ is the total heat produced by shivering and $V_{i}$ is the volume of node $i$. Total heat produced by shivering is calculated as (15):

$$
\begin{gathered}
S h=10\left[\tanh \left(0.51 \Delta T_{s k, \text { mean }}+4.19\right)-1\right] \Delta T_{\text {sk,mean }}-27.5 \Delta T_{h y} \\
-28.2+1.9 \Delta T_{\text {sk,mean }} \frac{d T_{\text {sk,mean }}}{d t}
\end{gathered}
$$

To account for the maximum amount of heat that can be reached by shivering, the upper limit for shivering is set to $S h_{\max }=350 \mathrm{~W}$.

\section{Heat transport}

Heat transport inside the body is regulated by blood flow. In thermoneutral conditions tissues are perfused by the basal blood flows $\left(\omega_{\text {bas }}\right)$. In ThermoSEM blood flow is directly expressed in the heat equivalent $\beta_{b a s}=\rho_{b} c_{b} \omega_{b, b a s}$. When metabolic rate of tissues changes, blood flow changes accordingly. This is calculated as:

$$
\beta_{i}=\beta_{i, b a s}+\mu_{b}\left(q_{m, i}-q_{m, i, b a s}\right)
$$

here, $\mu_{b}$ is the constant that accounts for the proportional change in blood flow $\left(\mu_{b}=0.932^{\circ} \mathrm{C}^{-1}\right)$ for a given change in metabolic rate $\left(q_{m, i}-q_{m, i, b a s}\right)$.

For skin blood flow regulation, both the original Fiala and the neurophysiological approach were implemented. First, the Fiala approach is presented; thereafter the neurophysiological approach is described.

\section{1) Fiala skin blood flow model}

Fiala formulated regulation of skin as follows (15): 


$$
\beta_{i}=\frac{\beta_{i, b a s}+a_{d l, i} D l}{1+a_{c s, i} C s \times e^{-D l / 80}} \times Q_{10}
$$

here, $D l$ and $C s$ are the central stimuli for dilation and constriction respectively, $a_{d l, i}$ and $a_{c s, i}$ are local distribution coefficients for the central stimuli (values in Table 5) and $Q_{10}=2^{\frac{\left(T_{i}-T_{i, b a s}\right)}{10}}$ accounts for the local regulation (i.e. $Q_{10}$ effect) of skin blood flow.

The central signal for vasoconstriction is given by (15):

$$
\begin{aligned}
& C s=35\left[\tanh \left(0.34 \Delta T_{s k, \text { mean }}+1.07\right)-1\right] \Delta T_{s k, \text { mean }} \\
& +3.9 \Delta T_{\text {sk,mean }} \frac{d T_{s k, \text { mean }}}{d t}
\end{aligned}
$$

and the central signal for vasodilation is given by:

$$
\begin{aligned}
D l & =21\left[\tanh \left(0.79 \Delta T_{s k, \text { mean }}-0.70\right)+1\right] \Delta T_{s k, \text { mean }} \\
& +32\left[\tanh \left(3.29 \Delta T_{h y}-1.46\right)+1\right] \frac{d T_{s k, \text { mean }}}{d t}
\end{aligned}
$$

\section{2) Neurophysiological skin blood flow model}

The neurophysiological approach for skin blood flow regulation was implemented as:

$$
\beta_{i}=\beta_{i, b a s} \times N \times Q_{10}
$$

Here $N$ is the neural regulation signal for skin blood flow. $N$ is calculated as:

$$
N=\gamma_{1}-\gamma_{2}\left(H_{\text {warm }}-P_{\text {cold }}\right)-\gamma_{3}\left(H_{\text {warm }}+P_{\text {warm }}\right) \quad 9.6
$$

Here $H_{\text {warm }}$ is the neuron fire rate of temperature sensitive neurons in the hypothalamus $H_{\text {warm }}, P_{\text {cold }}$ is the peripheral cold stimulus and $P_{\text {warm }}$ is the peripheral warm stimulus. $\gamma_{1}$ is the model constant which represents the averaged combined effect of non-thermal factors that affect skin blood flow (e.g. blood pressure) and $\gamma_{2}$ and $\gamma_{3}$ (given in Table 5) define the inhibition strength of the hypothalamus on the vasomotor center (see Chapter 5 for physiological descriptions).

The afferent peripheral cold and warm stimuli are calculated as the mean neuron fire rate of skin temperature sensitive neurons:

$$
\begin{aligned}
P_{\text {cold }} & =\frac{1}{n} \sum_{i=1}^{n} f_{s k, \text { cold }} \\
P_{\text {warm }} & =\frac{1}{n} \sum_{n=1}^{n} f_{s k, \text { warm }}
\end{aligned}
$$

Here, $f_{s k, c o l d}$ and $f_{s k, w a r m}$ are the fire rate of a skin cold and warm sensitive neuron respectively, and, for completeness, $H_{\text {warm }}=f_{\text {hy,warm }}$. The fire rate of temperature sensitive neurons is composed of steady state fire rate and dynamic response to temperature changes and is calculated according to Mekjavic and Morrison (17): 


$$
f=\frac{1}{\Delta t} \sum_{j=0}^{j=\Delta t-1} S_{t-1}+\left(G_{0}\left(1-e^{-j / K}\right)+D \cdot G\left(e^{-j / K_{e x c}}-e^{-j / K_{\text {inh }}}\right)\right)
$$

Here $S_{t-1}$ is the steady state neuron fire rate at $t=t-1, G_{0}$ and $G$ are gain factors that depend on the difference of steady state fire rates between two moments of time $\left(G_{0}=S_{t-1}-S_{t}\right.$ and $\left.G=5.0 \cdot S_{t-1} \cdot\left|G_{0}\right|\right) . K=5.5, K_{\text {exc }}=5.5$ and $K_{\text {inh }}=3.3$ are static, excitatory and inhibitory gain factors respectively. $D$ is a sign operator indicating an excitatory or inhibitory response. When cold sensitive neurons are heated $D$ is negative, when the same neurons are cooled, $D$ is positive and vice versa for warm sensitive neurons. The steady state fire rate of neurons is calculated as:

$$
S_{t}=\sum_{j} s_{j} T_{i}^{j}
$$

Where $s_{j}$ is the j-th order coefficient as given in Table 6 and $T_{i}^{j}$ is the local temperature. The steady state response of core temperature neurons is also calculated according to Mekjavic and Morrison by shifting core temperature by $-2^{\circ} \mathrm{C}(17)$.

\section{Heat loss}

The sweat rate is calculated as:

$$
\frac{d m_{s w, i}}{d t}=a_{s w, j} \frac{A_{s k, i, j}}{A_{s k, j}} S w \times 2^{\frac{\left(T_{i}-T_{i, b a s}\right)}{10}}
$$

here $a_{s w, j}$, is the element specific sweat distribution coefficient for element $j$ given in Table 5, $S w$ is the total amount of sweat produced by the body, $\frac{A_{s k, i, j}}{A_{s k, j}}$ is the skin area ratio between sector $i$ and element $j$. The total amount of sweat produced by the body is calculated as:

$$
\begin{gathered}
S w=\left[0.65 \tanh \left(0.82 \Delta T_{s k, \text { mean }}-0.47\right)+1.15\right] \Delta T_{s k, \text { mean }} \\
+\left[5.6 \tanh \left(3.14 \Delta T_{h y}-1.83\right)+6.4\right] \Delta T_{h y}
\end{gathered}
$$




\section{Model parameters}

The properties of the passive and active model parameters are given in the Tables below.

Table 1: Length (L), Counter current heat exchange ( $h x)$ and convective heat transfer coefficients ( $h c$, mix) for each element. Values based on Fiala et al. (6).

\begin{tabular}{llllll}
\hline & $L$ & $h_{x}$ & & & \\
\cline { 3 - 5 } Element & $x 10^{-2}[\mathrm{~m}]$ & {$\left[W^{\circ} \mathrm{C}^{-1}\right]$} & $a_{\text {nat }}$ & $a_{f r c}$ & $a_{\text {mix }}$ \\
\hline 1.Head & $*$ & 0.0 & 3.0 & 113 & -5.7 \\
2.Face & 9.84 & 0.0 & 3.0 & 113 & -5.7 \\
3.Neck & 8.42 & 0.0 & 1.6 & 130 & -6.5 \\
4.Shoulders (2x) & 16.00 & 0.4 & 5.9 & 216 & -10.8 \\
5.Thorax & 30.60 & 0.0 & 0.5 & 180 & -7.4 \\
6.Abdomen & 55.20 & 0.0 & 1.2 & 180 & -9.0 \\
7.Arms (4x) & 31.85 & 1.0325 & 8.3 & 216 & -10.8 \\
8.Hands (2x) & 31.00 & 0.2850 & 8.3 & 216 & -10.8 \\
9.Legs (4x) & 34.75 & 1.725 & 5.3 & 220 & -11.0 \\
10.Feet (2x) & 24.00 & 1.700 & 6.8 & 210 & -10.5 \\
\hline
\end{tabular}


Table 2A: Number of nodes ( $n)$, radius ( $r)$, conductivity ( $k$ ), density ( $\rho)$, heat capacity $(c)$, blood perfusion rate $(\omega)$ and metabolic heat production $\left(q_{m}\right)$ per tissue and element. Values based on ref. (6).

\begin{tabular}{|c|c|c|c|c|c|c|c|c|}
\hline Element & Tissue & $n$ & $\begin{array}{l}r \\
\times 10^{-2}[\mathrm{~m}]\end{array}$ & $\begin{array}{l}k \\
{\left[\mathrm{~W} \mathrm{~m}{ }^{-1} \circ \mathrm{C}^{-1}\right]}\end{array}$ & $\begin{array}{l}\rho \\
{\left[\mathrm{kgm}^{-3}\right]}\end{array}$ & $\begin{array}{l}\mathrm{C} \\
{\left[\mathrm{J} \mathrm{kg}^{-1}{ }^{\circ} \mathrm{C}^{-1}\right]}\end{array}$ & $\begin{array}{l}\omega_{b l} \\
{\left[\mathrm{Ls}^{-1} \mathrm{~m}^{-3}\right]}\end{array}$ & $\begin{array}{l}q_{m} \\
{\left[\mathrm{Wm}^{-3}\right]}\end{array}$ \\
\hline \multirow{5}{*}{ 1.Head } & Brain & 3 & 8.60 & 0.75 & 1080 & 3850 & 10.1320 & 13400 \\
\hline & Bone & 1 & 10.05 & 0.42 & 1500 & 1591 & 0 & 0 \\
\hline & Fat & 1 & 10.20 & 0.16 & 850 & 2300 & 0.0036 & 58 \\
\hline & Inner skin & 1 & 10.30 & 0.47 & 1085 & 3680 & 5.4800 & 743.21 \\
\hline & Outer skin & 1 & 10.40 & 0.47 & 1085 & 3680 & 0 & 0 \\
\hline \multirow{6}{*}{ 2.Face } & Muscle & 1 & 2.68 & 0.42 & 1085 & 3768 & 0.5380 & 684 \\
\hline & Bone & 1 & 5.42 & 1.16 & 1500 & 1591 & 0 & 0 \\
\hline & Muscle & 1 & 6.80 & 0.42 & 1085 & 3768 & 0.5380 & 684 \\
\hline & Fat & 2 & 7.60 & 0.16 & 850 & 2300 & 0.0036 & 58 \\
\hline & Inner skin & 1 & 5.64 & 0.47 & 1085 & 3680 & 11.170 & 740.82 \\
\hline & Outer skin & 1 & 5.67 & 0.47 & 1085 & 3680 & 0 & 0 \\
\hline \multirow{5}{*}{ 3.Neck } & Bone & 1 & 1.90 & 0.75 & 1357 & 1700 & 0 & 0 \\
\hline & Muscle & 2 & 5.46 & 0.42 & 1085 & 3768 & 0.5380 & 684 \\
\hline & Fat & 1 & 5.56 & 0.16 & 850 & 2300 & 0.0036 & 58 \\
\hline & Inner skin & 1 & 5.64 & 0.47 & 1085 & 3680 & 6.8000 & 507.36 \\
\hline & Outer skin & 1 & 5.67 & 0.47 & 1085 & 3680 & 0 & 0 \\
\hline \multirow{5}{*}{ 4.Shoulders } & Bone & 1 & 3.70 & 0.75 & 1357 & 1700 & 0 & 0 \\
\hline & Muscle & 1 & 3.90 & 0.42 & 1085 & 3768 & 0.5380 & 684 \\
\hline & Fat & 2 & 4.40 & 0.16 & 850 & 2300 & 0.0036 & 58 \\
\hline & Inner skin & 1 & 4.50 & 0.47 & 1085 & 3680 & 1.0100 & 744.28 \\
\hline & Outer skin & 1 & 4.60 & 0.47 & 1085 & 3680 & 0 & 0 \\
\hline \multirow{6}{*}{ 5.Thorax } & Lung & 1 & 7.73 & 0.28 & 550 & 3718 & 4.3000 & 600 \\
\hline & Bone & 1 & 8.91 & 0.75 & 1357 & 1700 & 0 & 0 \\
\hline & Muscle & 1 & 12.34 & 0.42 & 1085 & 3768 & 0.5380 & 684 \\
\hline & Fat & 2 & 12.68 & 0.16 & 850 & 2300 & 0.0036 & 58 \\
\hline & Inner skin & 1 & 12.80 & 0.47 & 1085 & 3680 & 1.5800 & 677.3 \\
\hline & Outer skin & 1 & 12.90 & 0.47 & 1085 & 3680 & 0 & 0 \\
\hline
\end{tabular}


Table 2B: Number of nodes ( $n)$, radius ( $r)$, conductivity ( $k$ ), density $(\rho)$, heat capacity (c), blood perfusion rate $(\omega)$ and metabolic heat production $\left(q_{m}\right)$ per tissue and element. Values based on ref. (6).

\begin{tabular}{|c|c|c|c|c|c|c|c|c|}
\hline Element & Tissue & $n$ & $\begin{array}{l}r \\
\times 10^{-2}[\mathrm{~m}]\end{array}$ & $\begin{array}{l}k \\
{\left[\mathrm{~W} \mathrm{~m}^{-1 \circ} \mathrm{C}^{-1}\right]}\end{array}$ & $\begin{array}{l}\rho \\
{\left[\mathrm{kgm}^{-3}\right]}\end{array}$ & $\begin{array}{l}\mathrm{C} \\
{\left[\mathrm{J} \mathrm{kg}^{-1 \circ} \mathrm{C}^{-1}\right]}\end{array}$ & $\begin{array}{l}\omega_{b l} \\
{\left[\mathrm{Ls}^{-1} \mathrm{~m}^{-3}\right]}\end{array}$ & $\begin{array}{l}q_{m} \\
{\left[\mathrm{Wm}^{-3}\right]}\end{array}$ \\
\hline \multirow{6}{*}{ 6.Abdomen } & Guts & 1 & 7.85 & 0.53 & 1000 & 3697 & 4.3100 & 4100 \\
\hline & Bone & 1 & 8.34 & 0.75 & 1357 & 1700 & 0 & 0 \\
\hline & Muscle & 1 & 10.90 & 0.42 & 1085 & 3768 & 0.5380 & 684 \\
\hline & Fat & 2 & 12.44 & 0.16 & 850 & 2300 & 0.0036 & 58 \\
\hline & Inner skin & 1 & 12.54 & 0.47 & 1085 & 3680 & 1.4400 & 590.2 \\
\hline & Outer skin & 1 & 12.60 & 0.47 & 1085 & 3680 & 0 & 0 \\
\hline \multirow{5}{*}{ 7.Arms } & Bone & 1 & 1.53 & 0.75 & 1357 & 1700 & 0 & 0 \\
\hline & Muscle & 2 & 3.43 & 0.42 & 1085 & 3768 & 0.5380 & 684 \\
\hline & Fat & 1 & 4.01 & 0.16 & 850 & 2300 & 0.0036 & 58 \\
\hline & Inner skin & 1 & 4.11 & 0.47 & 1085 & 3680 & 1.1000 & 631 \\
\hline & Outer skin & 1 & 4.18 & 0.47 & 1085 & 3680 & 0 & 0 \\
\hline \multirow{5}{*}{ 8.Hands } & Bone & 1 & 0.70 & 0.75 & 1357 & 1700 & 0 & 0 \\
\hline & Muscle & 1 & 1.74 & 0.42 & 1085 & 3768 & 0.5380 & 684 \\
\hline & Fat & 1 & 2.04 & 0.16 & 850 & 2300 & 0.0036 & 58 \\
\hline & Inner skin & 1 & 2.16 & 0.47 & 1085 & 3680 & 4.5400 & 744.43 \\
\hline & Outer skin & 1 & 2.26 & 0.47 & 1085 & 3680 & 0 & 0 \\
\hline \multirow{5}{*}{ 9.Legs } & Bone & 1 & 2.20 & 0.75 & 1357 & 1700 & 0 & 0 \\
\hline & Muscle & 2 & 4.80 & 0.42 & 1085 & 3768 & 0.5380 & 684 \\
\hline & Fat & 2 & 5.33 & 0.16 & 850 & 2300 & 0.0036 & 58 \\
\hline & Inner skin & 1 & 5.43 & 0.47 & 1085 & 3680 & 1.0500 & 742.8 \\
\hline & Outer skin & 1 & 5.53 & 0.47 & 1085 & 3680 & 0 & 0 \\
\hline \multirow{5}{*}{ 10.Feet } & Bone & 1 & 2.00 & 0.75 & 1357 & 1700 & 0 & 0 \\
\hline & Muscle & 1 & 2.50 & 0.42 & 1085 & 3768 & 0.5380 & 684 \\
\hline & Fat & 2 & 3.26 & 0.16 & 850 & 2300 & 0.0036 & 58 \\
\hline & Inner skin & 1 & 3.40 & 0.47 & 1085 & 3680 & 1.5000 & 640.3 \\
\hline & Outer skin & 1 & 3.50 & 0.47 & 1085 & 3680 & 0 & 0 \\
\hline
\end{tabular}


Table 3: Angle $(\varphi)$, view factor $(\psi)$ and emissivity $(\varepsilon)$ for each element and sector. Values based on Fiala et al. (6).

\begin{tabular}{lllll}
\hline \multirow{2}{*}{ Element } & & $\varphi$ & $\psi$ & $\varepsilon$ \\
\hline 1.Head & Sector & {$\left[{ }^{\circ}\right]$} & {$[-]$} & {$[-]$} \\
2.Face & 1.Forehead & 10 & 1.0 & 0.99 \\
3.Neck & 2.Head & 170 & 0.9 & 0.80 \\
& 1.Face & 210 & 0.9 & 0.99 \\
4.Shoulders & 1.Anterior & 180 & 0.7 & 0.99 \\
5.Thorax & 2.Posterior & 180 & 0.75 & 0.99 \\
& 1.Shoulder & 130 & 0.90 & 0.99 \\
\multirow{3}{*}{ 6.Abdomen } & 1.Anterior & 150 & 0.80 & 0.99 \\
& 2.Posterior & 150 & 0.95 & 0.99 \\
& 3.Inferior & 60 & 0.05 & 0.99 \\
7.Arms & 1.Anterior & 150 & 0.80 & 0.99 \\
& 2.Posterior & 150 & 0.95 & 0.99 \\
& 3.Inferior & 60 & 0.20 & 0.99 \\
8.Hands & 1.Anterior & 135 & 0.75 & 0.99 \\
& 2.Posterior & 135 & 0.80 & 0.99 \\
9.Legs & 3.Inferior & 90 & 0.10 & 0.99 \\
& 1.Dorsal & 180 & 0.80 & 0.99 \\
10.Feet & 2.Ventral & 180 & 0.10 & 0.99 \\
& 1.Anterior & 150 & 0.85 & 0.99 \\
\hline \multirow{2}{*}{ 2.Posterior } & 150 & 0.95 & 0.99 \\
& 3.Inferior & 60 & 0.10 & 0.99 \\
& 1.Dorsal & 180 & 0.90 & 0.99 \\
& 2.Ventral & 180 & 0.90 & 0.99 \\
\hline
\end{tabular}

Table 4: Local insulative values of clothing parts. Values obtained from refs. (18) and (19).

\begin{tabular}{|c|c|c|c|}
\hline Garment & $I_{c l}[\mathrm{clo}]$ & $f_{c l}[-]$ & $i_{c l}[-]$ \\
\hline Shirt (65\%polyester $35 \%$ cotton) & 0.21 & 1.12 & 0.50 \\
\hline Sweater (cotton) & 0.23 & 1.06 & 0.41 \\
\hline Trousers (denim) & 0.24 & 1.09 & 0.37 \\
\hline Socks & 0.45 & 1.01 & 0.55 \\
\hline
\end{tabular}


Table 5: Distribution coefficients for thermoregulatory responses. Values from ref. (16) and Chapter 5.

\begin{tabular}{|c|c|c|c|c|c|c|c|c|}
\hline \multirow[b]{2}{*}{ Element } & \multicolumn{5}{|c|}{ Fiala et al. (1998) } & \multicolumn{3}{|c|}{ Kingma et al. (2011) } \\
\hline & $a_{s k}$ & $a_{s w}$ & $a_{s h}$ & $a_{d l}$ & $a_{c s}$ & $\gamma_{1}$ & $\gamma_{2}$ & $\gamma_{3}$ \\
\hline 1.Head & 0.0835 & 0.0950 & 0.0000 & 0.0550 & 0.0300 & 0.7906 & -0.1853 & -0.0816 \\
\hline 2.Face & 0.0418 & 0.0540 & 0.0020 & 0.0460 & 0.0330 & 0.7906 & -0.1853 & -0.0816 \\
\hline 3.Neck & 0.0417 & 0.0420 & 0.0020 & 0.0310 & 0.0250 & 0.7906 & -0.1853 & -0.0816 \\
\hline 4.Shoulders & 0.0300 & 0.0370 & 0.0002 & 0.0200 & 0.0100 & 0.7906 & -0.1853 & -0.0816 \\
\hline 5.Thorax & 0.1290 & 0.1010 & 0.6305 & 0.1410 & 0.0005 & 0.7906 & -0.1853 & -0.0816 \\
\hline 6.Abdomen & 0.1210 & 0.1810 & 0.2400 & 0.1610 & 0.0205 & 2.4250 & -0.1246 & 0.1658 \\
\hline 7.Arms & 0.1800 & 0.1330 & 0.0400 & 0.0950 & 0.1100 & -0.2321 & -0.0231 & -0.2126 \\
\hline 8.Hands & 0.0900 & 0.0490 & 0.0020 & 0.1210 & 0.1945 & 0.7368 & -0.2190 & -0.0704 \\
\hline 9.Legs & 0.2080 & 0.2610 & 0.0813 & 0.2300 & 0.2000 & 0.7906 & -0.1853 & -0.0816 \\
\hline 10.Feet & 0.0750 & 0.0470 & 0.0020 & 0.1000 & 0.3765 & 0.7368 & -0.2190 & -0.0704 \\
\hline
\end{tabular}

Values for $\gamma$ in bold indicate that the value was obtained from physiological experiments at that site; for the feet the ventral hand $\gamma$ set was used. For all other locations the $\gamma$ set obtained for the dorsal hand was used (see Chapter 5).

Table 6: Coefficients for static neuron fire rate (modified from ref. (17)).

\begin{tabular}{|c|c|c|}
\hline Coefficient & Cold sensitive neuron & Warm sensitive neuron \\
\hline $\mathrm{S}_{0}$ & $-0.19005313 e 6$ & $0.1526647 \mathrm{e} 5$ \\
\hline $\mathrm{s}_{1}$ & $0.85318078 \mathrm{e} 5$ & $-0.5147704 \mathrm{e} 4$ \\
\hline $\mathrm{S}_{2}$ & -0.16974919 e5 & $0.7707699 \mathrm{e} 3$ \\
\hline $\mathrm{S}_{3}$ & $0.19724509 \mathrm{e} 4$ & $-0.67475955 e 2$ \\
\hline $\mathrm{S}_{4}$ & $-0.14833377 e 3$ & $0.38244284 \mathrm{e} 1$ \\
\hline $\mathrm{S}_{5}$ & $0.75486723 \mathrm{e} 1$ & $-0.14664175 e 0$ \\
\hline $\mathrm{S}_{6}$ & $-0.26343323 e 0$ & $0.38526706 e-2$ \\
\hline $\mathrm{S}_{7}$ & $0.62289589 \mathrm{e}-2$ & $-0.68496075 e-4$ \\
\hline $\mathrm{S}_{8}$ & $-0.95563808 \mathrm{e}-4$ & $0.78889647 e-6$ \\
\hline $\mathrm{S}_{9}$ & $0.85949930 \mathrm{e}-6$ & $-0.53173142 e-8$ \\
\hline $\mathrm{s}_{10}$ & $-0.34432887 e-8$ & $0.15936041 \mathrm{e}-10$ \\
\hline
\end{tabular}




\section{References}

1. Parsons, K., Human Thermal Environments. 2 ed, ed. K.C.Parsons2003: Taylor \& Francis.

2. Huizenga, C., Z. Hui, and E. Arens, A model of human physiology and comfort for assessing complex thermal environments. Building and Environment, 2001. 36(6): p. 691-699.

3. Tanabe, S., et al., Evaluation of thermal comfort using combined multi-node thermoregulation (65MN) and radiation models and computational fluid dynamic (CFD). Energ. Buildings, 2002. 34: p. 637-646.

4. Gordon, R., The response of a human temperature reulatory system model in the cold, 1974, University of California: Santa Barbara.

5. Fiala, D., et al., Physiological modeling for technical, clinical and research applications. Frontiers in bioscience, 2010. 2: p. 939-68.

6. Fiala, D., K.J. Lomas, and M. Stohrer, A computer model of human thermoregulation for a wide range of environmental conditions: the passive system. J Appl Physiol, 1999. 87(5): p. 1957-72.

7. Gagge, A.P., Rational temperature indices of man's thermal environment and their use with a 2-node model of his temperature regulatin. Fed Proc, 1973. 32(5): p. 1572-1582.

8. Werner, J., M. Buse, and A. Foegen, Lumped versus distributed thermoregulatory control: results from a three-dimensional dynamic model. Biological cybernetics, 1989. 62(1): p. 63-73.

9. Tindall, M.J., et al., Understanding post-operative temperature drop in cardiac surgery: a mathematical model. Mathematical medicine and biology : a journal of the IMA, 2008. 25(4): p. 323-35.

10. Wyndham, C.H. and A.R. Atkins, A physiological scheme and mathematical model of temperature regulation in man. Pflugers Archiv : European journal of physiology, 1968. 303(1): p. 14-30.

11. Stolwijk, E.J., A mathematical model of physiological temperature regulation in man, in Aeronautics and space administration1971, NASA: Washington DC.

12. Wissler, E.H., A Mathematical Model of the Human Thermal System. The Bulletin of mathematical biophysics, 1964. 26: p. 147-66.

13. Pennes, H.H., Analysis of tissue and arterial blood temperatures in the resting human forearm. J Appl Physiol, 1948. 1(2): p. 93-122.

14. Severens, N.M., Modelling Hypothermia in Patients Undergoing Surgery, in PhD-Thesis2008, Eindhoven University of Technology: Eindhoven.

15. Fiala, D., K.J. Lomas, and M. Stohrer, Computer prediction of human thermoregulatory and temperature responses to a wide range of environmental conditions. Int J Biometeorol, 2001. 45(3): p. 143-59. 
16. Fiala, D., Dynamic simulation of human heat transfer and thermal comfort., in Institute of Energy and Sustainable Development1998, De Montfort University: Leicester.

17. Mekjavic, I.B. and J.B. Morrison, A model of shivering thermogenesis based on the neurophysiology of thermoreception. IEEE Trans Biomed Eng, 1985. 32(6): p. 407-17.

18. McCullough, E.A., A Data Base for Determining the Evaporative Resistance of Clothing, 1989.

19. McCullough, E.A., B.W. Jones, and J. Huck, A Comprehensive Data Base for Estimating Clothing Insulation. ASHRAE, 1985. 



\section{Summary}




\section{Summary}

In modern western societies, people tend to live most of their life in buildings where conditions are kept stable and within the thermoneutral zone. However, being continuously in thermoneutral conditions is not necessarily healthy because the body needs little effort to defend body temperature with potential loss of regulatory capacity over time. This may have a causal relation to the development of obesity and pathologies related to obesity. Moreover, current environmental and economic issues concerning scarcity of fossil fuels require large-scale reductions in energy use. Maintaining a constant indoor climate in buildings forms about one third of the total energy use in developed countries. It may thus be beneficial to allow temperature in buildings to drift more according to the time of day and season; thereby reducing the carbon footprint for living and reducing the risk for developing obesity and its related diseases.

This thesis contains studies on the influence of the thermal environment on human physiology and the enhancement of a dynamic thermoregulation model that is based on physiological mechanisms. Special focus is set on skin blood flow and nonshivering metabolic heat production because these are the key players in human thermoregulation during mild thermal challenges. Furthermore, because of agerelated impairment of thermoregulation, this thesis pays special attention to the impact of mild thermal challenges on elderly.

The review in Chapter 2 covers the thermoneutral zone. The thermoneutral zone is the range in air temperature for which the body does not need to increase heat production, or sweating in order to maintain a stable body temperature. Chapter 2 shows that the thermoneutral zone varies between young adults and elderly but also between other subpopulations such as lean and obese (see Figure 1). Therefore, exposure to a mild thermal challenge may dispose one individual further from its thermoneutral zone than another. Furthermore, Chapter 2 indicated that the range of the thermoneutral zone varies mainly due to differences in insulation (e.g. regulation of skin blood flow, body composition or clothing).

The human body can regulate heat flow from the body core to the environment by increasing or decreasing skin blood flow. Normally the hands and face are the only skin areas that are directly exposed to the environment, the other areas are covered by clothing. Chapter 3 describes a study on the regulation of skin blood flow at the hand while only changing the local hand skin temperature. The results showed that the regulation of skin blood flow is not significantly affected by age Therefore, elderly maintain the ability to regulate heat loss at the hands. Nevertheless, in contrast to young adults, elderly failed to defend their core temperature during whole body mild cold exposure, as we showed in Chapter 4. Remarkably, young adults 
increased heat production (i.e. non-shivering thermogenesis) upon cold exposure, whereas elderly even decreased heat production. Clearly, in this case the thermoregulatory response is negatively affected by age. With respect to health, mild cold exposure caused increased systolic blood pressure in both age groups. Noteworthy, the mean increase was up to three times greater in elderly, reaching even over $190 \mathrm{mmHg}$ in some elderly individuals. In medical practice a systolic blood pressure over $180 \mathrm{mmHg}$ is considered a health risk.

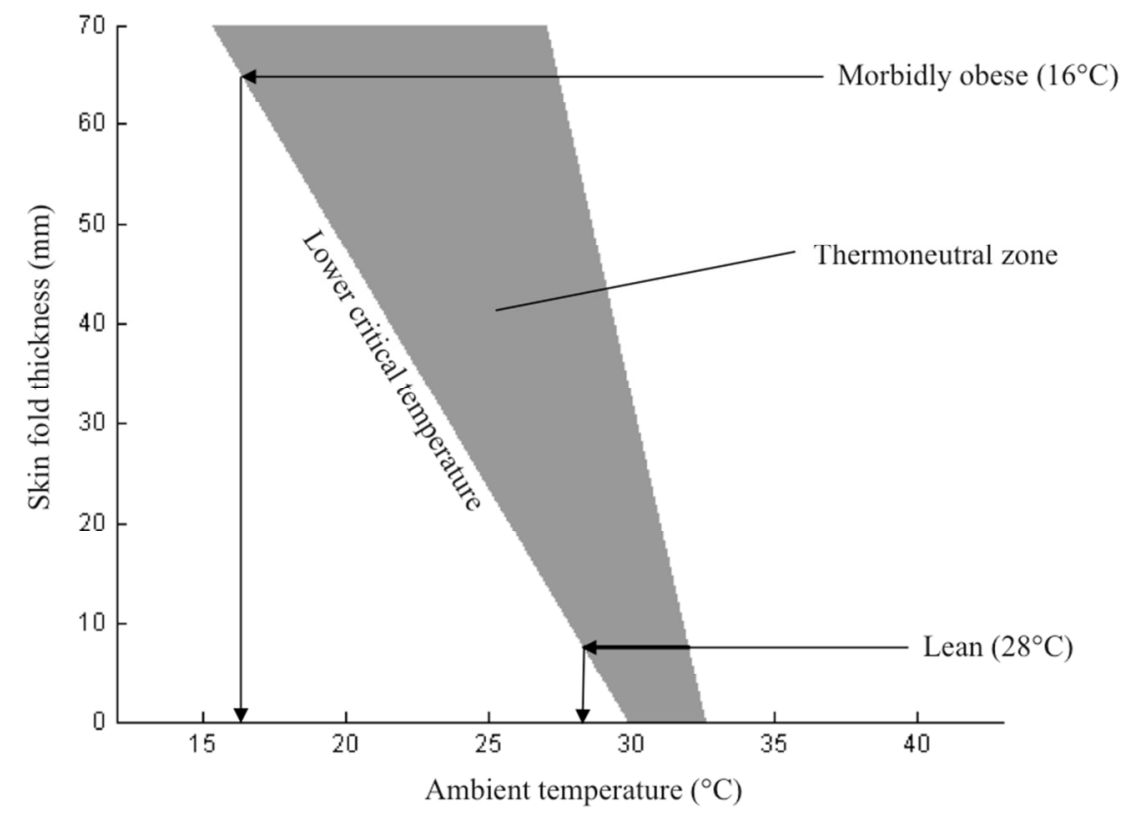

Figure 1: Thermoneutral zone over a range of subcutaneous fat thickness. The lower critical temperature defines the lower bound of the thermoneutral zone. Below the lower critical temperature heat production is increased to maintain thermal balance.

Systolic blood pressure remained at increased levels even after a $2 \mathrm{~h}$-rewarming period, which indicates a long lasting effect of mild cold. The elevated systolic blood pressure after rewarming was inversely related to non-shivering thermogenesis upon mild cold exposure. It is interesting to note that elderly with a greater body fat percentage showed significantly smaller increases in systolic blood pressure. Therefore, especially lean elderly should pay attention to their ambient environment.

Precise knowledge of the impact of mild temperature challenges on these subpopulations is necessary to make informed decisions and design new energy efficient buildings. Moreover, modern building design relies greatly on mathematical models to simulate both structural integrity and energy requirements. However, the in 
building design widely used Fanger model is only suitable for simulating thermal comfort on group-level under constant thermal environments. While current building designers require a model that can be used for individuals under transient environments. The mathematical thermoregulation model described in this thesis (i.e. ThermoSEM) contributes to this field by providing a relatively inexpensive method to indicate the thermal comfort of individuals under transient conditions. The classic "engineering" perspective to model thermoregulation includes the explicit definition of temperature set points. Thermoregulatory mechanisms such as skin blood flow, shivering or sweating are assumed to scale with the difference between the actual temperature and the set point temperature. Although these models may simulate the thermoregulatory response with great accuracy, they may lack coherence with physiological reality. In Chapter $\mathbf{5}$ we presented a neurophysiological approach to model thermoregulatory changes in skin blood flow. The neurophysiological approach is based on the principle that the human body does not sense temperature directly; instead the information is coded into neuron fire rates. In short the model used experimentally measured skin and core temperature as input variables. These temperature recordings were then transduced to their equivalent neuron discharge rate (i.e. the internal signal in the body). Finally, the neuron discharge rates were correlated with linear models to the experimentally measured skin blood flow. The developed skin blood flow model closely matched experimental results (mean squared residual < 8\%). Furthermore, using the neurophysiological skin blood flow model ThermoSEM was able to simulate mean skin temperature with great accuracy (root mean square error $=0.37^{\circ} \mathrm{C}$ ).

In Chapter 6 the neurophysiological modelling approach was expanded to model thermal sensation in young adult males. Thermal sensation dictates the satisfaction of persons with their environment. Using datasets of two independent physiological experiments the thermal sensation model was both developed and validated. The developed model explained $89 \%$ of the variance in thermal sensation. The neurophysiological approach can be highly beneficial for predicting thermal sensation of individuals under transient thermal environments.

Incorporating knowledge of the neurophysiology of thermoregulation in the mathematical model made it possible to capture the dynamic behaviour of skin blood flow regulation as well as thermal sensation during mild thermal transients. Furthermore, mathematical modelling offered insight in the possible obscuring effect of Arrhenius law on non-shivering thermogenesis and the possible role of counter current heat exchange in body temperature dynamics (Chapter 7). Overall, the studies presented in this thesis help to understand why young adults and elderly show different physiological responses to mild thermal challenges. Moreover, the presented knowledge is of great importance for the development of new studies on 
metabolic and health effects of thermal challenges in context of obesity and ageing. Therefore, this thesis forms a synergy between physiology and mathematical modelling. 

Samenvatting 


\section{Samenvatting}

In moderne westerse samenlevingen verblijven mensen het grootste deel van hun leven in gebouwen waar de omgevingscondities stabiel zijn en binnen de thermoneutrale zone worden gehouden. Dat wil echter niet zeggen dat het gezond is om constant in thermoneutrale omstandigheden te verkeren. Het lichaam hoeft zich dan immers weinig in te spannen om de lichaamstemperatuur te handhaven en zou daarmee de capaciteit kunnen verliezen om extra warmte te produceren. Mogelijk vormen deze omstandigheden een oorzakelijk verband met de ontwikkeling van obesitas en ziekten gerelateerd aan obesitas. Daarnaast is vanuit milieu- en economische oogpunt een grootschalige vermindering van het energiegebruik noodzakelijk. Ongeveer één derde van het totale energie gebruik van ontwikkelde landen is nodig om een constant binnenklimaat in gebouwen te creëren. Het kan dus nuttig zijn om de temperatuur in gebouwen af te stemmen op de variaties in de buitentemperatuur gedurende de dag en gedurende de seizoenen; hierdoor wordt zowel de "carbon footprint" verminderd alsook het risico op het ontwikkelen van obesitas en daaraan gerelateerde ziekten.

Dit proefschrift bevat studies over de invloed van de omgevingstemperatuur op de menselijke fysiologie en over de verfijning van een dynamisch thermoregulatiemodel dat is gebaseerd op fysiologische mechanismen. Er wordt speciale aandacht gegeven aan huiddoorbloeding en verhoogde metabole warmteproductie zonder rillen. Deze mechanismen spelen een sleutelrol bij de thermoregulatie tijdens milde temperatuurschommelingen. Vanwege leeftijd gerelateerde beperkingen in thermoregulatie wordt in dit proefschrift ook speciale aandacht geschonken aan de invloed van milde kou en milde warmte op de fysiologische respons bij ouderen.

Het review van Hoofdstuk 2 behandelt de thermoneutrale zone. Met de thermoneutrale zone wordt het interval in omgevingstemperatuur bedoeld waarbij het lichaam geen extra warmte hoeft te produceren of niet hoeft te zweten om de lichaamstemperatuur te handhaven. Hoofdstuk 2 laat zien dat de thermoneutrale zone bij jong volwassenen anders is dan bij ouderen, maar ook varieert tussen andere subgroepen (slank versus overgewicht, zie Figuur 1). Blootstelling aan een specifieke temperatuur kan daarom voor de een verder af liggen van de thermoneutrale zone dan voor een ander. Verder geeft Hoofdstuk 2 aan dat het interval van de thermoneutrale zone met name varieert door verschillen in isolatie (b.v. regeling van de huiddoorbloeding, lichaamssamenstelling en kleding).

Het lichaam kan de warmtestroom van de lichaamskern naar de omgeving regelen door middel van het verwijden of vernauwen van de bloedvaten in de huid. Hierdoor stijgt of daalt de huiddoorbloeding. Normaal gesproken zijn de handen en het gezicht de enige huidoppervlakken die direct blootgesteld worden aan de omgeving. 
Andere delen zijn veelal bedekt met kleding. In Hoofdstuk 3 is gekeken naar de regeling van huiddoorbloeding van de hand waarbij enkel de temperatuur van de huid van de hand werd gevarieerd. De resultaten tonen aan dat de regeling van huiddoorbloeding tijdens lokale koeling van de hand niet significant beïnvloed wordt door leeftijd. Ouderen behouden dus de mogelijkheid om warmteverlies te reguleren aan de handen.

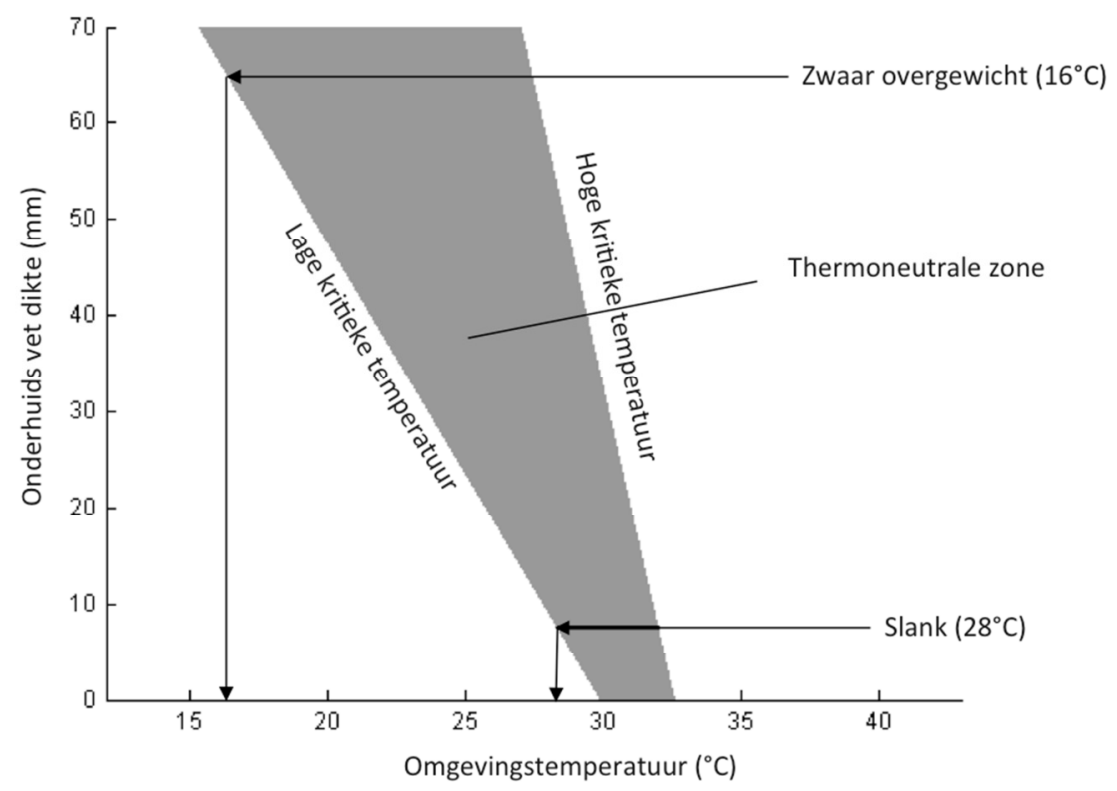

Figuur 1: Thermoneutrale zone (TNZ) over een bereik van onderhuids vet dikte (SFT). De lage kritieke temperatuur definieert de grens waaronder de warmteproductie wordt verhoogd om de lichaamstemperatuur te handhaven. De hoge kritieke temperatuur definieert de grens waarboven de zweetproductie wordt verhoogd.

Echter, in tegenstelling tot jong volwassen, waren ouderen niet in staat om hun kerntemperatuur te behouden wanneer het hele lichaam werd blootgesteld aan milde kou (Hoofdstuk 4). Opmerkelijk is dat jong volwassenen de warmteproductie konden verhogen zonder te rillen, terwijl ouderen zelfs de warmteproductie verminderden. Het is duidelijk dat in dit geval de thermoregulatie negatief werd beïnvloed door leeftijd. Met betrekking tot de gezondheid, veroorzaakte blootstelling aan milde kou een verhoogde bloeddruk (met name systolische bloeddruk) in beide leeftijdsgroepen. Echter de gemiddelde stijging was drie keer zo hoog bij ouderen en bereikte zelfs waarden boven $190 \mathrm{mmHg}$. In de medische wereld wordt een systolische bloeddruk hoger dan $180 \mathrm{mmHg}$ als een gezondheidsrisico beschouwd. Zelfs na een twee uur durende herstelprocedure bleef de systolische bloeddruk systematisch verhoogd, hetgeen een langdurend effect van de milde kou aangeeft. De verhoogde bloeddruk na opwarming was negatief gecorreleerd met de verhoging van 
de warmteproductie zonder te rillen gedurende de koude blootstelling. Met andere woorden: een verlies aan capaciteit om extra warmte te kunnen produceren gaat gepaard met een verhoging van de bloeddruk in de kou. Bij ouderen was er ook een effect van het lichaamsvet percentage: degenen met een hoger vetpercentage hadden een significant kleinere stijging van de systolische bloeddruk. Daarom moeten vooral slanke ouderen opletten in een koele omgeving.

Kennis over de invloed van variaties van de temperatuur binnenshuis op diverse subgroepen is nodig om weloverwogen beslissingen te nemen met betrekking tot het ontwikkelen van nieuwe energiezuinige gebouwen. Moderne gebouwontwikkelaars gebruiken wiskundige modellen om de structurele integriteit en energiegebruik van gebouwen te simuleren. Echter, het in dit veld veelgebruikte model van Fanger is enkel bruikbaar voor grote groepen en onder constante omgevingscondities. Voor de huidige vraag is juist een model nodig dat op individueel niveau en onder wisselende omstandigheden gebruikt kan worden. Het wiskundige thermoregulatiemodel dat in dit proefschrift is ontwikkeld (ThermoSEM; hoofdstuk 5) biedt op een relatief goedkope manier een goede indicatie over de thermo-fysiologische respons en thermisch sensatie (hoofdstuk 6) van individuen. Het klassieke "ingenieurs" perspectief om thermoregulatie te modelleren omvat het expliciet definiëren van set points. Aangenomen wordt dat huiddoorbloeding, rillen of zweten schalen met het verschil tussen de actuele lichaamstemperatuur en de set point temperatuur. Alhoewel deze modellen de thermoregulatie respons met redelijke nauwkeurigheid kunnen nabootsen, hebben ze geen fysiologische onderbouwing. In Hoofdstuk 5 presenteren we een alternatieve, neurofysiologische aanpak om veranderingen in huiddoorbloeding als functie van de temperatuur te modelleren. Deze aanpak is gebaseerd op het principe dat het menselijk lichaam temperatuur niet direct voelt, maar dat de informatie is gecodeerd in de vuurfrequentie van warme- en koudegevoelige neuronen. Het model gebruikt experimenteel gemeten huid- en kerntemperaturen als invoer variabelen. Deze temperaturen worden vervolgens omgerekend naar de equivalente vuurfrequenties. Tenslotte zijn deze vuurfrequenties met behulp van lineaire modellen vergeleken met de experimenteel gemeten huiddoorbloeding. De voorspelde huiddoorbloeding kwam goed overeen met de gemeten huiddoorbloeding (gemiddelde kwadratische afwijking $<8 \%$ ). Bovendien kon ThermoSEM de gemiddelde huidtemperatuur met grote nauwkeurigheid simuleren (wortel van gemiddelde kwadratische afwijking $=0.37^{\circ} \mathrm{C}$ ).

In hoofdstuk 6 is de neurofysiologische aanpak uitgebreid met het modeleren van thermische sensatie. Deze thermische sensatie bepaalt voor een groot deel de tevredenheid van personen met hun omgeving. Gebruikmakend van de gegevens van twee onafhankelijke experimenten uitgevoerd bij jong volwassen mannen, is het model zowel ontwikkeld als gevalideerd. Het ontwikkelde model kon $89 \%$ van de 
variatie in de gemeten thermische sensatie verklaren. De neurofysiologische aanpak kan zeer bruikbaar zijn voor het voorspellen van de thermische sensatie van individuen bij veranderingen in de omgevingscondities.

Toevoeging van neurofysiologie in het thermoregulatiemodel maakt het mogelijk de dynamiek te voorspellen van zowel een fysiologische respons (huiddoorbloeding) als de thermische sensatie bij schommelingen van het thermisch binnenklimaat. Verder heeft het wiskundig modelleren ook inzicht gegeven in het mogelijk effect van weefseltemperaturen op de verandering van de warmteproductie en de mogelijke rol van warmte-uitwisseling via het z.g. tegenstroomprincipe tussen bloedvaten tijdens veranderingen van de lichaamstemperatuur. Deze kennis is zeer nuttig om te begrijpen hoe milde schommelingen in de omgevingstemperatuur kunnen zorgen voor verschillende fysiologische reacties bij jongeren en ouderen. Tevens is deze kennis van groot belang onderzoek naar metabole- en gezondheidseffecten van temperatuurschommelingen in relatie tot obesitas en ouderen. Daarom vormt dit proefschrift een synergie tussen fysiologie en wiskundig modelleren. 

Dankwoord 


\section{Dankwoord}

Eindelijk ere wie ere toekomt, en terecht, want de hulp van velen is onmisbaar geweest voor de totstandkoming van dit proefschrift.

Allereerst wil ik mijn copromotoren Wouter en Arjan en promotoren Wim en Anton hartelijk bedanken voor alle ondersteuning.

I would like to express great gratitude to professor van der Vusse, professor Daanen, professor Peeters, professor Schrauwen, Dr. Bouvy and Dr. Fiala for critically evaluating this thesis. Professor Daanen and Dr. Fiala, thank you for travelling to Maastricht to be part of the corona.

Beste Wouter, met een warm gevoel denk ik terug aan de talloze discussies die we in de afgelopen jaren hebben gevoerd. Ook de mooie werkreizen maken een haast nostalgisch gevoel in me los. Je hebt me rondgeleid in de wondere wereld van de fysiologie, waar ik vier jaar geleden als kennistechnoloog op safari kwam. Als ik weer eens van het pad afdwaalde en verstrikt raakte in een wildernis van setpoints, neurofysiologie, $\mathrm{Q}_{10}$-effecten en logica in het algemeen, was jij er met uitgestoken hand om samen weer op het pad te geraken. Niet dat één van ons wist waar dat pad nou precies naar toe ging... daar draaide het ook helemaal niet om... het is immers het proces dat telt. Wouter, ik heb onbeschrijflijk veel van je geleerd en er valt nog zoveel te leren. Dankjewel.

Beste Arjan, ook wij hebben samen mooie gesprekken gevoerd en verre reizen gemaakt. De reis naar Japan spande natuurlijk de kroon. In Eindhoven hebben we samen uren naar Matlab-code zitten staren om een verloren 0.5 Watt terug te vinden... en uiteindelijk zat hij daar dan, zich een beetje te verstoppen in een klassieke niet ' $j$ ' maar ' $i$ '. Jammer eigenlijk, want achteraf was het wel gaaf geweest om die wet van behoud van energie een kleine foutmarge te geven. Arjan, het was bijzonder prettig om altijd bij jou terecht te kunnen om modelleervraagstukken en andere zaken te bespreken.

Beste Anton, ik ben je erg dankbaar voor de scherpte en diepte die je als promotor hebt aangebracht in mijn studies en analyses. Mede daardoor waren onze gesprekken altijd zeer vruchtbaar. Zeker in het begin betrad ik je kamer standaard met klamme zweethandjes om er vervolgens vol vertrouwen en nieuwe inzichten vandaan te komen. Later werden de zweethandjes wat minder, maar de inzichten des te groter. 
Beste Wim, bedankt voor je kritische blik en immer positieve houding. Deze zijn onmisbaar in het leven van een promovendus. Ook denk ik met veel plezier terug aan de uitstapjes (Bodies tentoonstelling in Brussel, etentje bij Desiree en Maartje) die je voor al je promovendi ondersteunde. Deze dienden vooral om breder te leren kijken dan het eigen vakgebied, te genieten van de andere zaken in het leven en om niet al te beroeps-gedeformeerd te geraken. De eerste twee zaken zijn er zeker mee geslaagd, van de laatste ben ik niet al te zeker.

Het secretariaat van HB (UM, Desiree en Claudia) en Energie technologie (TU/e, Linda en Marianne) wil ik ook hartelijk bedanken voor de prettige samenwerking. Zeker in de stresssituaties wanneer er op het laatste moment niet duidelijk was wanneer, waar en of een afspraak doorging kon ik altijd op jullie rekenen. De goede connectie tussen het secretariaat en de pepernoten leverancier van de Sint zal ook niet snel vergeten worden.

De collega-promovendi zijn voor mij van onschatbare waarde geweest. Ik ben jullie allemaal dankbaar om de geboden vriendschap, reflectie, lessen, troost en warmte. Sander, jij bent als senior promovendus natuurlijk een groot voorbeeld geweest. Het was dan ook een hele eer om je paranimf te mogen zijn toen jij 'eindelijk' je verdediging ging voeren. Natascha, je hebt me met veel passie en kunde wegwijs gemaakt in het combineren van fysiologische experimenten en het modeleren van thermoregulatie, iets om nooit te vergeten. Lisje, onze samenwerkings-chemie was werkelijk waar subliem. Het heeft dan ook geresulteerd in een gezamenlijke publicatie (Hoofdstuk 6) waar we samen super trots op kunnen zijn. Toch maak ik me soms zorgen over je gevoel voor nomenclatuur, daarom nog eventjes voor de duidelijkheid: het dier dat in de wei van de buren van Wouter staat is een hert en geen geit ;-). Guy, slechts weinigen zijn zo doortastend als jij. Als die schatkist op dat eiland in de Maas moet komen, dan zal het gebeuren ook. En als daarvoor bij donder en bliksem door de algendrab geploegd moet worden, nou, dat is dan jammer voor de algen. Jouw gave om leiding te geven en alles met kalmte te overzien is onovertrefbaar. Bovendien ben je een sympathieke gozer. Ik ben dan ook erg blij dat ik op jou kan rekenen als mijn paranimf. Maarten, jij bent mijn andere paranimf... en wat voor één. In korte tijd zijn we dikke maatjes geworden en hebben we vele praktische onderwerpen wetenschappelijk getackeld. Enkele voorbeelden zijn het ontdekken van de maximale, nog blusbare, methanolvlam, het bevestigen van Actie=Reactie met balletje-balletje $(n=106)$ en het bepalen van de resonantiefrequentie van tandglazuur. Je bent zeer creatief en hebt een bijzonder oog voor detail waardoor je uiterst scherp uit de hoek kunt komen in discussies. Ik heb daar erg van genoten en natuurlijk ook veel aan gehad. Tof dat je mijn paranimf wil zijn. De volgende is Anouk; jij bent inmiddels bijna het moedertje van onze onderzoeksgroep in Maastricht. Als we weer iets kwijt zijn, weet jij waar het is. Je bent een vrolijke meid 
die zich kranig weet te weren tussen al die botte mannentaal en als er iets geregeld moet worden kun je altijd op jou rekenen, bedankt daarvoor. Christel en Mark, jullie zijn net bij ons in het team begonnen en nu al onmisbaar. Ik ben er van overtuigd dat jullie bergen gaan verzetten, ook al begint dat met het dragen van stenen.

Ook wil ik de andere collega's bedanken en een hart onder de riem steken. Naast wetenschappelijke wisselwerking is er veel sociale wisselwerking geweest. Met andere woorden: zonder jullie had ik het waarschijnlijk in 3 jaar kunnen voltooien;). Maar ja, aangezien niet iedereen een helikopter heeft, moet kennis eerst zinken vooraleer ze overzien kan worden. En mogelijkheden om te zinken waren er veel, zoals de legendarische borrels, de licht-ontvlambare bbq's, de sprookjesachtige weekendjes naar de Ardennen, de kerstdiners, Ridder rondes, et cetera, et cetera. Jos en Guy Plasqui, de abt en prior van de abdij die HB heet. Het pater noster vind zijn belichaming in jullie, want jullie ontfermen je over alle promovendi en elke vrijdag vieren we met ons allen het sacrament van de eucharistie met zo'n warme rond-krokante hostie en hemelse vloeistof uit glazen kelk. Erik, met jou als kamergenoot is er altijd leven in de brouwerij. Soms denk ik wel eens dat je stiekem bang bent voor stilte. Ik ben je dankbaar voor de vele hulp die je geboden hebt over de jaren. Daarnaast ben je een van de gangmakers van het SBF-genootschap samen met de Mossel en de Butcher (+/- 150m hiervandaan)... ow yeah, where is it?! Marjet, ik heb genoten van je humor, wijsheden en voorliefde voor blauwe vinvissen. Het was een groot plezier om samen met jou paranimf van Maartje te zijn. Verder, en om het dankwoord toch enigszins beknopt te houden, wil ik Miranda, Silvie, JanWillem, Esther, Ruth, Tineke, Lauren, Antione, Sabina, Christian, Judith, Jasper, Bram Kleiheuvel, Dorien, Emanuel, Florence, Floortje, Vera, Freddy, Maartje, Ralf en allen die ik nu vergeten ben bedanken voor de support en gezelligheid.

De oude vrienden groep verdient natuurlijk ook een eigen paragraaf. Casper, Stefan, Viktor, Babak, Adriaan, 3k, Dr. M. Schadd, Bzzz. N. Lemmens, Maarten Vaessen (Figuur 2.2, bakkie?), Jo (Figuur 3.1), Philip, Mauke, DJ Lauke en stoomboot Guus. Ondanks dat onze studietijd al een paar horizonnen achter ons ligt, zien we elkaar nog geregeld en dan is het als vanouds gezellig. Dat is niet alleen knap, maar ook hartverwarmend.

Mijn lieve familie alsook die van Eva wil ik heel erg bedanken voor alle support en aanmoedigingen. Mama, bedankt dat je er altijd voor me bent en me altijd steunt. Mede doordat jij altijd hamerde op het belang van leren heb ik nu een mooi proefschrift kunnen afronden. Papa, bij jou kan ik ook altijd terecht. Bedankt voor al je wijze lessen, warmte en inzichten. Sanne, Bouke, Nikita en Anna, van jullie heb ik altijd veel liefde gevoeld. Ik ben daar heel erg dankbaar voor en ik ben erg fier op jullie. Lieve bobonne, bedankt voor al je warme interesse! 
Lieve Eva, soms schieten woorden te kort om gevoelens uit te drukken. Je bent er altijd voor me en ik vind het een genot om samen met jou door het leven te gaan.

$X=16 \sin ^{3}(\mathrm{t})$

$Y=13 \cos (t)-5 \cos (2 t)-2 \cos (3 t)-\cos (4 t)$

Ik hou van je. 

List of publications 


\section{Full papers}

1. Kingma BRM, Frijns AJH, Saris WHM, van Steenhoven AA, and van Marken Lichtenbelt WD. Incorporating neurophysiological concepts in mathematical thermoregulation models. J Biometeorology (submitted).

2. Droog RPJ, Kingma BRM, van Marken Lichtenbelt WD, Kooman JP, van der Sande FM, van Steenhoven AA, Frijns AJH. Mathematical modelling of thermal and circulatory effects during hemodialysis. Artificial Organs. (submitted)

3. Kingma BRM, Schellen L, Frijns AJH and van Marken Lichtenbelt WD. Thermal sensation: a mathematical model based on neurophysiology. Indoor Air (accepted)

4. Kingma BRM, Frijns AJH, and van Marken Lichtenbelt WD. The Thermoneutral Zone: implications for metabolic studies. Frontiers in bioscience (Elite edition) 4, 1975-1985, 2012.

5. Kingma BRM, Frijns AJH, Saris WHM, van Steenhoven AA, and van Marken Lichtenbelt WD. Increased Systolic blood pressure after mild cold and rewarming: relation to cold-induced thermogenesis and age. Acta Physiologica Epub, 2011.

6. Kingma BRM, Frijns AJH, Saris WHM, van Steenhoven AA, and van Marken Lichtenbelt WD. Cold induced vasoconstriction at forearm and hand skin sites: the effect of age. Eur J Appl Physiol 109: 915-921, 2010

7. Severens NMW, van Marken Lichtenbelt WD, Frijns AJH, Kingma BRM, de Mol BA, and van Steenhoven AA. Measurement of model coefficients of skin sympathetic vasoconstriction. Physiol Meas 31: 77-93, 2010.

\section{Book chapters}

1. Kingma BRM, Frijns AJH, Saris WHM, van Steenhoven AA, and van Marken Lichtenbelt WD. Mathematical modelling of human thermoregulation: a neuro-physiological approach to vasoconstriction. Studies in computational intelligence (in print by Springer-Verlag)

\section{Proceedings}

1. Kingma BRM, Frijns AJH, Saris WHM, van Steenhoven AA, and van Marken Lichtenbelt WD. Modelling Skin Blood Flow: a neuro-physiological approach. Proceedings of International Congress on Neural Computation (ICNC 2010, Valencia, Spain) 
LIST OF PUBLICATIONS 

Curriculum Vitae 


\section{Curriculum Vitae}

Boris René Motrona Kingma was born on the 19th of February 1982 in Wilrijk (B). In 2001 he finished secondary school at the Montessori College in Maastricht. Consecutively he followed the bachelor Knowledge Engineering and Computer Science at Maastricht University and the Transnational University Limburg. For his bachelor thesis he performed an internship at Kempenhaeghe institute for sleep and epilepsy where he investigated the use of accelerometers for classification of epileptic seizures. After graduating for his bachelor in 2005 he started the master Operations Research at Maastricht University. For his master thesis Boris performed an internship at the department of neurophysiology of the academic hospital Maastricht. During this master-internship he investigated the use of wavelet analysis to identify the regulation of cerebral blood flow as a function of mean arterial blood pressure. He graduated cum laude in 2006 and started to work at Capgemini B.V. as a consultant datamining and risk management. In May 2007 Boris started his PhD at the department of Human Biology of Maastricht University, as described in this thesis.

Since September 2011, he is working as a post-doc at Maastricht University. There he continues his efforts on mathematical modelling of human thermoregulation and extends this with modelling of human thermal behavior. 